CrossMark

$\leftarrow$ click for updates

Cite this: Org. Biomol. Chem., 2016, 14,10599

Received 8th August 2016, Accepted 5th October 2016

DOI: 10.1039/c6ob01718e

www.rsc.org/obc

\section{Effect of novel triazole-amino acid hybrids on growth and virulence of Candida species: in vitro and in vivo studies $\uparrow$}

\author{
Babita Aneja,,$_{t}^{a, b}$ Mohammad Irfan,,$_{t}^{a, c}$ Charu Kapil, ${ }^{d}$ Mohamad Aman Jairajpuri, ${ }^{d}$ \\ Ronan Maguire, ${ }^{e}$ Kevin Kavanagh, ${ }^{e}$ M. Moshahid A. Rizvi, ${ }^{f}$ Nikhat Manzoor, ${ }^{*} \xi^{c}$ \\ Amir Azam ${ }^{b}$ and Mohammad Abid* $\left.\right|^{a}$
}

\begin{abstract}
The increasing incidence of human candidiasis and the tendency of Candida species to become resistant to existing chemotherapies are well-recognized health problems. The present study demonstrates the successful synthesis of novel triazole-amino acid hybrids with potent in vitro and in vivo inhibitory activity against Candida species. Particularly, compounds $\mathbf{6 8}$ and $\mathbf{7 0}$ showed potent in vitro activity against fluconazole (FLC) resistant as well as sensitive clinical isolates of Candida albicans. Time kill curve analysis of lead inhibitors $\mathbf{6 8}$ and $\mathbf{7 0}$ showed their fungistatic nature. Secretion of hydrolytic enzymes, mainly proteinases and phospholipases, decreased considerably in the presence of $\mathbf{6 8}$ and $\mathbf{7 0}$ indicating their interference in fungal virulence. TEM analysis of Candida cells exposed to compounds $\mathbf{6 8}$ and $\mathbf{7 0}$ clearly showed morphological changes and intracellular damage as their possible mode of action. A preliminary mechanistic study carried out on the two most effective inhibitors (68 and 70) revealed the inhibition of ergosterol biosynthesis thereby causing the cells to lose their integrity and viability. The selected compounds did not show significant cytotoxicity up to a concentration of $200 \mu \mathrm{g} \mathrm{mL}^{-1}$ in the HEK293 cell line. An in silico analysis of $\mathbf{6 8}$ and $\mathbf{7 0}$ binding to a modeled C. albicans CYP51 showed critical H-bonding as well as hydrophobic interactions with the important active site residues indicating the basis of their anti-Candida role. Studies on the larvae of Galleria mellonella showed that the selected inhibitors (68 and 70) were non-toxic, did not provoke an immune response and significantly reduced Candida proliferation in vivo.

\footnotetext{
${ }^{a}$ Medicinal Chemistry Lab, Department of Biosciences, Jamia Millia Islamia (A Central University), Jamia Nagar, New Delhi 110025, India.

E-mail: mabid@jmi.ac.in; Fax: +91-11-26980229; Tel: +91-8750295095

${ }^{b}$ Department of Chemistry, Jamia Millia Islamia (A Central University), Jamia Nagar, New Delhi 110025, India

${ }^{c}$ Medical Mycology Lab, Department of Biosciences, Jamia Millia Islamia (A Central University), Jamia Nagar, New Delhi 110025, India. E-mail: nmanzoor@jmi.ac.in

${ }^{d}$ Protein Conformation and Enzymology Lab, Department of Biosciences, Jamia Millia Islamia (A Central University), Jamia Nagar, New Delhi 110025, India

${ }^{e}$ Department of Biology, Maynooth University, Co. Kildare, Ireland

${ }^{f}$ Genome Biology Lab, Department of Biosciences, Jamia Millia Islamia

(A Central University), Jamia Nagar, New Delhi 110025, India

$\dagger$ Electronic supplementary information (ESI) available. See DOI: 10.1039/ c6ob01718e

$\$$ These authors contributed equally to this work.

$\S$ Present address: College of Applied Medical Sciences, Taibah University, Al-Madinah Al-Munawarah, KSA.

ๆ Present address: Eppley Institute for Research in Cancer and Allied Diseases, University of Nebraska Medical Center, Omaha, NE 68198-6805, USA.
}

\section{Introduction}

Over the past three decades, the frequency of fungal infections in humans has increased dramatically worldwide despite the extensive efforts towards the discovery of novel antifungal agents and the availability of various drugs..$^{1-3}$ Of particular concern is the severity associated with the ever-increasing incidences of hospital-acquired systemic mycoses, caused by various species of Candida, responsible for the crude mortality rate of up to $50 \%$ in the United States alone. ${ }^{4}$ Adding to this disease burden, superficial infections of skin and nails in humans are affecting $\sim 25 \%$ of the general population worldwide. ${ }^{5}$ It has been reported that the use of broad-spectrum antibiotics, suppression of immune response during organ and bone marrow transplantation, cancer treatment and AIDS are increasing the chances of Candida infections thus further aggravating the condition. ${ }^{6}$ Among many Candida species, C. albicans is a prominent Candida species which is responsible for a major cause of candidiasis and isolated from approximately $80 \%$ of cases of candidemia. ${ }^{7}$ However, the 
number of infections caused by other non-Candida albicans Candida species (NCAC) which include C. glabrata, C. tropicalis and $C$. parapsilosis has also increased. ${ }^{8}$

During both superficial and systemic infection, pathogenicity of Candida species relies on a number of virulence factors including the capability to adhere onto the surface that assists them to colonize the host. Adhesion is mainly influenced by the profile of cell wall proteins and cell surface physicochemical properties. ${ }^{9}$ In addition to this, they also adhere to the surface of medical devices and form biofilms which limit the penetration of substances through the matrix and decrease the susceptibility of Candida to antifungal therapy. ${ }^{10}$ Candida also secrete different hydrolytic enzymes like proteinases, phospholipases and hemolysins and acquire nutrients and disseminate within the host. They also modulate the host immune response and cause destruction of host tissues. ${ }^{11}$

Treatment of Candida infections relies on a limited number of chemotherapeutic agents including polyenes, azoles, echinocandins, allylamines and flucytosine. ${ }^{12}$ Among them, azoles such as fluconazole (FLC), itraconazole, voriconazole, posaconazole, ketoconazole, miconazole and econazole (Fig. 1) are widely used for the treatment of both superficial and invasive fungal infections due to their favourable pharmacokinetics and safety profile. ${ }^{6}$ Azoles target the biosynthesis of ergosterol, a major component of the fungal membrane, by inhibiting the cytochrome P450-dependent enzyme lanosterol $14 \alpha$-demethylase (CYP51). The depletion of ergosterol and accumulation of toxic methylsterols in the membrane result in the alteration of membrane fluidity along with disruption of activity of membrane-bound enzymes leading to the inhibition of fungal growth and replication. ${ }^{13}$ Although azoles have an advantage of oral administration, they lack fungicidal effects as well as possess limited selectivity for fungal demethylase enzyme over mammalian cytochrome P450s thus posing serious side effects. ${ }^{14}$ Moreover, the increased use of azole
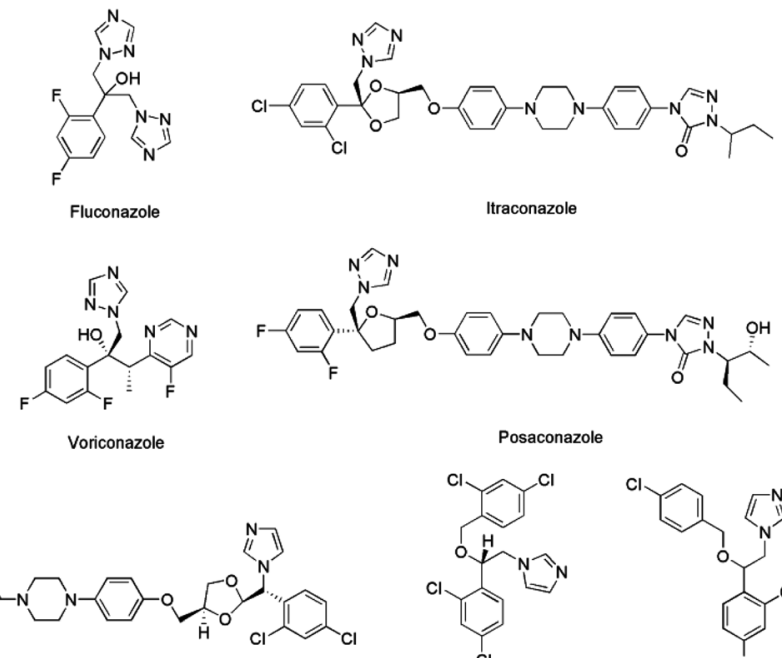

Ketoconazole
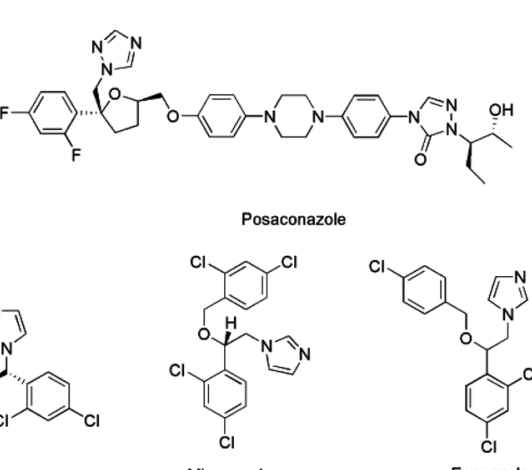

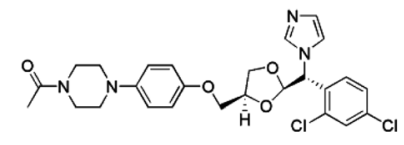

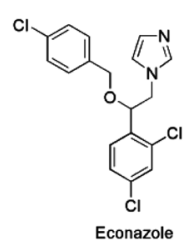

Fig. 1 Structure of common azole-based antifungal drugs. antifungals has contributed to the emerging resistance in Candida species which is prompting the medicinal chemists worldwide to develop novel and more effective antifungal agents with a broad spectrum, better pharmacokinetic profile and low toxicity. ${ }^{15}$

Previously, it was reported that triazole-amino acids clubbed with an indole moiety have potent antifungal effects as they caused detrimental effects on the sterol biosynthetic pathway of $C$. albicans thus inducing cell wall defects leading to cell death in combination with currently available azole antifungals. ${ }^{16}$ On the basis of these findings on triazoleamino acid scaffolds and in continuation of our efforts for the development of antimicrobial agents, ${ }^{17-19}$ we report herein the synthesis of a series of novel triazole-amino acid hybrids (65-88) and their screening against three species of Candida (C. albicans, C. glabrata and C. tropicalis). This leads to the identification of 1,2,3-triazoles bearing phenylalanine (68) and tryptophan tails (70) as potent antifungals against FLC sensitive and resistant clinical isolates of $C$. albicans. Moreover, compounds with comparatively lower $\mathrm{IC}_{50}$ values were also subjected to cell proliferation assay on the HEK293 (Human Embryonic Kidney) cell line and were found to be non-toxic up to a $200 \mu \mathrm{g} \mathrm{mL} \mathrm{m}^{-1}$ concentration. Various assays for growth (time kill curve) and virulence (proteinase and phospholipase secretion) performed on Candida cells exposed to lead inhibitors (68 and 70) also showed promising results. A detailed study of lead compounds (68 and 70) on the larvae of Galleria mellonella further confirmed their non-toxic behavior and a significant reduction in Candida proliferation in vivo. Because of the importance of CYP51 in the antifungal drug studies, molecular docking was performed for the most active compounds against the predicted three-dimensional model of CYP51 from $C$. albicans in order to shed light on the mechanism and plausible binding modes of the compounds to the target enzyme. Our study revealed that the triazole-amino acid hybrids (68 and 70) provide a suitable core to be exploited for lead optimization to develop potent antifungal agents.

\section{Results and discussion}

\section{Chemistry}

The multistep synthetic approach was adopted for the preparation of the title compounds (65-88) as given in Scheme 1. Substituted benzylamines (17-24) were obtained via a two-step sequence involving oximation of substituted aryl aldehydes (1-8) followed by $\mathrm{Zn} / \mathrm{HCl}$ mediated reduction. ${ }^{18}$ Then, in another set of reactions azidopropionic acid, 26, was obtained from 3-bromopropionic acid, 25, by direct azide replacement using sodium azide in anhyd. DMF at $85{ }^{\circ} \mathrm{C}$. Coupling of azidopropionic acid, 26, with substituted benzylamines 17-24 in the presence of 1-ethyl-3-(3-dimethylaminopropyl) carbodiimide (EDC.HCl) and 1-hydroxybenzotriazole (HOBt) in acetonitrile yielded the corresponding azide intermediates 27-34 in moderate yield. In a separate set of reactions, boc-protected L-amino acids (35-37) were treated with propargyl bromide in 


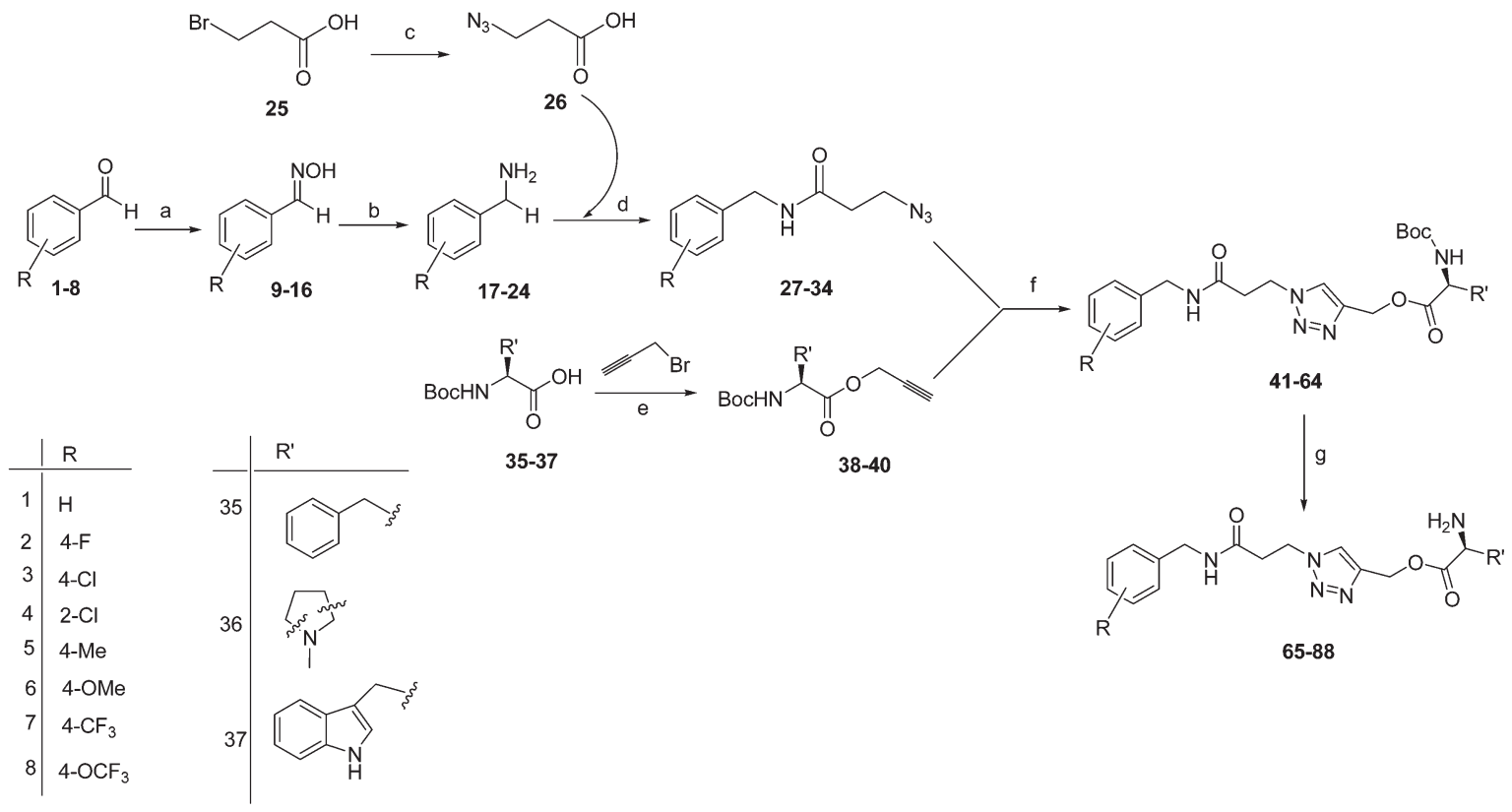

Scheme 1 Synthesis of triazole-amino acid hybrids. Reagents and conditions (a) $\mathrm{NH}_{2} \mathrm{OH} \cdot \mathrm{HCl}$, pyridine/ethanol (1:10), reflux; (b) $\mathrm{Zn}, \mathrm{HCl}$, ethanol, rt; (c) $\mathrm{NaN}_{3}, \mathrm{DMF}$, reflux; (d) $\mathrm{HOBt}, \mathrm{EDC} \cdot \mathrm{HCl}, \mathrm{NMM}, \mathrm{CH}_{3} \mathrm{CN}$, rt; (e) propargyl bromide, $\mathrm{K}_{2} \mathrm{CO}_{3}, \mathrm{DMF}$, rt; (f) CuSO $\mathrm{C}_{4} \cdot 5 \mathrm{H}_{2} \mathrm{O}$, sodium ascorbate, tertbutanol : water (1:2), rt; (g) pTSA, DCM, rt.

the presence of $\mathrm{K}_{2} \mathrm{CO}_{3}$ to provide alkyne intermediates (39-40) in excellent yield. Finally, the 1,2,3-triazole-amino acid hybrids (41-64) were synthesized via the Huisgen 1,3-dipolar cycloaddition reaction between alkynes $\mathbf{3 9 - 4 0}$ and azides 27-34 in the presence of copper sulphate and sodium ascorbate in a tert-butanol: water $(1: 2)$ mixture. The key intermediates, 41-64 were finally deprotected utilizing $p$-toluenesulfonic acid in dichloromethane to yield title compounds $\mathbf{6 5 - 8 8}$ in high yield (Table 1).

\section{In vitro anti-Candida activity}

We generated a library of 24 compounds that features the 1,2,3-triazole core and an amino acid (Phe/Pro/Trp) as a tail and screened all the analogues for in vitro anticandidal activity. Preliminary studies were done on three different Candida species: C. albicans, C. glabrata and C. tropicalis to see the effect of these analogues on the growth of Candida cells in vitro (Table 2). Fluconazole was used as a positive control. The unsubstituted and para-halogen substituted benzyl compounds with an L-phenylalanine tail showed modest activity (70.9-179.4 $\mu \mathrm{g} \mathrm{mL} \mathrm{m}^{-1}$ ) against most pathogenic C. albicans ATCC 90028 strain. Compound $\mathbf{6 8}$ with $p$-fluoro substitution and a phenylalanine tail emerged as the most potent $\left(\mathrm{IC}_{50}=\right.$ $70.9 \mu \mathrm{g} \mathrm{mL}^{-1}$ ) among all in the series as a selective inhibitor of C. albicans ATCC 90028 strain. Chloro substitution at the ortho position to the benzyl group (74) resulted in the decrease of activity $\left(340.0 \mu \mathrm{g} \mathrm{mL}^{-1}\right)$ in the same strain. The structureactivity relationship could not be established clearly in the case of analogues with an L-proline tail. Moreover, compound 66 bearing an unsubstituted benzyl group and an L-proline tail exhibited an $\mathrm{IC}_{50}$ value of $203.5 \mu \mathrm{g} \mathrm{mL} \mathrm{m}^{-1}$ in C. glabrata ATCC
90030 strain. It was found that the unsubstituted and parasubstituted triazole analogues with a tryptophan tail showed the best anticandidal activity against C. albicans ATCC 90028 strain. Compound 70 with $p$-fluoro substitution emerged as the most potent anticandidal agent $\left(\mathrm{IC}_{50}=22.4 \mu \mathrm{g} \mathrm{mL} \mathrm{L}^{-1}\right)$ compared to 67 , with no substitution, having $\mathrm{IC}_{50}=98.8 \mu \mathrm{g} \mathrm{mL}$ against C. albicans ATCC 90028 strain. It also inhibited the growth of C. glabrata with an $\mathrm{IC}_{50}$ of $163.2 \mu \mathrm{g} \mathrm{mL}^{-1}$. The $p$-methyl $\left(\mathbf{7 9}, \mathrm{IC}_{50}=168.7 \mu \mathrm{g} \mathrm{mL} \mathrm{L}^{-1}\right)$ and $p$-methoxy $\left(\mathbf{8 2}, \mathrm{IC}_{50}=\right.$ $\left.163.9 \mu \mathrm{g} \mathrm{mL} \mathrm{m}^{-1}\right)$ substitution were well tolerated compared to $p$-trifluoromethyl $\left(85, \mathrm{IC}_{50}=282.6 \mu \mathrm{g} \mathrm{mL} \mathrm{mL}^{-1}\right)$ and $p$-trifluoromethoxy $\left(88, \mathrm{IC}_{50}=1142.7 \mu \mathrm{g} \mathrm{mL}^{-1}\right)$ substitution where the activity was completely lost against C. albicans ATCC 90028 strain. Based on the results obtained with standard Candida strains, seven compounds $(67,68,70,71,73,79$ and 82) were selected for further investigation against both FLC-sensitive and resistant clinical C. albicans strains. Compounds with $p$-fluoro substitution with phenylalanine (68) and tryptophan (70) tails emerged as the most potent inhibitors for clinical strains too. Compound 68 showed a moderate inhibitory effect on clinically isolated C. albicans with $\mathrm{IC}_{50}$ in the range of 154.9-188.3 $\mu \mathrm{g} \mathrm{mL}^{-1}$. Similarly, compound 70 also showed inhibition of clinically isolated Candida cells with $\mathrm{IC}_{50}$ in the range of $149.63-176.1 \mu \mathrm{g} \mathrm{mL} \mathrm{m}^{-1}$. Both compounds, 68 and 70 showed potent inhibitory activity against FLC-resistant C. albicans with $\mathrm{IC}_{50}$ values of 671.08 and $634.98 \mu \mathrm{g} \mathrm{mL} \mathrm{m}^{-1}$, respectively, which otherwise is tolerant to $\mathrm{FLC}\left(\mathrm{IC}_{50}>1000 \mu \mathrm{g}\right.$ $\mathrm{mL}^{-1}$ ) (Table 3). The results prompted us to further explore the effect of these two lead inhibitors (68 and 70) on the growth of Candida sp. The fungistatic or fungicidal nature of lead compounds ( 68 and 70 ) was determined by time kill curve studies 
Table 1 Structure of triazole-amino acid hybrids

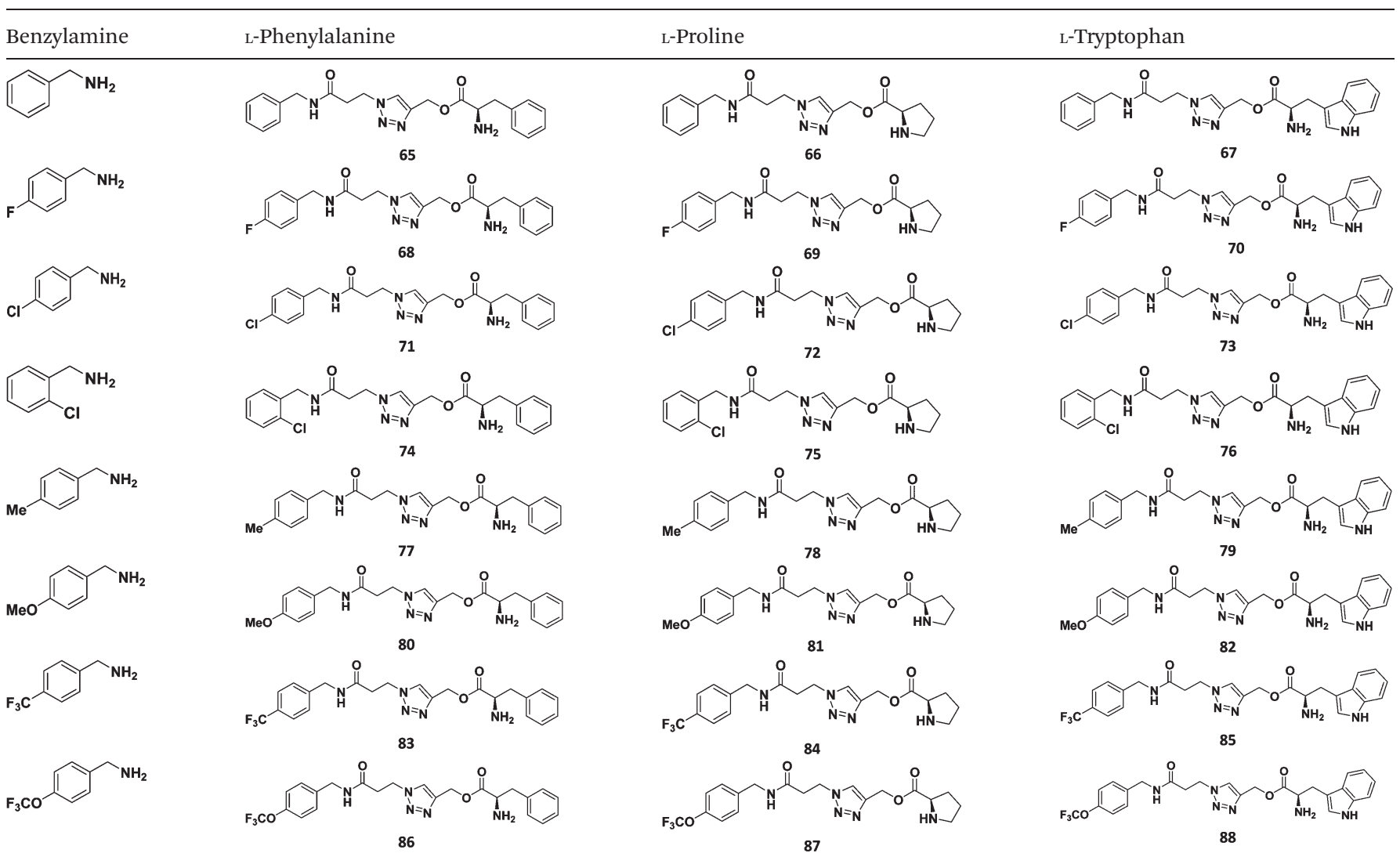

Table 2 In vitro anticandidal activity of compounds $65-88\left(\mathrm{IC}_{50}\right.$ in $\mu \mathrm{g}$ $\mathrm{mL}^{-1}$ ) against standard strains of Candida

\begin{tabular}{lrrrr}
\hline Comp. & C. alb. & C. gla. & C. tro. & ${ }^{1}$ C. alb. \\
\hline $\mathbf{6 5}$ & 179.4 & 506.5 & 364.7 & 377.0 \\
$\mathbf{6 6}$ & 473.8 & 203.5 & 741.5 & 541.3 \\
$\mathbf{6 7}$ & 98.8 & 944.1 & 475.7 & 303.7 \\
$\mathbf{6 8}$ & 70.9 & 1352.0 & 503.0 & 335.6 \\
$\mathbf{6 9}$ & 326.3 & 912.2 & 678.9 & 369.3 \\
$\mathbf{7 0}$ & 22.4 & 163.2 & 349.0 & 269.5 \\
$\mathbf{7 1}$ & 164.1 & 1065.3 & 389.4 & 314.9 \\
$\mathbf{7 2}$ & 420.2 & 267.4 & 927.1 & 351.8 \\
$\mathbf{7 3}$ & 161.0 & 975.5 & 556.4 & 313.3 \\
$\mathbf{7 4}$ & 340.0 & 383.6 & 421.4 & 303.5 \\
$\mathbf{7 5}$ & 376.0 & 247.5 & 852.0 & 333.8 \\
$\mathbf{7 6}$ & 227.1 & 684.3 & 542.3 & 378.7 \\
$\mathbf{7 7}$ & 294.4 & 851.3 & 497.7 & 300.3 \\
$\mathbf{7 8}$ & 478.7 & 326.9 & 684.3 & 636.5 \\
$\mathbf{7 9}$ & 168.7 & 1074.0 & 618.3 & 379.0 \\
$\mathbf{8 0}$ & 300.2 & 1121.1 & 447.8 & 292.7 \\
$\mathbf{8 1}$ & 554.0 & 265.6 & 571.2 & 562.3 \\
$\mathbf{8 2}$ & 163.9 & 427.2 & 423.6 & 340.9 \\
$\mathbf{8 3}$ & 315.3 & 371.1 & 407.6 & 310.0 \\
$\mathbf{8 4}$ & 526.0 & 268.3 & 468.0 & 580.3 \\
$\mathbf{8 5}$ & 282.6 & 272.4 & 662.3 & 321.3 \\
$\mathbf{8 6}$ & 865.4 & 1103.7 & 923.8 & 747.2 \\
$\mathbf{8 7}$ & 985.0 & 1006.4 & 971.4 & 966.0 \\
$\mathbf{8 8}$ & 1142.7 & 1081.6 & 991.0 & 998.8 \\
$\mathbf{F L C}$ & 15.6 & 7.8 & 8.5 & n.d.
\end{tabular}

Abbreviations: C. alb. $=$ C. albicans ATCC 90028; C. gla. $=$ C. glabrata ATCC 90030; C. tro. $=$ C. tropicalis ATCC $750 ;{ }^{1}$ C. alb. $=$ C. albicans ATCC 1026; n.d. = not done; NA = not active; FLC = fluconazole.
Table 3 In vitro anticandidal activity of selected potential compounds against clinical isolate of $C$. albicans

\begin{tabular}{lrrrr}
\hline Compound & ${ }^{*}$ C. alb. & ${ }^{*}$ C. alb. & ${ }^{*}$ C. alb. & ${ }^{\dagger}$ C. alb. \\
\hline $\mathbf{6 7}$ & 192.86 & 343.63 & 322.05 & $>1000$ \\
$\mathbf{6 8}$ & 154.92 & 188.37 & 183.13 & 671.08 \\
$\mathbf{7 0}$ & 149.63 & 153.19 & 176.10 & 634.98 \\
$\mathbf{7 1}$ & 387.90 & 206.48 & 368.69 & $>1000$ \\
$\mathbf{7 3}$ & 237.52 & 358.43 & 344.70 & $>1000$ \\
$\mathbf{7 9}$ & 563.93 & 249.64 & 258.77 & $>1000$ \\
$\mathbf{8 2}$ & 297.62 & 199.52 & 341.76 & $>1000$ \\
FLC & $<7.81$ & $<7.81$ & $<7.81$ & $>1000$
\end{tabular}

Abbreviations: ${ }^{*} C$. alb. $=$ C. albicans (fluconazole sensitive) $;$ C. alb. $=$ C. albicans (fluconazole resistant).

on FLC-sensitive as well as resistant strains of $C$. albicans. Both compounds showed a fungistatic effect on the growth of C. albicans with an efficacy much superior to that of the conventional standard drug fluconazole. Furthermore, no significant changes in growth were observed at the concentrations lower than $120 \mu \mathrm{g} \mathrm{mL}^{-1}$ of compounds 68 and 70 (Fig. 2).

Extracellular hydrolytic enzymes (e.g. phospholipases and proteinases) are potent virulence factors which play an important role in the establishment of Candida infection. ${ }^{20}$ To investigate whether the lead compounds (68 and 70) have any effect on the extracellular secretion of these enzymes, an inhibition 

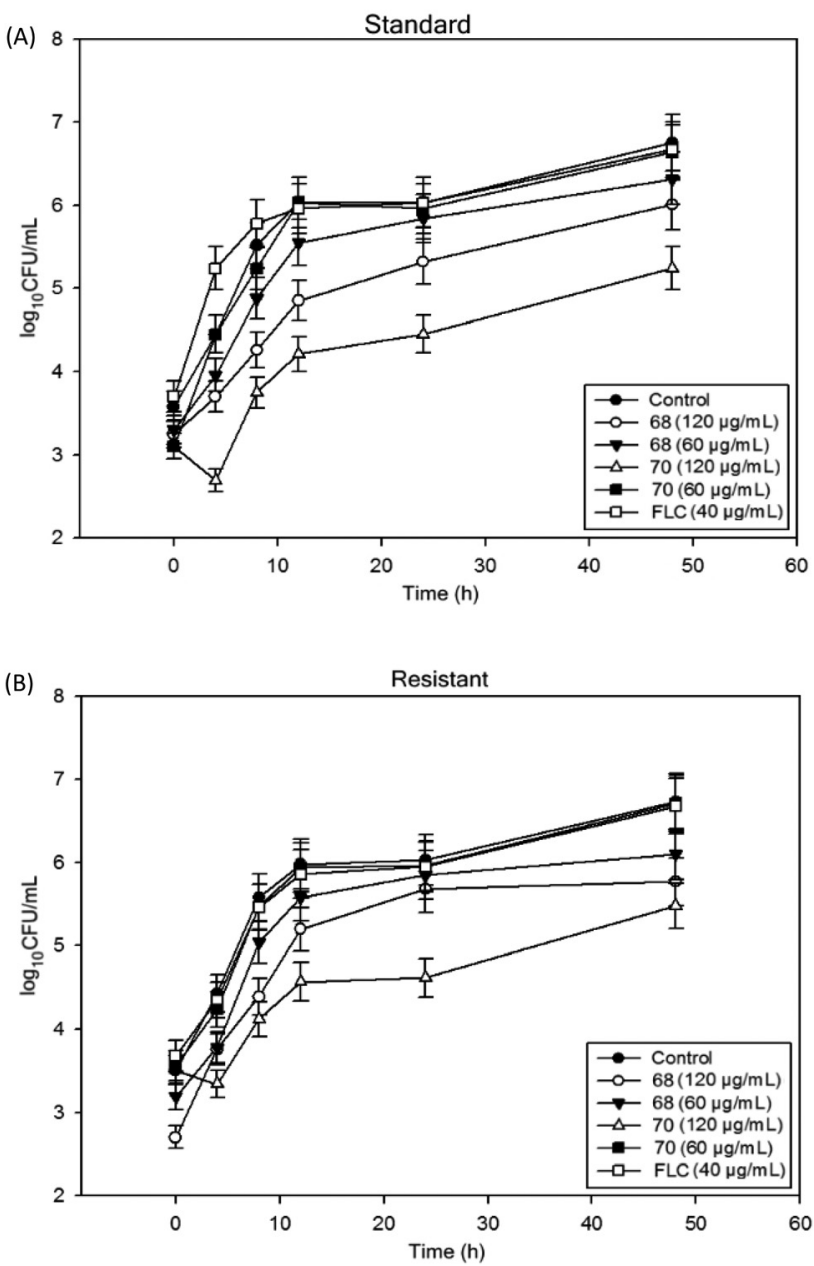

Fig. 2 Time kill curves of (A) fluconazole sensitive C. albicans ATCC 90028; (B) fluconazole resistant C. albicans at various concentrations of 68 and 70. The results indicate the fungi-static nature of these compounds.

assay was performed using standard as well as resistant C. albicans strains. The results showed that on treatment with $120 \mu \mathrm{g} \mathrm{mL} \mathrm{m}^{-1}$ of compound 68, proteinase secretion was decreased by 29, 22 and $23.5 \%$ in standard, FLC-sensitive and resistant strains of $C$. albicans, respectively, while at the same concentration, compound $\mathbf{7 0}$ decreased the proteinase secretion by 30,33 and $17 \%$ against the respective strains. Similar results were obtained at a $60 \mu \mathrm{g} \mathrm{mL} \mathrm{m}^{-1}$ concentration of both compounds, 68 and 70, with no significant differences in the inhibition of proteinase secretion (Fig. 3A). At similar concentrations, compound 68 caused 40, 38, and 38\% inhibition in phopholipase secretion whereas compound 70 decreased the secretions respectively by 36, 27 and 38\% in standard, FLC-sensitive and resistant strains of C. albicans (Fig. 3B). Our results suggest that both compounds (68 and 70) significantly reduce the secretion of proteinases and phospholipases in Candida spp. which are vital to fungal invasion of host tissues and immunosuppression.
(A)

Proteinase assay

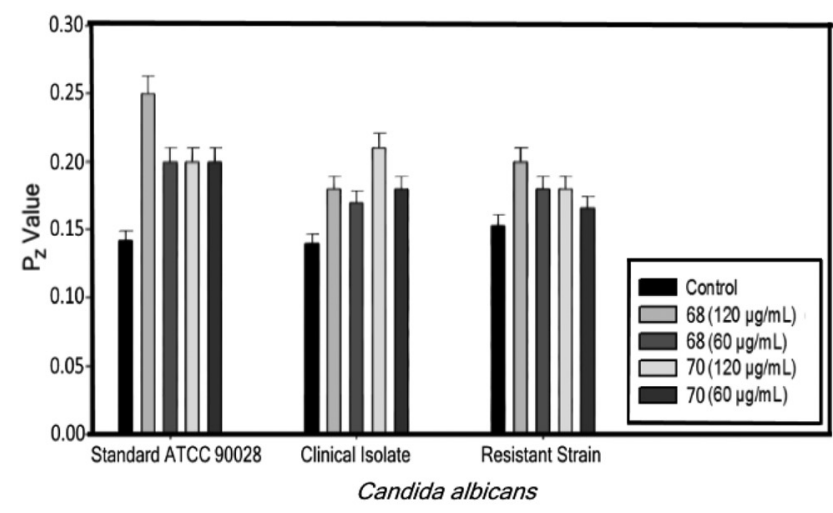

(B)

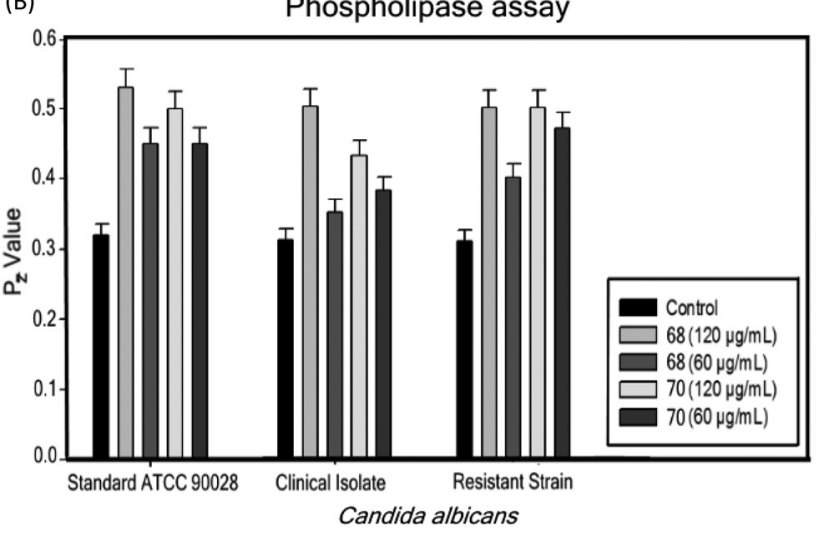

Fig. 3 Effect of compounds 68 and 70 on (A) proteinase secretion and; (B) phospholipase secretion. These hydrolytic enzymes act as a potent virulence factor and play an important role in the establishment of Candida infection. The higher $P_{z}$ value indicates the lower secretion of enzyme. At a $125 \mu \mathrm{g} \mathrm{mL}^{-1}$ concentration, compounds 68 and 70 cause 17 to $38 \%$ decrease in secretion of these enzymes.

The effect of lead compounds (68 and 70) on the morphology of $C$. albicans was monitored by transmission electron microscopy (TEM) which led to the exploration of the possible antifungal mechanism of action. Candida cells treated with $120 \mu \mathrm{g} \mathrm{mL} \mathrm{m}^{-1}$ of 68 and 70 and the untreated control cells were used for TEM analysis. It was observed, as shown in Fig. 4,

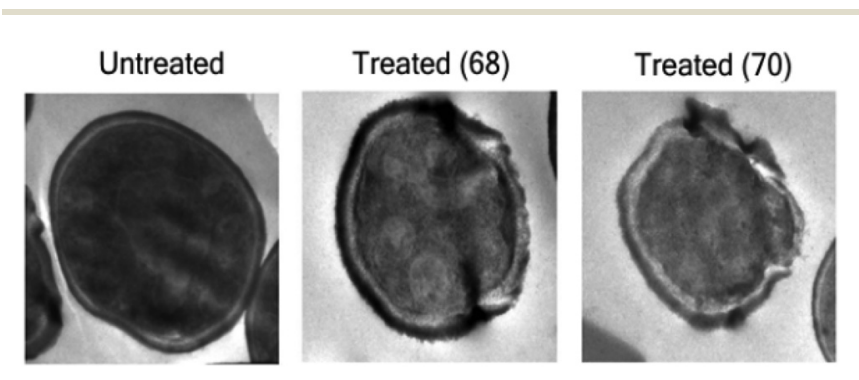

Fig. 4 Representative transmission electron micrographs of $C$. albicans ATCC 90028 cells exposed to 68 and 70 at their respective MICs. The figure showed significant damage to Candida cells. The shape of the cell became abnormal and the cell wall lost its integrity, became irregular and ruptured. 
that the untreated cells are normal in shape with uniform cell density and an intact cell wall while the treated cells showed several deformations. On exposure to 68 or 70, significant damage could be seen in Candida cells wherein the cell shape became abnormal and the cell wall lost its integrity becoming irregular and ruptured. The intracellular organelles disappeared indicating the necrotic mode of cell death. Thus, we can conclude from the results of TEM analysis that the lead compounds (68 and 70) may be interfering with the biosynthesis of the cell membrane.

It is well known that azole drugs like FLC inhibit ergosterol biosynthesis by destroying both membrane integrity and the function of some membrane-bound proteins and therefore affecting fungal cell growth and proliferation. ${ }^{21}$ The effect of the lead compounds (68 and 70) was studied on ergosterol biosynthesis in $C$. albicans to further support our suggestion that these compounds interfere with the biosynthesis of the cell membrane. The ergosterol content of the exposed cells was estimated in FLC-sensitive and resistant Candida cells by a method reported previously by Arthington-Skaggs et $a l^{22}$ and FLC was used as a positive control. The results showed a dose dependent decrease in the ergosterol content when the cells were grown in varying concentrations of 68 and 70 (Fig. 5). The mean decrease in the total ergosterol content for standard strains was found to be $5 \%$ at $30 \mu \mathrm{g} \mathrm{mL} \mathrm{m}^{-1}, 27 \%$ at $60 \mu \mathrm{g} \mathrm{mL}$ and $73 \%$ at $120 \mu \mathrm{g} \mathrm{mL}^{-1}$ of compound 68 . The mean decrease in the total ergosterol content for FLC-resistant $C$. albicans was found to be $2 \%$ at $30 \mu \mathrm{g} \mathrm{mL} L^{-1}, 23 \%$ at $60 \mu \mathrm{g} \mathrm{mL} \mathrm{m}^{-1}$ and $79 \%$ at
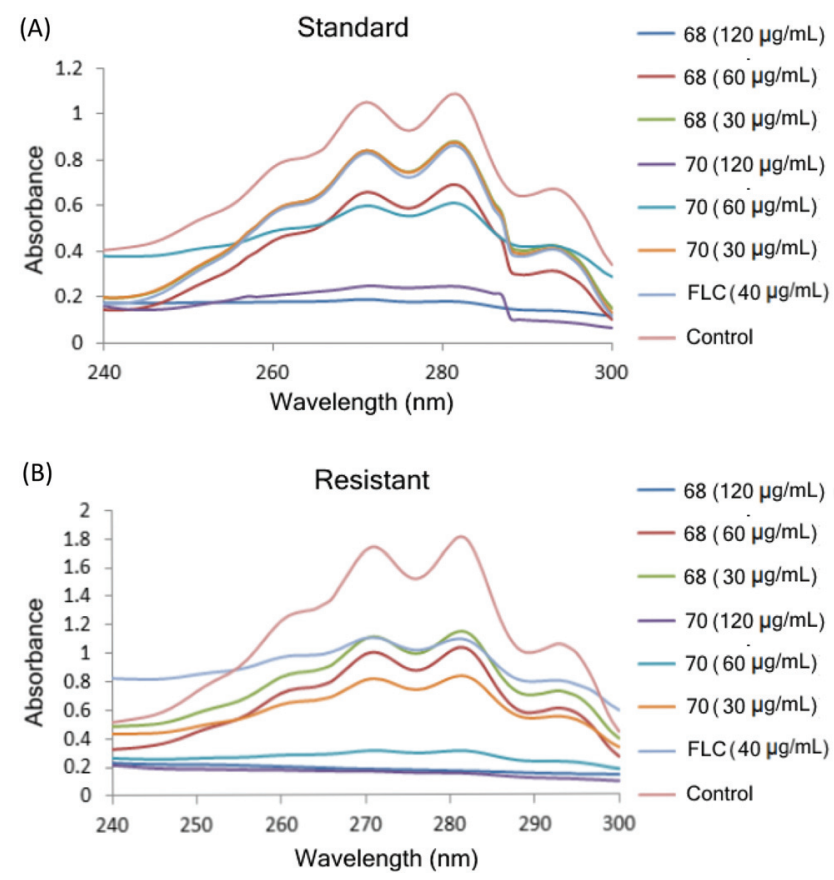

Fig. 5 UV spectrophotometric sterol profiles of (A) fluconazole sensitive standard C. albicans ATCC 90028 and; (B) fluconazole resistant C. albicans. At $120 \mu \mathrm{g} \mathrm{mL} \mathrm{m}^{-1}$, the mean decrease in total ergosterol content for standard as well as resistant $C$. albicans were found in the range of $48-96 \%$.
$120 \mu \mathrm{g} \mathrm{mL} \mathrm{m}^{-1}$ of compound 68. Similarly, the mean decrease in the total ergosterol content for standard C. albicans was found to be $15 \%$ at $30 \mu \mathrm{g} \mathrm{mL} \mathrm{m}^{-1}, 37 \%$ at $60 \mu \mathrm{g} \mathrm{mL}^{-1}$ and $48 \%$ at $120 \mu \mathrm{g} \mathrm{mL} \mathrm{m}^{-1}$ of $\mathbf{7 0}$. However, the decrease in the total ergosterol content for FLC-resistant C. albicans was $7 \%$ at 30

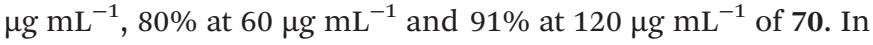
the presence of $100 \mu \mathrm{g} \mathrm{mL}{ }^{-1}$ of FLC, the decrease in the ergosterol content was $25 \%$ and $28 \%$, respectively, for standard and FLC-resistant $C$. albicans (Fig. 5). Our results suggest that compounds 68 and 70 inhibit the total ergosterol content more effectively in comparison to FLC in all the Candida strains tested here. In conclusion, the lead compounds (68 and 70) caused ergosterol depletion resulting in the disruption of the cell membrane which is consistent with the results of TEM analysis.

The cytotoxicity of the compounds with comparatively lower $\mathrm{IC}_{50}$ values $(\mathbf{6 5}, \mathbf{6 7 - 7 1}, \mathbf{7 3 - 7 4}, \mathbf{7 9}, \mathbf{8 2 - 8 3}, \mathbf{8 5})$ was checked by the MTT assay using the HEK293 cell line (Fig. 6). It is evident from the results that all the twelve selected compounds $(\mathbf{6 5}$, 67-71, 73-74, 79, 82-83, 85) displayed more than $85 \%$ cell viability at $50 \mu \mathrm{g} \mathrm{mL} \mathrm{mL}^{-1}$ concentration. Out of 12 , eight compounds $(67-71,73,79,82-83)$ displayed more than $70 \%$ cell viability even at a concentration of $200 \mu \mathrm{g} \mathrm{mL}{ }^{-1}$ which indicated the non-cytotoxic nature of these compounds. On increasing the concentration from 400 to $600 \mu \mathrm{g} \mathrm{mL}{ }^{-1}$ for all the selected compounds, the cells were found to be more than $50 \%$ viable. The hemolytic assay was also performed with lead inhibitors 68 and 70 to exclude any possible toxicity on human RBCs. At $125 \mu \mathrm{g} \mathrm{mL} \mathrm{mL}^{-1}$, compounds $\mathbf{6 8}$ and 70 caused $10 \%$ and $15 \%$ cell lysis, respectively, in comparison to $36 \%$ cell lysis caused by FLC at the same concentration (Fig. 7). More interestingly, compounds $\mathbf{6 8}$ and $\mathbf{7 0}$ were found negligibly toxic up to $500 \mu \mathrm{g} \mathrm{mL} \mathrm{m}^{-1}$, with only $18 \%$ and $22 \%$ cell lysis, respectively.

\section{Modeling and in silico docking}

The lanosterol 14- $\alpha$ demethylase enzyme (CYP51) is a member of the cytochrome P450 superfamily which catalyses the

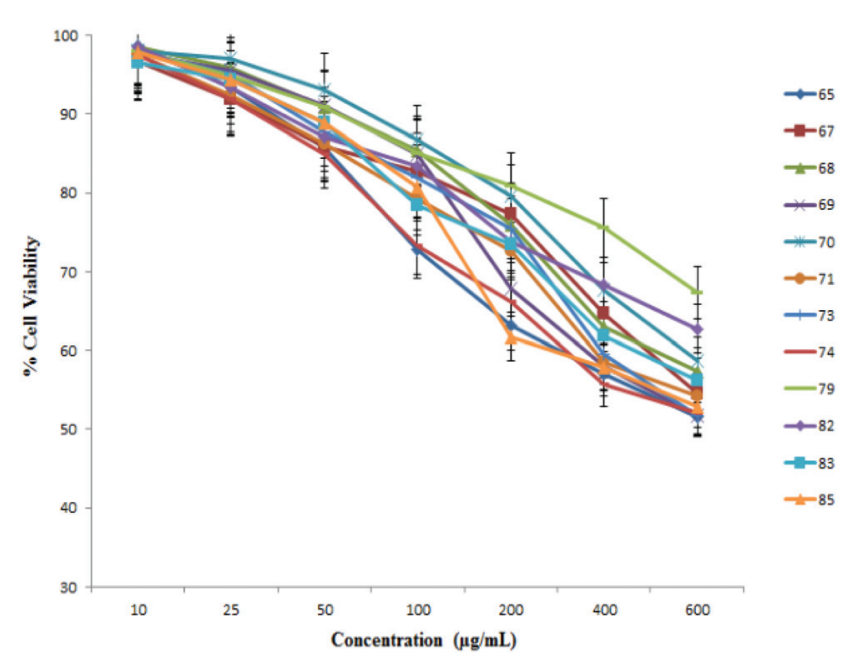

Fig. 6 Cell viability assay on the HEK293 cell line. 


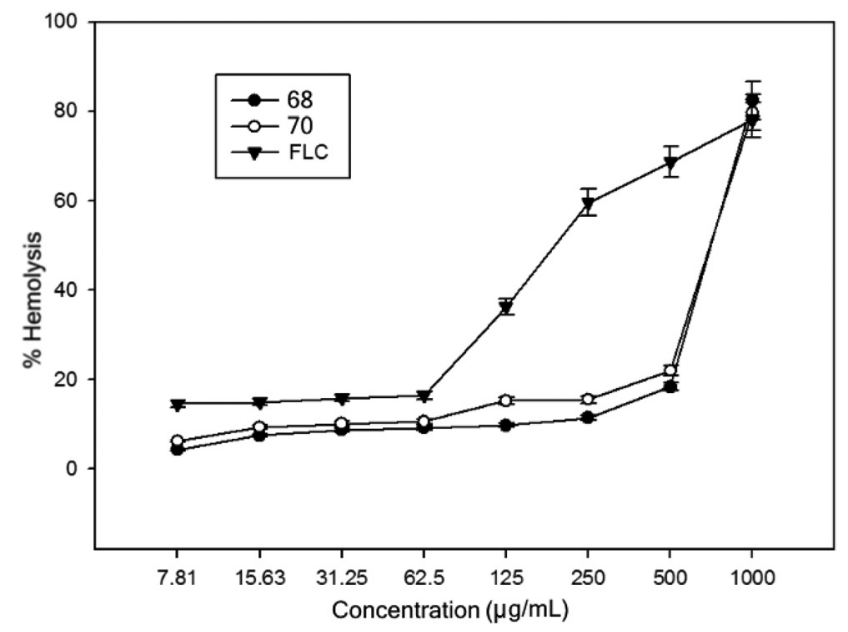

Fig. 7 Hemolytic assay for compounds 68 and 70 on human red blood cells (hRBCs).

oxidative removal of the 14- $\alpha$ methyl group from lanosterol in the ergosterol biosynthesis pathway. Inhibition of CYP51 is shown to directly deplete ergosterol resulting in the inhibition of fungal growth, making it the primary target for the azole based antifungal drugs. ${ }^{23}$ Our results have established that the synthesis of ergosterol is inhibited, which may cause deformation of the cell membrane and its leakage indicating a classical azole based effect on the fungal CYP51. CYP51 is a membrane bound protein that is difficult to purify and structural assessment is only possible by modelling closely related structures. In this study, we have modeled C. albicans like CYP51 from $S$. cerevisiae. A structure based sequence alignment showed that CYP51 from $S$. cerevisiae has $65 \%$ sequence homology with the CYP51 of C. albicans (Fig. 8). The crystal structure of $S$. cerevisiae CYP51 (PDB.4LXJ) was used as a template to

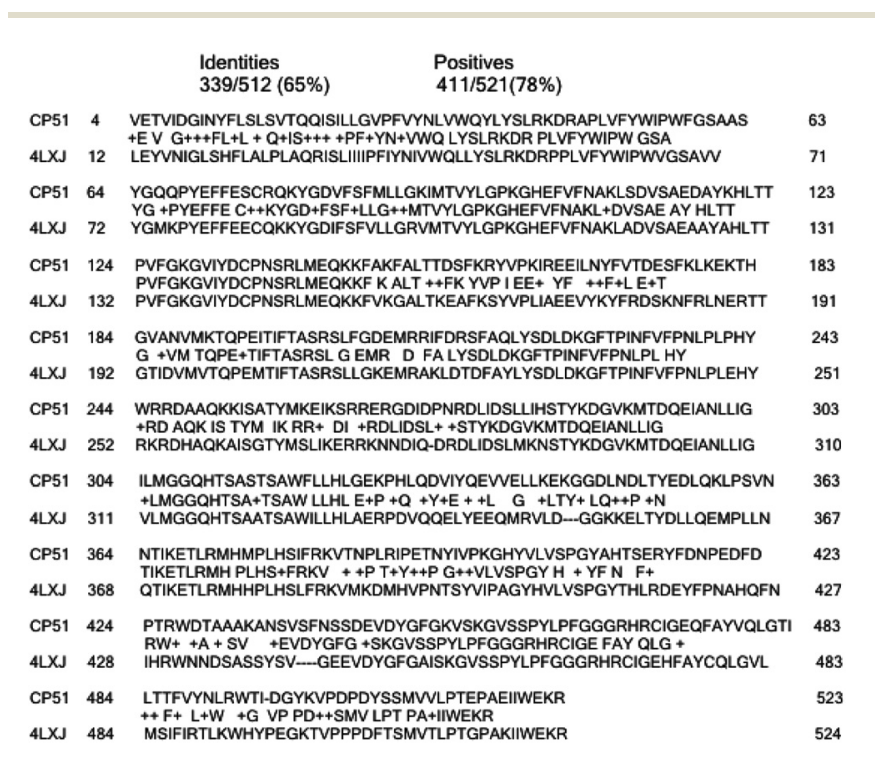

Fig. 8 Structure based sequence alignment of CYP51 from S. cerevisiae and CYP51 of C. albicans. construct a model of C. albicans CYP51. The model was further refined using energy minimization and molecular dynamics simulation. We generated 5 model structures for CYP51 from C. albicans and checked their Ramachandaran plot values. Among the 5 models, model 3 showed a nearly $89 \%$ Ramachandaran value, by careful analysis of the residues in the disallowed region. Structural superimposition of model 3 with its template $4 \mathrm{LXJ}$, showed an RMSD value of 0.248 across 501 atom pairs (Fig. 9A). The mode of binding of lead inhibitors 68 and 70 with modeled C. albicans like CYP51 was identified using molecular docking with Autodock Vina and Ligplot (Fig. 9B-E). Since both lead compounds have an azole group flanked by fluorobenzyl and hydrophobic side chains (Phe in 68 and Trp in 70) we have also performed hydrophobic interaction analysis using LIGPLOT to better characterize the interactions that leads to in vitro antifungal activity. The results revealed that proline attached to azole showed significantly less hydrogen bonding and hydrophobic interactions and the compounds were consequently less effective as inhibitors (Tables 1 and 2). Tryptophan and phenylalanine based compounds 68 and 70 with a common terminal $p$-fluorobenzyl group (Table 1) are shown to be more effective inhibitors. The center of the active site is positioned between the I and F helices with heme sitting in the center of the core. Docking studies showed that both $\mathbf{6 8}$ and $\mathbf{7 0}$ were bound very close to the heme group in the active site pocket of CYP51 interacting with active site residues with high binding affinities $(68=$ $-10.1 \mathrm{kcal} \mathrm{mol}^{-1}$ and $70=-9.2 \mathrm{kcal} \mathrm{mol}^{-1}$ ). A longer side chain of the compound compared to the fluconazole appeared to be accommodated in the active site pocket (Fig. 9B and D). The amino group of compound $\mathbf{6 8}$ formed a H-bond with the Ser506 residue and the terminal $p$-fluorobenzyl group was very close to the heme, residue Ser506 in the $\beta$-turn connecting $\beta 4-1$ and $\beta 4-2$ and interacted with the heme group. A number of hydrophobic interactions were observed with Leu376, Phe228, Tyr132, Ile131 and Thr122 (Fig. 9B and C). The terminal $p$-fluorobenzyl group of the inhibitor was found to be extremely close to the Tyr132 and Phe228 phenyl rings showing a possible $\pi-\pi$ stacking. Tyr132 has been found to play an important role in fluconazole susceptibility of CYP51 with a fluconazole resistant isolate of $C$. albicans showing mutation in Tyr $132 .{ }^{24}$ Lead compound 70 similarly showed hydrogen bonding with Asp214 and Glu194 with the side chain of tryptophan at the entrance of the substrate binding pocket. A number of important hydrophobic interactions were detected with Gln309, Ser222, Tyr221, Ala218, Phe213 and Ile197, all these residues are parts of the helix F, helix I and FG loop in the active site pocket of the CYP51 (Fig. 9D and E). Several residues that are important in the active site were identified as common residues that showed interaction with both 68 and 70 and interacted laterally and spanned the length of the active site close to the heme group. The $\mathrm{N}$-terminal of the helix I together with the BC loop forms the entrance of the substrate access channel and a strong interaction close to the substrate binding site might affect the architecture of the active site which can distort the specificity 


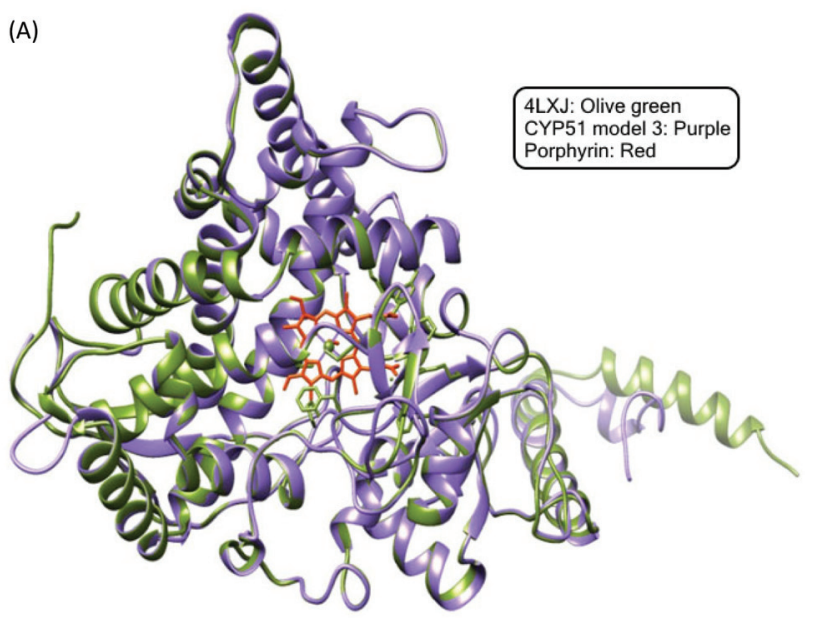

68
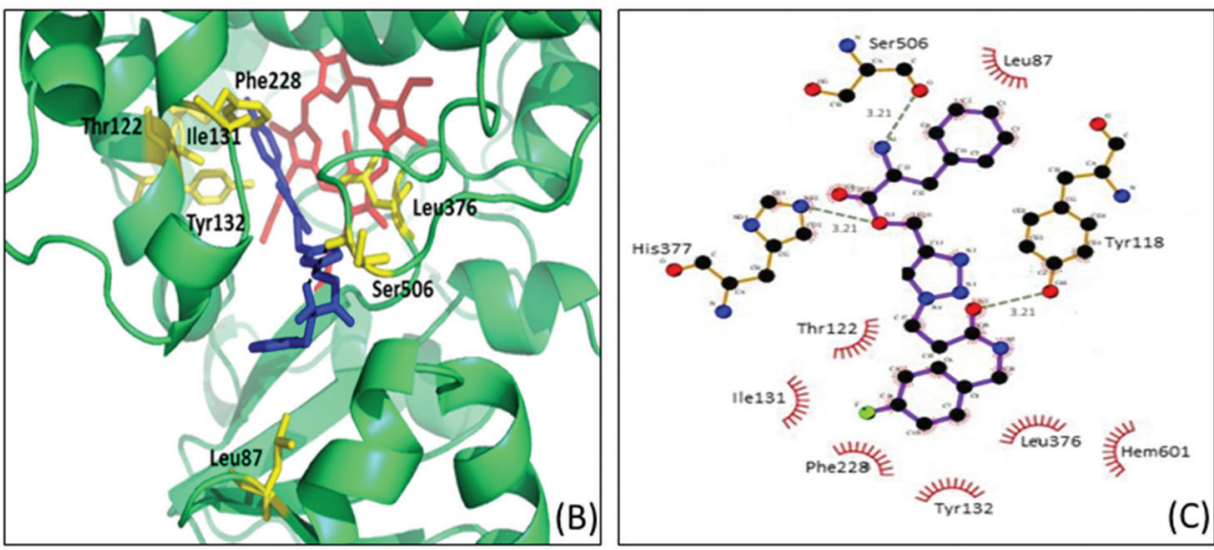

70
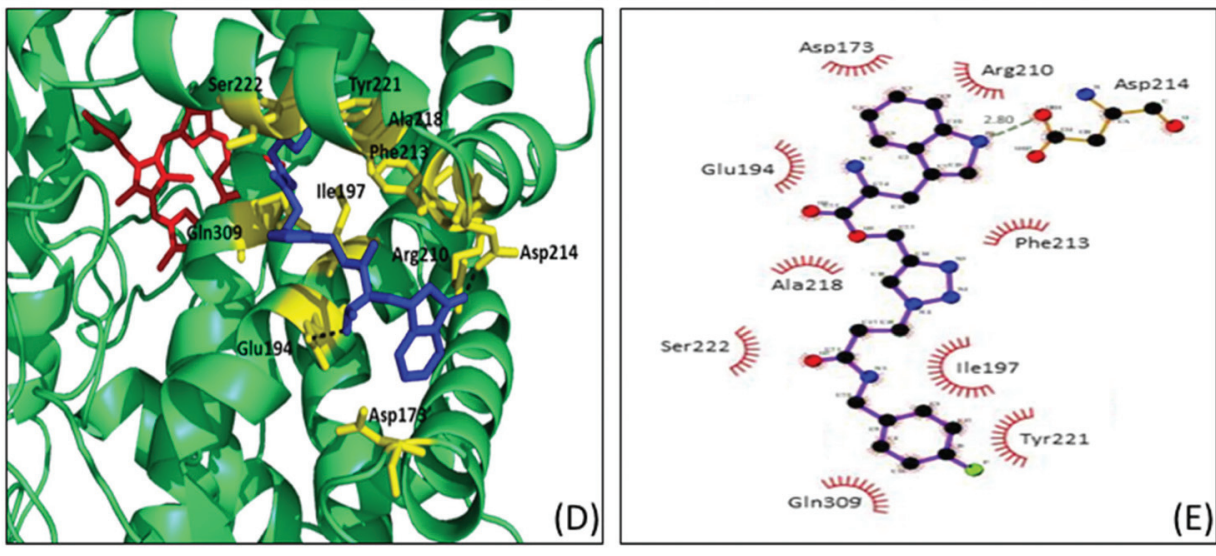

Binding energy: $68=-10.1 \mathrm{kcal} / \mathrm{mol} ; 70=-9.2 \mathrm{kcal} / \mathrm{mol}$

Fig. 9 (A) Structural superimposition of model 3 with its template $4 \mathrm{LXJ}$; (B) the plausible mode of binding of 68 in the active site of modeled CYP51; (C) LIGPLOT analysis of binding of 68; (D) the possible mode of binding of 70 in the active site of modeled CYP51; (E) LIGPLOT analysis of binding of 70. Binding energy: $68=-10.1 \mathrm{kcal} \mathrm{mol}^{-1} ; 70=-9.2 \mathrm{kcal} \mathrm{mol}{ }^{-1}$

of the substrate. In the absence of the crystal structure of CYP51 from C. albicans interacting with its natural substrate, the interaction with the modeled CYP51 provides a rationale for designing lead inhibitors based on the active site and optimization of the structure activity relationship.

\section{In vivo assessment against Galleria mellonella}

The insect immune response bears many similarities to the innate immune response of mammals and as a consequence insects may be used to evaluate the virulence of microbial 
pathogens or assess the toxicity of antimicrobial drugs. The larvae of G. mellonella have been used previously to assess the toxicity of novel antifungal compounds and the results showed a strong correlation with those obtained using mammals. ${ }^{25} \mathrm{An}$ in vivo study on the larvae of $G$. mellonella indicated significant anticandidal potential of compounds 68 and 70. The viability of larvae was not affected following the administration of the compounds up to a concentration of $2.5 \mathrm{mg} \mathrm{mL}^{-1}$ which showed a non-toxic behaviour towards the larvae (Fig. 10A-C). Again, at the same concentration no significant alteration in the haemocyte density of the larvae was found which indicated the lack of an immune response (Fig. 10D). The administration of a dose of $2.5 \mathrm{mg} \mathrm{mL}^{-1}$ of compounds 68 and 70 to the larvae previously infected with $C$. albicans reduced yeast replication in vivo by $50 \%$ and $70 \%$, respectively, as measured at 24 h (Fig. 10E).

\section{Experimental section}

\section{Chemistry}

All the chemicals and solvents (analytical grade) were purchased from Sigma-Aldrich, USA. Thin-layer chromatographic analysis was carried out on precoated Merck silica gel $60 \mathrm{~F}_{254}$ TLC aluminium sheets and the spots were visualized under UV light at $254 \mathrm{~nm}$, by iodine-vapor staining or ninhydrin test. IR spectra were recorded on an Agilent Cary 630 FT-IR spectrometer. ${ }^{1} \mathrm{H}$ and ${ }^{13} \mathrm{C}$ NMR spectra were obtained in $\mathrm{CDCl}_{3} / \mathrm{DMSO} d_{6}$ as a solvent with tetramethylsilane (TMS) as an internal standard on either a Bruker Spectrospin DPX-300 spectrometer at $300 \mathrm{MHz}$ and $75 \mathrm{MHz}$, respectively, or a Bruker Avance II 400 spectrometer at $400 \mathrm{MHz}$. 2D spectra (COSY and HETCOR) were recorded on a Jeol, JNM-EXCP 400 spectrometer. Splitting patterns are designated as follows: $\mathrm{s}$ (singlet), d (doublet), $\mathrm{t}$ (triplet), q (quartet), m (multiplet) or brs (broad). ${ }^{1} \mathrm{H}$ NMR chemical shift $(\delta)$ values are reported in parts per million (ppm) relative to the residual solvent $\left(\mathrm{CDCl}_{3}, \delta 7.26\right.$ and DMSO- $d_{6}$, $\delta 2.54) .{ }^{13} \mathrm{C}$ NMR chemical shifts $(\delta)$ are reported in ppm relative to $\mathrm{CDCl}_{3}, \delta 77.16$ and DMSO- $d_{6}, \delta 39.5$ and coupling constants $(J)$ are expressed in hertz $(\mathrm{Hz})$. Mass spectra were recorded on a Waters Tandem Quadrupole Detector (TQD) integrated with an electron spray ionization mass spectrometer and on an Agilent RRLC MS 6320 Ion Trap spectrometer fitted with an electrospray ionization (ESI) interface. Melting points were measured on a digital Buchi melting point apparatus (M-560) and are uncorrected. The specific rotation of 41-64 was recorded on an Anton Paar MCP-100 digital polarimeter at $20^{\circ} \mathrm{C}$ using sodium D light at a conc. of $1 \mathrm{~g}$ per $100 \mathrm{~mL}$ in ethanol. Purification of the compounds was carried out by silica gel column chromatography (230-400 mesh size, Merck, Germany) with the indicated eluent.

General procedure for the synthesis of oximes (9-16). Example: synthesis of 4-fluorobenzaldehyde oxime (10)

4-Fluorobenzaldehyde oxime was synthesized by reacting 4-fluorobenzaldehyde (2) (12 mmol, $1.29 \quad \mathrm{~mL})$ with
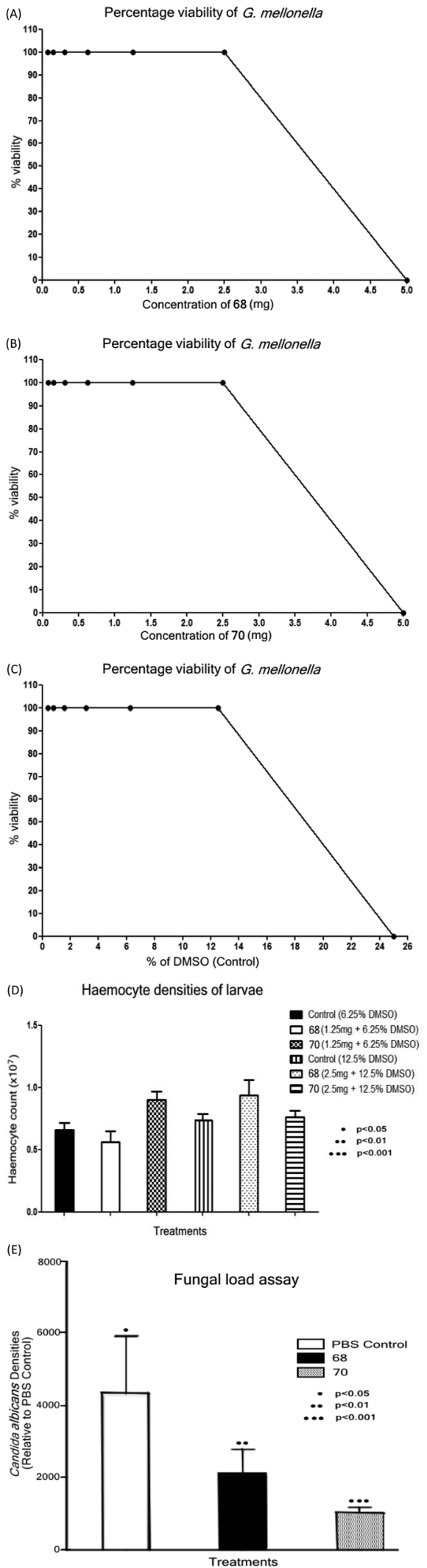

Fig. 10 Percentage viability of Galleria mellonella in the presence of (A) 68; (B) 70; (C) DMSO; (D) haemocyte densities of larvae and (E) fungal load assay. 
hydroxylamine hydrochloride (13 mmol, $0.90 \mathrm{~g}$ ) in ethanol $(20 \mathrm{~mL})$ and pyridine $(2.0 \mathrm{~mL})$ mixture under reflux for 21-23 h. After cooling, the solvent was evaporated under vacuo and water was added to this residue. This mixture was stirred in an ice bath until the oxime crystallizes. The solid was filtered and washed with water. The product was crystallized from ethanol. ${ }^{18}$

Benzaldehyde oxime (9). Colorless oil, yield $80 \% . R_{\mathrm{f}}=0.58$ (20\% EtOAc in hexane). ${ }^{1} \mathrm{H}$ NMR (300 $\left.\mathrm{MHz} \mathrm{CDCl}_{3}\right) \delta: 8.67$ (s, 1H), 8.17 (s, 1H), 7.59-7.56 (m, 2H), $7.38(\mathrm{t}, J=3.3 \mathrm{~Hz}, 3 \mathrm{H})$. IR $\nu_{\max }($ neat $) / \mathrm{cm}^{-1} 3275(\mathrm{O}-\mathrm{H}), 1640(\mathrm{C}=\mathrm{N})$ and $952(\mathrm{~N}-\mathrm{O})$.

4-Fluorobenzaldehyde oxime (10). White solid, yield $84 \%$. $R_{\mathrm{f}}=0.50$ (20\% EtOAc in hexane). Mp 86-88 ${ }^{\circ} \mathrm{C} .{ }^{1} \mathrm{H} \mathrm{NMR}$ $\left(300 \mathrm{MHz}, \mathrm{CDCl}_{3}\right) \delta: 8.55(\mathrm{~s}, 1 \mathrm{H}), 8.13(\mathrm{~s}, 1 \mathrm{H}), 7.58-7.53(\mathrm{~m}$, 2H), 7.10-7.05 (m, 2H). IR $\nu_{\max }$ (neat) $/ \mathrm{cm}^{-1} 3253(\mathrm{O}-\mathrm{H}), 1689$ $(\mathrm{C}=\mathrm{N})$ and $963(\mathrm{~N}-\mathrm{O})$.

4-Chlorobenzaldehyde oxime (11). White solid, yield $89 \%$. $R_{\mathrm{f}}=0.61$ (20\% EtOAc in hexane). Mp 102-104 ${ }^{\circ} \mathrm{C} .{ }^{1} \mathrm{H}$ NMR $\left(400 \mathrm{MHz} \mathrm{CDCl}_{3}\right) \delta: 8.10(\mathrm{~s}, 1 \mathrm{H}), 7.52(\mathrm{~d}, J=8.4 \mathrm{~Hz}, 2 \mathrm{H}), 7.36$ $(\mathrm{d}, J=8.5 \mathrm{~Hz}, 2 \mathrm{H})$. IR $\nu_{\max }($ neat $) / \mathrm{cm}^{-1} 3257(\mathrm{O}-\mathrm{H}), 1659$ $(\mathrm{C}=\mathrm{N})$ and $959(\mathrm{~N}-\mathrm{O})$.

2-Chlorobenzaldehyde oxime (12). White crystalline solid, yield $94 \% . R_{\mathrm{f}}=0.58$ (20\% EtOAc in hexane). Mp $72-74{ }^{\circ} \mathrm{C}$. ${ }^{1} \mathrm{H}$ NMR (300 MHz, $\left.\mathrm{CDCl}_{3}\right) \delta: 8.88(\mathrm{~s}, 1 \mathrm{H}), 8.59(\mathrm{~s}, 1 \mathrm{H}), 7.84(\mathrm{~d}$, $J=7.2 \mathrm{~Hz}, 1 \mathrm{H}), 7.41(\mathrm{~d}, J=7.8 \mathrm{~Hz}, 1 \mathrm{H}), 7.36-7.26(\mathrm{~m}, 2 \mathrm{H})$. IR $\nu_{\max }($ neat $) / \mathrm{cm}^{-1} 3242(\mathrm{O}-\mathrm{H}), 1659(\mathrm{C}=\mathrm{N})$ and $970(\mathrm{~N}-\mathrm{O})$.

4-Methylbenzaldehyde oxime (13). White solid, yield $90 \%$. $R_{\mathrm{f}}=0.56$ (20\% EtOAc in hexane). Mp 74-76 ${ }^{\circ} \mathrm{C} .{ }^{1} \mathrm{H}$ NMR $\left(400 \mathrm{MHz}, \mathrm{CDCl}_{3}\right) \delta: 8.10(\mathrm{~s}, 1 \mathrm{H}), 7.52(\mathrm{~d}, J=8.4 \mathrm{~Hz}, 2 \mathrm{H}), 7.36$ $(\mathrm{d}, J=8.4 \mathrm{~Hz}, 2 \mathrm{H}), 2.53(\mathrm{~s}, 3 \mathrm{H})$. IR $\nu_{\max }($ neat $) / \mathrm{cm}^{-1} 3260$ $(\mathrm{O}-\mathrm{H}), 1659(\mathrm{C}=\mathrm{N})$ and $963(\mathrm{~N}-\mathrm{O})$.

4-Methoxybenzaldehyde oxime (14). Yellow oil, yield $90 \%$. $R_{\mathrm{f}}=0.43$ (20\% EtOAc in hexane). ${ }^{1} \mathrm{H}$ NMR (400 $\mathrm{MHz}, \mathrm{CDCl}_{3}$ ) $\delta: 8.10(\mathrm{~s}, 1 \mathrm{H}), 7.52(\mathrm{~d}, J=8.8 \mathrm{~Hz}, 2 \mathrm{H}), 6.91(\mathrm{~d}, J=8.8 \mathrm{~Hz}, 2 \mathrm{H})$, $3.83(\mathrm{~s}, 3 \mathrm{H})$. IR $\nu_{\max }$ (neat) $/ \mathrm{cm}^{-1} 3234(\mathrm{O}-\mathrm{H}), 1611(\mathrm{C}=\mathrm{N})$ and $952(\mathrm{~N}-\mathrm{O})$.

4-(Trifluoromethyl)benzaldehyde oxime (15). Light yellow solid, yield $88 \%$. $R_{\mathrm{f}}=0.55$ (20\% EtOAc in hexane). Mp 88-90 ${ }^{\circ} \mathrm{C} .{ }^{1} \mathrm{H}$ NMR (400 MHz, $\mathrm{CDCl}_{3}$ ) $\delta: 8.17$ (s, 1H), $7.70(\mathrm{~d}$, $J=8.0 \mathrm{~Hz}, 2 \mathrm{H}), 7.64(\mathrm{~d}, J=8.4 \mathrm{~Hz}, 2 \mathrm{H}) . \mathrm{IR} \nu_{\max }$ (neat) $/ \mathrm{cm}^{-1}$ $3272(\mathrm{O}-\mathrm{H}), 1622(\mathrm{C}=\mathrm{N})$ and $974(\mathrm{~N}-\mathrm{O})$.

4-(Trifluoromethoxy)benzaldehyde oxime (16). Colourless crystals, yield 90\%. $R_{\mathrm{f}}=0.61$ (20\% EtOAc in hexane). Mp 47-49 ${ }^{\circ} \mathrm{C} .{ }^{1} \mathrm{H}$ NMR (400 MHz, $\mathrm{CDCl}_{3}$ ) $\delta: 8.13(\mathrm{~s}, 1 \mathrm{H}), 7.61$ (d, $J=8.4 \mathrm{~Hz}, 2 \mathrm{H}), 7.24(\mathrm{~d}, J=8.0 \mathrm{~Hz}, 2 \mathrm{H}) . \mathrm{IR} \nu_{\max }$ (neat) $/ \mathrm{cm}^{-1}$ $3267(\mathrm{O}-\mathrm{H}), 1696(\mathrm{C}=\mathrm{N})$ and $977(\mathrm{~N}-\mathrm{O})$.

General procedure for the synthesis of amines (17-24). Example: synthesis of (4-fluorophenyl)methanamine (18)

To a solution of 10 (11.51 mmol, $1.6 \mathrm{~g}$ ) in ethanol (35 mL), a mixture of water $(6.0 \mathrm{~mL})$ and conc. $\mathrm{HCl}(12 \mathrm{~mL})$ was added. The reaction mixture was stirred at room temperature for $15 \mathrm{~min}$ and then it was allowed to cool to $0{ }^{\circ} \mathrm{C}$. Zinc dust $(69.04 \mathrm{mmol}, 4.38 \mathrm{~g}$ ) was added slowly to the reaction mixture and it was refluxed for $1 \mathrm{~h}$ at $80-90{ }^{\circ} \mathrm{C}$. Progress of the reaction was monitored by TLC. The reaction mixture was filtered and concentrated under vacuo to yield the hydrochloride salt of amine. The hydrochloride salt was then treated with dried amberlyst A-21 to afford the corresponding free amine. ${ }^{18}$

Phenylmethanamine (17). Light yellow oil, yield 75\%. $R_{\mathrm{f}}=$ 0.0 (40\% EtOAc in hexane). ${ }^{1} \mathrm{H}$ NMR (300 $\mathrm{MHz}, \mathrm{CDCl}_{3}$ ) $\delta: 7.43-7.24(\mathrm{~m}, 5 \mathrm{H}), 3.88(\mathrm{~s}, 2 \mathrm{H}) . \mathrm{IR} \nu_{\max }($ neat $) / \mathrm{cm}^{-1} 3367$ $\left(\mathrm{NH}_{2}\right)$.

(4-Fluorophenyl)methanamine (18). Light yellow oil, yield $82 \% . R_{\mathrm{f}}=0.0$ (40\% EtOAc in hexane). ${ }^{1} \mathrm{H}$ NMR $(300 \mathrm{MHz}$, $\left.\mathrm{CDCl}_{3}\right) \delta: 7.34-7.26(\mathrm{~m}, 2 \mathrm{H}), 7.06-6.99(\mathrm{~m}, 2 \mathrm{H}), 3.84(\mathrm{~s}, 2 \mathrm{H})$. IR $\nu_{\max }$ (neat) $/ \mathrm{cm}^{-1} 3372\left(\mathrm{NH}_{2}\right)$.

(4-Chlorophenyl)methanamine (19). Light yellow oil, yield $86 \% . R_{\mathrm{f}}=0.0$ (40\% EtOAc in hexane). ${ }^{1} \mathrm{H}$ NMR $(400 \mathrm{MHz}$, $\left.\mathrm{CDCl}_{3}\right) \delta: 7.29(\mathrm{~d}, J=8.4 \mathrm{~Hz}, 2 \mathrm{H}), 7.24(\mathrm{~d}, J=8.3 \mathrm{~Hz}, 2 \mathrm{H}), 3.83$ (s, 2H). IR $\nu_{\max }$ (neat) $/ \mathrm{cm}^{-1} 3365\left(\mathrm{NH}_{2}\right)$.

(2-Chlorophenyl)methanamine (20). Light yellow oil, yield $78 \% . R_{\mathrm{f}}=0.0$ (40\% EtOAc in hexane). ${ }^{1} \mathrm{H}$ NMR $(300 \mathrm{MHz}$, $\left.\mathrm{CDCl}_{3}\right) \delta: 7.39-7.36(\mathrm{~m}, 2 \mathrm{H}), 7.28-7.18(\mathrm{~m}, 2 \mathrm{H}), 3.94(\mathrm{~s}, 2 \mathrm{H})$. IR $\nu_{\max }$ (neat) $/ \mathrm{cm}^{-1} 3372\left(\mathrm{NH}_{2}\right)$.

(4-Methylphenyl)methanamine (21). Light yellow oil, yield $73 \% . R_{\mathrm{f}}=0.0$ (40\% EtOAc in hexane). ${ }^{1} \mathrm{H}$ NMR $(400 \mathrm{MHz}$, $\left.\mathrm{CDCl}_{3}\right) \delta: 7.20(\mathrm{~d}, J=7.8 \mathrm{~Hz}, 2 \mathrm{H}), 7.15(\mathrm{~d}, J=7.9 \mathrm{~Hz}, 2 \mathrm{H}), 3.82$ (s, 2H), 2.34 (s, 3H). IR $\nu_{\max }$ (neat) $/ \mathrm{cm}^{-1} 3382\left(\mathrm{NH}_{2}\right)$.

(4-Methoxyphenyl)methanamine (22). Light yellow oil, yield $81 \% . R_{\mathrm{f}}=0.0$ (40\% EtOAc in hexane). ${ }^{1} \mathrm{H}$ NMR $(400 \mathrm{MHz}$, $\left.\mathrm{CDCl}_{3}\right) \delta: 7.22(\mathrm{~d}, J=8.5 \mathrm{~Hz}, 2 \mathrm{H}), 6.87(\mathrm{~d}, J=8.6 \mathrm{~Hz}, 2 \mathrm{H}), 3.79$ (brs, 5H). IR $\nu_{\max }$ (neat) $/ \mathrm{cm}^{-1} 3367\left(\mathrm{NH}_{2}\right)$.

(4-(Trifluoromethyl)phenyl)methanamine (23). Light yellow oil, yield $67 \%$. $R_{\mathrm{f}}=0.0$ (40\% EtOAc in hexane). ${ }^{1} \mathrm{H}$ NMR $\left(400 \mathrm{MHz}, \mathrm{CDCl}_{3}\right) \delta: 7.91(\mathrm{~d}, J=8.0 \mathrm{~Hz}, 2 \mathrm{H}), 7.69(\mathrm{~d}, J=7.9 \mathrm{~Hz}$, $2 \mathrm{H}), 3.95$ (s, 2H). IR $\nu_{\max }$ (neat) $/ \mathrm{cm}^{-1} 3384\left(\mathrm{NH}_{2}\right)$.

(4-(Trifluoromethoxy)phenyl)methanamine (24). Light yellow oil, yield $71 \% . R_{\mathrm{f}}=0.0$ (40\% EtOAc in hexane). ${ }^{1} \mathrm{H}$ NMR $\left(400 \mathrm{MHz}, \mathrm{CDCl}_{3}\right) \delta: 7.95(\mathrm{~d}, J=8.6 \mathrm{~Hz}, 2 \mathrm{H}), 7.35(\mathrm{~d}, J=8.3 \mathrm{~Hz}$, $2 \mathrm{H}), 4.52(\mathrm{~s}, 2 \mathrm{H})$. IR $\nu_{\max }$ (neat) $/ \mathrm{cm}^{-1} 3394\left(\mathrm{NH}_{2}\right)$.

General procedure for the synthesis of azides (27-34). Example: synthesis of $\mathrm{N}$-(4-fluorobenzyl)-3-azidopropanamide (28)

To a solution of 3-bromopropionic acid, 25 (19.61 mmol, $3.0 \mathrm{~g}$ ) in anhyd. DMF (10 $\mathrm{mL})$ was added sodium azide $(39.22 \mathrm{mmol}$, $2.55 \mathrm{~g}$ ). The reaction mixture was heated at $85{ }^{\circ} \mathrm{C}$ for $3 \mathrm{~h}$. The crude reaction mixture was diluted with ethyl acetate which was then washed with $0.1 \mathrm{~N} \mathrm{HCl}$, water and brine. The organic layer was dried over anhyd. sodium sulphate, filtered and concentrated under vacuo to yield 3-azidopropionic acid, 26 which was used directly in the next reaction without further purification. $^{26}$ The prepared azido acid $(13.03 \mathrm{mmol}, 1.5 \mathrm{~g})$ was dissolved in acetonitrile $(15 \mathrm{~mL})$ and stirred at $0{ }^{\circ} \mathrm{C}$. To this cold solution, HOBt $(15.54 \mathrm{mmol}, 2.09 \mathrm{~g})$ and $\mathrm{EDC} \cdot \mathrm{HCl}$ (14.02 $\mathrm{mmol}, 2.69 \mathrm{~g}$ ) were added. The reaction was stirred for $40 \mathrm{~min}$ and then a mixture of NMM (15.54 mmol, $1.71 \mathrm{~mL})$ and 18 (13.03 mmol, $1.28 \mathrm{~mL}$ ) was added. The reaction mixture was stirred overnight at room temperature. The solid was filtered and the acetonitrile was removed under vacuo. The residue was dissolved in $50 \mathrm{~mL}$ ethyl acetate, washed with 
saturated citric acid solution, $5 \%$ aq. sodium bicarbonate solution and brine. The organic layer was dried over anhyd. sodium sulphate, filtered, evaporated and gave crude azide. The crude product was purified by column chromatography eluted by using a solution of ethyl acetate : hexane $(4: 6)$ to yield pure azide (28). ${ }^{27}$

$\boldsymbol{N}$-Benzyl-3-azidopropanamide (27). Yellow oil, yield $37 \%$. $R_{\mathrm{f}}=0.48$ (40\% EtOAc in hexane). ${ }^{1} \mathrm{H}$ NMR (300 $\mathrm{MHz}, \mathrm{CDCl}_{3}$ ) $\delta$ : 7.38-7.27 (m, 5H), 6.17 (brs, $1 \mathrm{H}), 4.45(\mathrm{~d}, J=5.7 \mathrm{~Hz}, 2 \mathrm{H})$, $3.63(\mathrm{t}, J=6.3 \mathrm{~Hz}, 2 \mathrm{H}), 2.45(\mathrm{t}, J=6.4 \mathrm{~Hz}, 2 \mathrm{H}) .{ }^{13} \mathrm{C} \mathrm{NMR}$ $\left(75 \mathrm{MHz}, \mathrm{CDCl}_{3}\right) \delta: 171.45,141.63,128.94,128.66,127.32$, 45.76, 41.56, 33.82. IR $\nu_{\max }$ (neat) $/ \mathrm{cm}^{-1} 2093$ (azide), 1644 $(\mathrm{C}=\mathrm{O})$ and $1544(\mathrm{NH})$. MS (ESI), $m / z: 205.07[\mathrm{M}+\mathrm{H}]^{+}$.

$\mathrm{N}$-(4-Fluorobenzyl)-3-azidopropanamide (28). Light yellow solid, yield $49 \%$. $R_{\mathrm{f}}=0.45$ (40\% EtOAc in hexane). Mp 36-38 ${ }^{\circ} \mathrm{C} .{ }^{1} \mathrm{H}$ NMR (300 MHz, $\left.\mathrm{CDCl}_{3}\right) \delta: 7.28-7.23(\mathrm{~m}, 2 \mathrm{H})$, 7.05-6.99 (m, 2H), 6.10 (brs, 1H), 4.42 (d, $J=5.7 \mathrm{~Hz}, 2 \mathrm{H}), 3.64$ $(\mathrm{t}, J=6.3 \mathrm{~Hz}, 2 \mathrm{H}), 2.45(\mathrm{t}, J=6.3 \mathrm{~Hz}, 2 \mathrm{H}) .{ }^{13} \mathrm{C} \mathrm{NMR}(75 \mathrm{MHz}$, $\left.\mathrm{CDCl}_{3}\right) \delta: 169.85,160.58,133.80,129.50,115.73,47.39,42.99$, 35.82. IR $\nu_{\max }$ (neat) $/ \mathrm{cm}^{-1} 2086$ (azide), $1641(\mathrm{C}=\mathrm{O})$ and 1553 (NH). MS (ESI), $m / z: 223.1[\mathrm{M}+\mathrm{H}]^{+}$.

$\mathrm{N}$-(4-Chlorobenzyl)-3-azidopropanamide (29). Light yellow solid, yield $36 \%$. $R_{\mathrm{f}}=0.31$ (40\% EtOAc in hexane). Mp 33-35 ${ }^{\circ} \mathrm{C} .{ }^{1} \mathrm{H}$ NMR $\left(300 \mathrm{MHz}, \mathrm{CDCl}_{3}\right) \delta: 7.32(\mathrm{~d}, J=8.1 \mathrm{~Hz}, 2 \mathrm{H})$, $7.23(\mathrm{~d}, J=7.2 \mathrm{~Hz}, 2 \mathrm{H}), 6.04(\mathrm{~s}, 1 \mathrm{H}), 4.44(\mathrm{~d}, J=5.4 \mathrm{~Hz}, 2 \mathrm{H})$, $3.66(\mathrm{t}, J=6.0 \mathrm{~Hz}, 2 \mathrm{H}), 2.47(\mathrm{t}, J=6.1 \mathrm{~Hz}, 2 \mathrm{H}) .{ }^{13} \mathrm{C} \mathrm{NMR}$ $\left(75 \mathrm{MHz}, \mathrm{CDCl}_{3}\right) \delta: 169.98,136.56,133.35,129.04,128.84$, 47.39, 42.96, 35.77. IR $\nu_{\max }$ (neat) $/ \mathrm{cm}^{-1} 2095$ (azide), 1640 $(\mathrm{C}=\mathrm{O})$ and $1544(\mathrm{NH})$. MS (ESI), $m z: 239.1[\mathrm{M}+\mathrm{H}]^{+}$.

$\mathrm{N}$-(2-Chlorobenzyl)-3-azidopropanamide (30). Light yellow solid, yield $39 \%$. $R_{\mathrm{f}}=0.48$ (40\% EtOAc in hexane). Mp 38-40 ${ }^{\circ} \mathrm{C} .{ }^{1} \mathrm{H}$ NMR $\left(300 \mathrm{MHz}, \mathrm{CDCl}_{3}\right) \delta: 7.39-7.35(\mathrm{~m}, 2 \mathrm{H})$, 7.29-7.22 (m, 2H), 6.26 (brs, 1H), 4.55 (d, $J=5.7 \mathrm{~Hz}, 2 \mathrm{H}), 3.63$ $(\mathrm{t}, J=6.4 \mathrm{~Hz}, 2 \mathrm{H}), 2.46(\mathrm{t}, J=6.3 \mathrm{~Hz}, 2 \mathrm{H}) .{ }^{13} \mathrm{C}$ NMR $(75 \mathrm{MHz}$, $\left.\mathrm{CDCl}_{3}\right) \delta: 169.81,135.33,133.63,130.24,129.57,129.08$, 127.17, 47.37, 41.65, 35.78. IR $\nu_{\max }$ (neat) $/ \mathrm{cm}^{-1} 2102$ (azide), $1644(\mathrm{C}=\mathrm{O})$ and $1551(\mathrm{NH})$. MS (ESI), $m / z: 239.1[\mathrm{M}+\mathrm{H}]^{+}$.

$\mathrm{N}$-(4-Methylbenzyl)-3-azidopropanamide (31). Yellow oil, yield $53 \%$. $\quad R_{\mathrm{f}}=0.33(40 \%$ EtOAc in hexane $) .{ }^{1} \mathrm{H}$ NMR $\left(400 \mathrm{MHz}, \mathrm{CDCl}_{3}\right) \delta: 7.19-7.14(\mathrm{~m}, 4 \mathrm{H}), 5.80$ (brs, 1H), 4.42 (d, $J=5.6 \mathrm{~Hz}, 2 \mathrm{H}), 3.66(\mathrm{t}, J=6.4 \mathrm{~Hz}, 2 \mathrm{H}), 2.44(\mathrm{t}, J=6.4 \mathrm{~Hz}, 2 \mathrm{H})$, $2.34(\mathrm{~s}, \quad 3 \mathrm{H}) .{ }^{13} \mathrm{C} \quad \mathrm{NMR}\left(75 \mathrm{MHz}, \mathrm{CDCl}_{3}\right) \quad \delta:$ 169.58, 137.39, 134.88, 129.44, 127.84, 47.44, 43.56, 35.90, 21.08. IR $\nu_{\max }$ (neat) $/ \mathrm{cm}^{-1} 2102$ (azide), $1618(\mathrm{C}=\mathrm{O})$ and $1585(\mathrm{NH})$. MS (ESI), $m / z: 218.9[\mathrm{M}+\mathrm{H}]^{+}$.

$\mathrm{N}$-(4-Methoxybenzyl)-3-azidopropanamide (32). Light yellow solid, yield $41 \% . R_{\mathrm{f}}=0.41$ ( $40 \%$ EtOAc in hexane). Mp 58-60 ${ }^{\circ} \mathrm{C} .{ }^{1} \mathrm{H}$ NMR $\left(300 \mathrm{MHz}, \mathrm{CDCl}_{3}\right) \delta: 7.14(\mathrm{~d}, J=8.4 \mathrm{~Hz}, 2 \mathrm{H})$, $6.80(\mathrm{~d}, J=8.7 \mathrm{~Hz}, 2 \mathrm{H}), 5.77$ (brs, $1 \mathrm{H}), 4.32$ (d, $J=5.4 \mathrm{~Hz}, 2 \mathrm{H})$, $3.73(\mathrm{~s}, 3 \mathrm{H}), 3.58(\mathrm{t}, J=6.4 \mathrm{~Hz}, 2 \mathrm{H}), 2.36(\mathrm{t}, J=6.4 \mathrm{~Hz}, 2 \mathrm{H})$. ${ }^{13} \mathrm{C}$ NMR $\left(75 \mathrm{MHz}, \mathrm{CDCl}_{3}\right) \delta: 169.85,160.58,133.80,129.50$, 115.73, 57.04, 47.39, 42.99, 35.82. IR $\nu_{\max }$ (neat) $/ \mathrm{cm}^{-1} 2091$ (azide), $1637(\mathrm{C}=\mathrm{O})$ and $1559(\mathrm{NH})$. MS (ESI), m/z: 234.9 $[\mathrm{M}+\mathrm{H}]^{+}$.

$\mathrm{N}$-(4-(Trifluoromethyl)benzyl)-3-azidopropanamide

Light yellow oil, yield 56\%. $R_{\mathrm{f}}=0.43$ (40\% EtOAc in hexane).
${ }^{1} \mathrm{H}$ NMR (400 MHz, $\left.\mathrm{CDCl}_{3}\right) \delta: 7.60(\mathrm{~d}, J=8.0 \mathrm{~Hz}, 2 \mathrm{H}), 7.40(\mathrm{~d}$, $J=7.7 \mathrm{~Hz}, 2 \mathrm{H}), 5.96(\mathrm{brs}, 1 \mathrm{H}), 4.53(\mathrm{~d}, J=5.8 \mathrm{~Hz}, 2 \mathrm{H}), 3.68(\mathrm{t}$, $J=6.2 \mathrm{~Hz}, 2 \mathrm{H}), 2.48(\mathrm{t}, J=6.2 \mathrm{~Hz}, 2 \mathrm{H}) .{ }^{13} \mathrm{C} \mathrm{NMR}(75 \mathrm{MHz}$, $\left.\mathrm{CDCl}_{3}\right) \delta: 170.01,142.05,129.67,127.87,125.71,122.24,47.38$, 43.18, 35.86. IR $\nu_{\max }$ (neat) $/ \mathrm{cm}^{-1} 2107$ (azide), $1654(\mathrm{C}=\mathrm{O})$ and 1547 (NH). MS (ESI), $m / z: 272.9[\mathrm{M}+\mathrm{H}]^{+}, 271.1[\mathrm{M}-\mathrm{H}]^{-}$.

$\mathrm{N}$-(4-(Trifluoromethoxy)benzyl)-3-azidopropanamide Yellow oil, yield 45\%. $R_{\mathrm{f}}=0.27$ (40\% EtOAc in hexane). ${ }^{1} \mathrm{H}$ NMR (400 MHz, $\mathrm{CDCl}_{3}$ ) $\delta: 7.32(\mathrm{~d}, J=8.4 \mathrm{~Hz}, 2 \mathrm{H}), 7.19$ (d, $J=8.2 \mathrm{~Hz}, 2 \mathrm{H}), 5.90(\mathrm{brs}, 1 \mathrm{H}), 4.46(\mathrm{~d}, J=7.1 \mathrm{~Hz}, 2 \mathrm{H}), 3.67(\mathrm{t}$, $J=6.2 \mathrm{~Hz}, 2 \mathrm{H}), 2.46(\mathrm{t}, J=6.3 \mathrm{~Hz}, 2 \mathrm{H}) .{ }^{13} \mathrm{C} \mathrm{NMR}(75 \mathrm{MHz}$, $\left.\mathrm{CDCl}_{3}\right) \delta: 169.85,158.72,134.58,129.50,123.53,115.76,47.39$, 42.99, 35.82. IR $\nu_{\max }$ (neat) $/ \mathrm{cm}^{-1} 2102$ (azide), $1652(\mathrm{C}=\mathrm{O})$ and 1547 (NH). MS (ESI), m/z: $289.45[\mathrm{M}+\mathrm{H}]^{+}$.

General procedure for the synthesis of propargyl ester of boc-protected alkynes (38-40). Example: synthesis of propargyl ester of boc-L-phenylalanine (38)

Boc-protected L-phenylalanine (11.31 mmol, $3.0 \mathrm{~g})$ was dissolved in anhyd. DMF (10 mL) and the solution was allowed to cool to $0^{\circ} \mathrm{C}$. Anhyd. potassium carbonate (16.96 mmol, $2.34 \mathrm{~g}$ ) was added to this cold solution and stirred for $15 \mathrm{~min}$. Propargyl bromide (11.31 mmol, $1.26 \mathrm{~mL}, 80 \mathrm{wt} \%$ in toluene) was added dropwise to the mixture and stirred at $0{ }^{\circ} \mathrm{C}$ for $1 \mathrm{~h}$. The reaction mixture was allowed to attain room temperature. After removal of DMF under vacuo, the residue was dissolved in ethyl acetate. The organic layer was washed with saturated citric acid solution, water and brine which was dried over anhyd. sodium sulphate and concentrated. The crude product was then purified by column chromatography eluted by using ethyl acetate : hexane $(2: 8)$ to yield pure alkyne $(38){ }^{28}$

Propargyl ester of boc-L-phenylalanine (38). Light yellow oil, yield $87 \% . \quad R_{\mathrm{f}}=0.52\left(20 \%\right.$ EtOAc in hexane). ${ }^{1} \mathrm{H}$ NMR $\left(300 \mathrm{MHz}, \mathrm{CDCl}_{3}\right) \delta: 7.34-7.26(\mathrm{~m}, 3 \mathrm{H}), 7.19-7.17(\mathrm{~m}, 2 \mathrm{H}), 4.97$ (d, $J=7.5 \mathrm{~Hz}, 1 \mathrm{H}), 4.82-4.64(\mathrm{~m}, 3 \mathrm{H}), 3.20-3.06(\mathrm{~m}, 2 \mathrm{H}), 2.53$ $(\mathrm{s}, 1 \mathrm{H}), 1.43(\mathrm{~s}, 9 \mathrm{H}) .{ }^{13} \mathrm{C} \mathrm{NMR}\left(75 \mathrm{MHz}, \mathrm{CDCl}_{3}\right) \delta: 171.16$, $155.07,135.70,129.41,128.61,127.13,80.06,75.47,54.31$, 52.65, 38.10, 28.28. IR $\nu_{\max }$ (neat) $/ \mathrm{cm}^{-1} 3365(\equiv \mathrm{CH}), 2129$ $(\mathrm{C} \equiv \mathrm{C}), 1762(\mathrm{C}=\mathrm{O}$, ester), $1687(\mathrm{C}=\mathrm{O}$, amide) and $1510(\mathrm{NH})$. MS (ESI), $m / z: 326.2[\mathrm{M}+\mathrm{Na}]^{+}, 629.4[2 \mathrm{M}+\mathrm{Na}]^{+}$.

Propargyl ester of boc-L-proline (39). Light yellow oil, yield $85 \% . R_{\mathrm{f}}=0.64$ (20\% EtOAc in hexane). ${ }^{1} \mathrm{H}$ NMR $(300 \mathrm{MHz}$, $\left.\mathrm{CDCl}_{3}\right) \delta: 4.78-4.69(\mathrm{~m}, 2 \mathrm{H}), 4.29-4.25(\mathrm{~m}, 1 \mathrm{H}), 3.58-3.40(\mathrm{~m}$, $2 \mathrm{H}), 2.48(\mathrm{~s}, 1 \mathrm{H}), 2.26-2.23(\mathrm{~m}, 1 \mathrm{H}), 2.05-1.91(\mathrm{~m}, 3 \mathrm{H}), 1.42(\mathrm{~s}$, 9H). ${ }^{13} \mathrm{C} \mathrm{NMR}\left(75 \mathrm{MHz}, \mathrm{CDCl}_{3}\right) \delta: 172.42,153.70,80.06,75.11$, $58.91,52.23,46.30,30.79,28.28,23.61$. IR $\nu_{\max }$ (neat) $/ \mathrm{cm}^{-1}$ $3246(\equiv \mathrm{CH}), 2129(\mathrm{C} \equiv \mathrm{C}), 1754(\mathrm{C}=\mathrm{O}$, ester $)$ and $1693(\mathrm{C}=\mathrm{O}$, amide). MS (ESI), $m / z: 254.4[\mathrm{M}+\mathrm{H}]^{+}$.

Propargyl ester of boc-L-tryptophan (40). Light yellow solid, yield $88 \% . R_{\mathrm{f}}=0.31$ (20\% EtOAc in hexane). Mp 95-96 ${ }^{\circ} \mathrm{C} .{ }^{1} \mathrm{H}$ NMR (300 MHz, $\left.\mathrm{CDCl}_{3}\right) \delta: 8.17(\mathrm{~s}, 1 \mathrm{H}), 7.60(\mathrm{~d}, J=7.8 \mathrm{~Hz}, 1 \mathrm{H})$, 7.38 (d, $J=7.8 \mathrm{~Hz}, 1 \mathrm{H}), 7.21-7.12(\mathrm{~m}, 2 \mathrm{H}), 7.07$ (s, 1H), 5.08 (d, $J=8.1 \mathrm{~Hz}, 1 \mathrm{H}), 4.77-4.63(\mathrm{~m}, 3 \mathrm{H}), 3.35-3.33(\mathrm{~m}, 2 \mathrm{H}), 2.50(\mathrm{~s}$, $1 \mathrm{H}), 1.44$ (s, 9H). ${ }^{13} \mathrm{C} \mathrm{NMR}\left(75 \mathrm{MHz}, \mathrm{CDCl}_{3}\right) \delta: 171.54,155.24$, 136.12 , 127.71, 122.95, 122.24, 119.69, 118.76, 111.20, 109.92, 79.99, 75.37, 54.23, 52.65, 28.32, 27.76. IR $\nu_{\max }$ (neat) $/ \mathrm{cm}^{-1}$ 
3397 ( $\equiv \mathrm{CH}), 2147(\mathrm{C} \equiv \mathrm{C}), 1736$ ( $\mathrm{C}=\mathrm{O}$, ester), $1698(\mathrm{C}=\mathrm{O}$, amide) and $1503(\mathrm{NH})$. MS (ESI), $m / z: 365.09[\mathrm{M}+\mathrm{Na}]^{+}, 707.4$ $[2 \mathrm{M}+\mathrm{Na}]^{+}$.

Synthesis of boc-protected triazole-amino acid hybrids (41-64). Example: synthesis of $(R)$-(1-(3-(4-fluorobenzylamino)-3-oxopropyl)-1H-1,2,3-triazol-4-yl)methyl 2-[(tertbutoxycarbonyl)amino]-3-phenylpropanoate (44)

Azide 28 (1.35 mmol, $0.3 \mathrm{~g}$ ) and alkyne 38 (1.35 mmol, $0.41 \mathrm{~g}$ ) were dissolved in tert-butanol $(4.0 \mathrm{~mL})$ and $\mathrm{H}_{2} \mathrm{O}(8.0 \mathrm{~mL})$. The copper sulphate, $\mathrm{CuSO}_{4} \cdot 5 \mathrm{H}_{2} \mathrm{O}(0.013 \mathrm{mmol}, 0.033 \mathrm{~g})$ and sodium ascorbate $(0.067 \mathrm{mmol}, 0.013 \mathrm{~g})$ were added and the reaction mixture was stirred at room temperature. Progress of the reaction was monitored by TLC. After completion of the reaction, the content of the reaction was washed with brine and the compound was extracted with ethyl acetate, dried over anhyd. sodium sulphate and concentrated. The product was purified by column chromatography eluted with ethyl acetate : hexane $(3: 7)$ to yield the pure product in quantitative yield. ${ }^{29}$

(R)-(1-(3-(Benzylamino)-3-oxopropyl)-1H-1,2,3-triazol-4-yl)methyl 2-[(tert-butoxycarbonyl)amino]-3-phenylpropanoate (41). Off white solid, yield $86 \% . R_{\mathrm{f}}=0.76(10 \% \mathrm{MeOH}$ in DCM). Mp 93-95 ${ }^{\circ} \mathrm{C}$. $[\alpha]_{\mathrm{D}}^{20}=-28.00 .{ }^{1} \mathrm{H}$ NMR $\left(300 \mathrm{MHz}, \mathrm{CDCl}_{3}\right) \delta: 7.50$ (s, 1H), 7.26-7.15 (m, 7H), 7.10 (d, $J=7.5 \mathrm{~Hz}, 2 \mathrm{H}), 6.99-6.97$ (m, 1H), 5.91 (brs, 1H), $5.14(\mathrm{~s}, 2 \mathrm{H}), 4.88$ (d, $J=7.2 \mathrm{~Hz}, 1 \mathrm{H})$, $4.62(\mathrm{t}, J=5.6 \mathrm{~Hz}, 2 \mathrm{H}), 4.47-4.45(\mathrm{~m}, 1 \mathrm{H}), 4.32(\mathrm{~d}, J=5.7 \mathrm{~Hz}$, $2 \mathrm{H}), 3.02-2.95(\mathrm{~m}, 2 \mathrm{H}), 2.78(\mathrm{t}, J=6.3 \mathrm{~Hz}, 2 \mathrm{H}), 1.33(\mathrm{~s}, 9 \mathrm{H})$. ${ }^{13} \mathrm{C}$ NMR (75 MHz, $\mathrm{CDCl}_{3}$ ) $\delta: 171.65,168.99,155.08,142.07$, 137.79, 135.82, 129.33, 128.69, 128.50, 127.69, 127.59, 126.99, 125.09, 80.03, 58.23, 54.40, 46.25, 43.67, 38.05, 36.32, 28.28. IR $\nu_{\max }($ neat $) / \mathrm{cm}^{-1} 3078(\mathrm{CH}), 1598(\mathrm{C}=\mathrm{C})$ and $1460(\mathrm{~N}=\mathrm{N})$. MS (ESI), $m / z: 508.3[\mathrm{M}+\mathrm{H}]^{+}$.

(R)-(1-(3-(Benzylamino)-3-oxopropyl)-1H-1,2,3-triazol-4-yl) methyl 1-(tert-butoxycarbonyl)pyrrolidine-2-carboxylate (42). Light yellow oil, yield $84 \% . R_{\mathrm{f}}=0.84(10 \% \mathrm{MeOH}$ in DCM). $[\alpha]_{\mathrm{D}}^{20}=-48.00 .{ }^{1} \mathrm{H} \mathrm{NMR}\left(300 \mathrm{MHz}, \mathrm{CDCl}_{3}\right) \delta: 7.71(\mathrm{~s}, 1 \mathrm{H})$, 7.31-7.19 (m, 5H), 6.04 (brs, 1H), 5.26-5.21 (m, 2H), 4.73-4.71 $(\mathrm{m}, 2 \mathrm{H}), 4.41(\mathrm{~s}, 2 \mathrm{H}), 4.25-4.16(\mathrm{~m}, 1 \mathrm{H}), 3.53-3.39(\mathrm{~m}, 2 \mathrm{H})$, 2.89-2.84 (m, 2H), 2.21-2.15 (m, 1H), 1.94-1.86 (m, 3H), 1.45 $(\mathrm{s}, 9 \mathrm{H}) .{ }^{13} \mathrm{C} \mathrm{NMR}\left(75 \mathrm{MHz}, \mathrm{CDCl}_{3}\right) \delta: 173.02,168.97,154.44$, $142.91,137.75,128.70,127.69,124.98,79.94,58.99,57.94$, $46.63,43.66,36.58,30.79,29.79,28.41,24.33$. IR $\nu_{\max }$ (neat)/ $\mathrm{cm}^{-1} 3067(\mathrm{CH}), 1549(\mathrm{C}=\mathrm{C})$ and $1454(\mathrm{~N}=\mathrm{N}) . \mathrm{MS}(\mathrm{ESI}), \mathrm{m} / \mathrm{z}$ : $358.3[\mathrm{M}+\mathrm{H}-\mathrm{Boc}]^{+}, 458.4[\mathrm{M}+\mathrm{H}]^{+}$.

(R)-(1-(3-(Benzylamino)-3-oxopropyl)-1H-1,2,3-triazol-4-yl)methyl 2-[(tert-butoxycarbonyl)amino]-3-(1H-indol-3-yl)propanoate (43). Light yellow solid, yield 92\%. $R_{\mathrm{f}}=0.67(10 \% \mathrm{MeOH}$ in DCM). Mp 68-70 ${ }^{\circ} \mathrm{C} .[\alpha]_{\mathrm{D}}^{20}=-20.00 .{ }^{1} \mathrm{H}$ NMR $\left(300 \mathrm{MHz}, \mathrm{CDCl}_{3}\right) \delta: 8.74$ $(\mathrm{s}, 1 \mathrm{H}), 7.47(\mathrm{~d}, J=7.8 \mathrm{~Hz}, 1 \mathrm{H}), 7.30(\mathrm{~d}, J=7.8 \mathrm{~Hz}, 1 \mathrm{H})$, 7.26-7.19 (m, 4H), 7.12-6.99 (m, 4H), 6.46 (s, 1H), 6.13 (s, 1H), 5.23-5.16 (m, 1H), 5.04-5.00 (m, 2H), 4.60-4.44 (m, 3H), $4.32(\mathrm{t}, J=6.0 \mathrm{~Hz}, 2 \mathrm{H}), 3.16-3.14(\mathrm{~m}, 2 \mathrm{H}), 2.90-2.77(\mathrm{~m}, 2 \mathrm{H})$, 1.37 (s, 9H). ${ }^{13} \mathrm{C} \mathrm{NMR}\left(75 \mathrm{MHz}, \mathrm{CDCl}_{3}\right) \delta: 172.12,169.48$, 155.24, 142.43, 137.63, 136.09, 128.74, 127.61, 127.51, 124.99, $123.29,121.91,119.45,118.75,111.34,109.41,79.97,58.23$, $54.52,46.11,43.71,35.64,28.35,28.06$. IR $\nu_{\max }$ (neat) $/ \mathrm{cm}^{-1}$
$3060(\mathrm{CH}), 1525(\mathrm{C}=\mathrm{C})$ and $1458(\mathrm{~N}=\mathrm{N})$. MS $(\mathrm{ESI}), \mathrm{m} / z: 547.3$ $[\mathrm{M}+\mathrm{H}]^{+}$.

(R)-(1-(3-(4-Fluorobenzylamino)-3-oxopropyl)-1H-1,2,3-triazol4-yl)methyl 2-[(tert-butoxycarbonyl)amino]-3-phenylpropanoate (44). Creamish solid, yield $89 \% . R_{\mathrm{f}}=0.77(10 \% \mathrm{MeOH}$ in DCM). Mp 88-90 ${ }^{\circ} \mathrm{C} .[\alpha]_{\mathrm{D}}^{20}=-4.00 .{ }^{1} \mathrm{H} \mathrm{NMR}\left(300 \mathrm{MHz}, \mathrm{CDCl}_{3}\right)$ $\delta: 7.57(\mathrm{~s}, 1 \mathrm{H}), 7.22(\mathrm{~m}, 3 \mathrm{H}), 7.14$ (brs, 2H), 7.06 (brs, 2H), 7.00-6.95 (m, 2H), 6.36 (brs, 1H), 5.19 (s, 2H), 4.96 (brs, 1H), 4.67 (brs, 2H), 4.51 (m, 1H), 4.35 (brs, 2H), 3.04 (m, 2H), 2.86 (brs, 2H), 1.39 (s, 9H). ${ }^{13} \mathrm{C}$ NMR (75 MHz, $\mathrm{CDCl}_{3}$ ) $\delta: 171.66$, $168.97,160.77,155.33$, 142.18, 140.27, 135.81, 133.66, 129.47, $128.52,127.01,125.03,115.39,80.07,58.23,54.44,46.23$, 42.96, 38.05, 36.30, 28.27. IR $\nu_{\max }$ (neat) $/ \mathrm{cm}^{-1} 3057(\mathrm{CH}), 1514$ $(\mathrm{C}=\mathrm{C})$ and $1458(\mathrm{~N}=\mathrm{N})$. MS (ESI), $m / z: 526.1[\mathrm{M}+\mathrm{H}]^{+}, 548.1$ $[\mathrm{M}+\mathrm{Na}]^{+}$.

(R)-(1-(3-(4-Fluorobenzylamino)-3-oxopropyl)-1H-1,2,3-triazol4-yl)methyl 1-(tert-butoxycarbonyl)pyrrolidine-2-carboxylate (45). Light yellow oil, yield $80 \% . R_{\mathrm{f}}=0.70(10 \% \mathrm{MeOH}$ in DCM). $[\alpha]_{\mathrm{D}}^{20}=-44.00 .{ }^{1} \mathrm{H} \mathrm{NMR}\left(300 \mathrm{MHz}, \mathrm{CDCl}_{3}\right) \delta: 7.73(\mathrm{~d}, J=$ $11.1 \mathrm{~Hz}, 1 \mathrm{H}), 7.20-7.12$ (m, 2H), 7.04-6.97 (m, 2H), 6.55 (brs, $1 \mathrm{H}), 5.33-5.22(\mathrm{~m}, 2 \mathrm{H}), 4.79-4.66(\mathrm{~m}, 2 \mathrm{H}), 4.39-4.37(\mathrm{~m}, 2 \mathrm{H})$, 4.26-4.23 (m, 1H), 3.52-3.39 (m, 2H), 2.92-2.85 (m, 2H), 2.21-1.84 (m, 4H), $1.44(\mathrm{~s}, 9 \mathrm{H}) .{ }^{13} \mathrm{C} \mathrm{NMR}$ (75 $\mathrm{MHz}, \mathrm{CDCl}_{3}$ ) $\delta: 172.99,169.24,153.67,142.68,138.75,134.33,129.39$, 124.95, 115.37, 79.83, 58.92, 46.63, 46.28, 42.59, 35.96, 30.76, 28.39, 23.59. IR $\nu_{\max }$ (neat) $/ \mathrm{cm}^{-1} 3075(\mathrm{CH}), 1512(\mathrm{C}=\mathrm{C})$ and $1452(\mathrm{~N}=\mathrm{N})$. MS (ESI), m/z: $376.05[\mathrm{M}+\mathrm{H}-\mathrm{Boc}]^{+}, 476.04$ $[\mathrm{M}+\mathrm{H}]^{+}, 498.2[\mathrm{M}+\mathrm{Na}]^{+}$.

(R)-(1-(3-(4-Fluorobenzylamino)-3-oxopropyl)-1H-1,2,3-triazol4-yl)methyl 2-[(tert-butoxycarbonyl)amino]-3-(1H-indol-3-yl)propanoate (46). Light yellow solid, yield 90\%. $R_{\mathrm{f}}=0.71(10 \%$ $\mathrm{MeOH}$ in DCM). Mp 62-64 ${ }^{\circ} \mathrm{C}$. $[\alpha]_{\mathrm{D}}^{20}=-20.00 .{ }^{1} \mathrm{H} \mathrm{NMR}$ $\left(300 \mathrm{MHz}, \mathrm{CDCl}_{3}\right) \delta: 8.88(\mathrm{~s}, 1 \mathrm{H}, \mathrm{NH}), 7.53(\mathrm{~d}, J=7.5 \mathrm{~Hz}, 1 \mathrm{H}$, $\mathrm{Ar}-\mathrm{H}), 7.35$ (d, $J=8.1 \mathrm{~Hz}, 1 \mathrm{H}, \mathrm{Ar}-\mathrm{H}), 7.17-7.05$ (m, 5H, Ar-H), $6.96(\mathrm{t}, J=8.6 \mathrm{~Hz}, 2 \mathrm{H}, \mathrm{Ar}-\mathrm{H}), 6.56-6.52(\mathrm{~m}, 2 \mathrm{H}, \mathrm{Ar}-\mathrm{H}, \mathrm{NH})$, 5.25-5.21 (m, 1H, NH), 5.14-5.05 (m, 2H, $\left.\mathrm{OCH}_{2}\right), 4.65-4.49$ (m, $3 \mathrm{H}, \mathrm{CH}, \mathrm{CH}_{2}$ ), 4.33-4.32 (m, 2H, $\mathrm{CH}_{2}$ ), 3.23 (brs, 2H, $\mathrm{CH}_{2}$ ), 2.94-2.82 (m, 2H, $\mathrm{CH}_{2}$ ), 1.43 (s, 9H, Boc). ${ }^{13} \mathrm{C} \mathrm{NMR}(75 \mathrm{MHz}$, $\left.\mathrm{CDCl}_{3}\right) \delta: 172.11,169.45,163.82,155.26,142.52,136.09$, $133.43,129.31,127.74,125.01,123.22,121.97,119.49,118.76$, 115.69, 111.29, 109.48, 79.98, 58.21, 54.51, 46.08, 43.01, 35.59, 28.33, 27.97. IR $\nu_{\max }$ (neat) $/ \mathrm{cm}^{-1} 3080(\mathrm{CH}), 1512(\mathrm{C}=\mathrm{C})$ and $1460(\mathrm{~N}=\mathrm{N})$. MS (ESI), $m / z: 565.3[\mathrm{M}+\mathrm{H}]^{+}$.

(R)-(1-(3-(4-Chlorobenzylamino)-3-oxopropyl)-1H-1,2,3-triazol4-yl)methyl 2-[(tert-butoxycarbonyl)amino]-3-phenylpropanoate (47). White solid, yield $88 \% . R_{\mathrm{f}}=0.72(10 \% \mathrm{MeOH}$ in DCM). Mp 98-100 ${ }^{\circ} \mathrm{C} .[\alpha]_{\mathrm{D}}^{20}=-16.00 .{ }^{1} \mathrm{H} \mathrm{NMR}\left(300 \mathrm{MHz}, \mathrm{CDCl}_{3}\right)$ $\delta: 7.56(\mathrm{~s}, 1 \mathrm{H}), 7.27-7.22(\mathrm{~m}, 5 \mathrm{H}), 7.10-7.04(\mathrm{~m}, 4 \mathrm{H}), 6.60$ (brs, $1 \mathrm{H}), 5.18(\mathrm{~s}, 2 \mathrm{H}), 4.98(\mathrm{~d}, J=7.8 \mathrm{~Hz}, 1 \mathrm{H}), 4.68-4.63(\mathrm{~m}, 2 \mathrm{H})$, 4.50-4.46 (m, 1H), 4.34 (d, $J=5.7 \mathrm{~Hz}, 2 \mathrm{H}), 3.08-2.98(\mathrm{~m}, 2 \mathrm{H})$, $2.87(\mathrm{t}, J=6.3 \mathrm{~Hz}, 2 \mathrm{H}), 1.39(\mathrm{~s}, 9 \mathrm{H}) .{ }^{13} \mathrm{C} \mathrm{NMR}\left(75 \mathrm{MHz}, \mathrm{CDCl}_{3}\right.$ ) $\delta: 171.66,169.09,155.13,142.17,136.45,135.79,133.32$, $129.31,129.04,128.78,128.52,127.02,125.07,80.06,58.20$, $54.43,46.25,42.93,38.01,36.26,28.27$. IR $\nu_{\max }$ (neat) $/ \mathrm{cm}^{-1}$ $3067(\mathrm{CH}), 1521(\mathrm{C}=\mathrm{C})$ and $1462(\mathrm{~N}=\mathrm{N}) . \mathrm{MS}(\mathrm{ESI}), \mathrm{m} / \mathrm{z:} 542.5$ $[\mathrm{M}+\mathrm{H}]^{+}$. 
(R)-(1-(3-(4-Chlorobenzylamino)-3-oxopropyl)-1H-1,2,3-triazol4-yl)methyl 1-(tert-butoxycarbonyl)pyrrolidine-2-carboxylate (48). Colorless oil, yield $87 \% . R_{\mathrm{f}}=0.67(10 \% \mathrm{MeOH}$ in DCM $) \cdot[\alpha]_{\mathrm{D}}^{20}=$ -44.00. ${ }^{1} \mathrm{H}$ NMR (300 MHz, $\left.\mathrm{CDCl}_{3}\right) \delta: 7.62(\mathrm{~s}, 1 \mathrm{H}), 7.19(\mathrm{~d}, J=$ $9.0 \mathrm{~Hz}, 2 \mathrm{H}), 7.05-6.98(\mathrm{~m}, 2 \mathrm{H}), 6.59$ (brs, 1H), 5.17-5.10 (m, $2 \mathrm{H}), 4.68-4.51$ (m, 2H), 4.29-4.24 (m, 2H), 4.20-4.16 (m, 1H), 3.41-3.27 (m, 2H), 2.84-2.74 (m, 2H), 2.11-1.98 (m, 2H), 1.86-1.77 (m, 2H), 1.35-1.26 (m, 9H). ${ }^{13} \mathrm{C}$ NMR (75 MHz, $\left.\mathrm{CDCl}_{3}\right) \delta: 173.02,169.15,154.46,143.01,136.57,133.31$, 129.05, 128.76, 125.02, 79.97, 58.99, 58.06, 46.67, 42.89, 36.59, 30.78, 29.78, 28.41, 24.34. IR $\nu_{\max }$ (neat) $/ \mathrm{cm}^{-1} 3089(\mathrm{CH}), 1547$ $(\mathrm{C}=\mathrm{C})$ and $1495(\mathrm{~N}=\mathrm{N})$. MS (ESI), $m / z: 392.5[\mathrm{M}+\mathrm{H}-\mathrm{Boc}]^{+}$, $492.4[\mathrm{M}+\mathrm{H}]^{+}$.

(R)-(1-(3-(4-Chlorobenzylamino)-3-oxopropyl)-1H-1,2,3-triazol4-yl)methyl 2-[(tert-butoxycarbonyl)amino]-3-(1H-indol-3-yl)propanoate (49). Light yellow solid, yield $87 \% . R_{\mathrm{f}}=0.73(10 \%$ $\mathrm{MeOH}$ in DCM). Mp 70-72 ${ }^{\circ} \mathrm{C}$. $[\alpha]_{\mathrm{D}}^{20}=-20.00 .{ }^{1} \mathrm{H}$ NMR $\left(300 \mathrm{MHz} \mathrm{CDCl}_{3}\right) \delta: 8.88(\mathrm{~s}, 1 \mathrm{H}), 7.53(\mathrm{~d}, J=7.5 \mathrm{~Hz}, 1 \mathrm{H}), 7.34$ $(\mathrm{d}, J=8.1 \mathrm{~Hz}, 1 \mathrm{H}), 7.26-7.22(\mathrm{~m}, 2 \mathrm{H}), 7.18-7.13(\mathrm{~m}, 2 \mathrm{H})$, $7.10-7.03(\mathrm{~m}, 3 \mathrm{H}), 6.65$ (brs, $1 \mathrm{H}), 6.53(\mathrm{~s}, 1 \mathrm{H}), 5.25-5.20(\mathrm{~m}$, $1 \mathrm{H}), 5.09-5.04(\mathrm{~m}, 2 \mathrm{H}), 4.64-4.48(\mathrm{~m}, 3 \mathrm{H}), 4.31(\mathrm{~d}, J=6.0 \mathrm{~Hz}$, $2 \mathrm{H}), 3.23-3.21(\mathrm{~m}, 2 \mathrm{H}), 2.94-2.82(\mathrm{~m}, 2 \mathrm{H}), 1.43(\mathrm{~s}, 9 \mathrm{H})$. ${ }^{13} \mathrm{C}$ NMR $\left(75 \mathrm{MHz}, \mathrm{CDCl}_{3}\right) \delta: 172.12,169.56,155.26,142.51$, 136.26, 136.08, 133.33, 128.86, 128.80, 127.72, 125.04, 123.24, $121.96,119.49,118.75,111.31,109.45,79.99,58.19,54.50$, 46.10, 42.99, 35.55, 28.33, 27.97. IR $\nu_{\max }$ (neat) $/ \mathrm{cm}^{-1} 3083$ $(\mathrm{CH}), 1514(\mathrm{C}=\mathrm{C})$ and $1462(\mathrm{~N}=\mathrm{N})$. MS (ESI), $m / z: 579.2$ $[\mathrm{M}-\mathrm{H}]^{-}, 581.1[\mathrm{M}+\mathrm{H}]^{+}$.

(R)-(1-(3-(2-Chlorobenzylamino)-3-oxopropyl)-1H-1,2,3-triazol4-yl)methyl 2-[(tert-butoxycarbonyl)amino]-3-phenylpropanoate (50). White solid, yield $84 \% . R_{\mathrm{f}}=0.73(10 \% \mathrm{MeOH}$ in DCM). Mp 118-120 ${ }^{\circ} \mathrm{C}$. $[\alpha]_{\mathrm{D}}^{20}=-16.00 .{ }^{1} \mathrm{H}$ NMR (300 MHz, $\mathrm{CDCl}_{3}$ ) $\delta: 7.48$ (s, 1H), 7.29-7.13 (m, 7H), 6.99-6.97 (m, 2H), 6.05 (brs, $1 \mathrm{H}), 5.13(\mathrm{~s}, 2 \mathrm{H}), 4.89(\mathrm{~d}, J=7.5 \mathrm{~Hz}, 1 \mathrm{H}), 4.61(\mathrm{t}, J=5.8 \mathrm{~Hz}$, $2 \mathrm{H}), 4.48-4.47(\mathrm{~m}, 1 \mathrm{H}), 4.41(\mathrm{~d}, J=5.7 \mathrm{~Hz}, 2 \mathrm{H}), 3.05-2.90(\mathrm{~m}$, 2H), $2.78(\mathrm{t}, J=6.2 \mathrm{~Hz}, 2 \mathrm{H}), 1.33(\mathrm{~s}, 9 \mathrm{H}) .{ }^{13} \mathrm{C} \mathrm{NMR}(75 \mathrm{MHz}$, $\left.\mathrm{CDCl}_{3}\right) \delta: 171.60,168.97,155.28,143.42,137.44,135.82$, 133.62, 130.05, 129.52, 129.29, 129.07, 128.45, 127.05, 126.94, 125.33, 79.98, 58.20, 54.31, 46.10, 41.60, 37.98, 36.24, 28.23. IR $\nu_{\max }$ (neat) $/ \mathrm{cm}^{-1} 3062(\mathrm{CH}), 1521(\mathrm{C}=\mathrm{C})$ and $1445(\mathrm{~N}=\mathrm{N})$. MS (ESI), $m / z: 542.1[\mathrm{M}+\mathrm{H}]^{+}$.

(R)-(1-(3-(2-Chlorobenzylamino)-3-oxopropyl)-1H-1,2,3-triazol4-yl)methyl 1-(tert-butoxycarbonyl)pyrrolidine-2-carboxylate (51). Colorless oil, yield $83 \% . R_{\mathrm{f}}=0.77(10 \% \mathrm{MeOH}$ in DCM $) \cdot[\alpha]_{\mathrm{D}}^{20}=$ -48.00. ${ }^{1} \mathrm{H}$ NMR (300 MHz, $\left.\mathrm{CDCl}_{3}\right) \delta: 7.69$ (d, $\left.J=7.5 \mathrm{~Hz}, 1 \mathrm{H}\right)$, 7.39-7.23 (m, 4H), 6.43 (brs, 1H), 5.26-5.20 (m, 2H), 4.78-4.63 $(\mathrm{m}, 2 \mathrm{H}), 4.50(\mathrm{~d}, J=5.4 \mathrm{~Hz}, 2 \mathrm{H}), 4.26-4.23(\mathrm{~m}, 1 \mathrm{H}), 3.55-3.39$ $(\mathrm{m}, 2 \mathrm{H}), 2.91-2.83(\mathrm{~m}, 2 \mathrm{H}), 2.21-2.10(\mathrm{~m}, 1 \mathrm{H}), 1.95-1.84(\mathrm{~m}$, $3 \mathrm{H}), 1.45$ (s, 9H). ${ }^{13} \mathrm{C} \mathrm{NMR}\left(75 \mathrm{MHz}, \mathrm{CDCl}_{3}\right) \delta: 173.21,167.98$, $154.44,142.91,137.75,133.45,128.70,126.98,124.98,79.94$, 58.10, 57.99, 46.44, 43.66, 36.58, 30.79, 29.79, 28.41, 23.60. IR $\nu_{\max }($ neat $) / \mathrm{cm}^{-1} 3073(\mathrm{CH}), 1544(\mathrm{C}=\mathrm{C})$ and $1447(\mathrm{~N}=\mathrm{N})$. MS (ESI), $m / z: 492.3[\mathrm{M}+\mathrm{H}]^{+}$.

(R)-(1-(3-(2-Chlorobenzylamino)-3-oxopropyl)-1H-1,2,3-triazol4-yl)methyl 2-[(tert-butoxycarbonyl)amino]-3-(1H-indol-3-yl)propanoate (52). Light yellow solid, yield $88 \%$. $R_{\mathrm{f}}=0.41(10 \%$
$\mathrm{MeOH}$ in DCM). Mp 58-62 ${ }^{\circ} \mathrm{C}$. $[\alpha]_{\mathrm{D}}^{20}=-16.00 .{ }^{1} \mathrm{H}$ NMR $\left(300 \mathrm{MHz} \mathrm{CDCl}_{3}\right) \delta: 8.83(\mathrm{~s}, 1 \mathrm{H}), 7.56(\mathrm{~d}, J=7.8 \mathrm{~Hz}, 1 \mathrm{H})$, 7.41-7.35 (m, 3H), 7.29-7.08 (m, 5H), 6.60 (s, 1H), 6.36 (brs, $1 \mathrm{H}), 5.29-5.25(\mathrm{~m}, 1 \mathrm{H}), 5.14-5.09(\mathrm{~m}, 2 \mathrm{H}), 4.68-4.54(\mathrm{~m}, 3 \mathrm{H})$, 4.49 (brs, 2H), 3.26-3.19 (m, 2H), 2.95-2.88 (m, 2H), 1.46 (s, 9H). ${ }^{13} \mathrm{C}$ NMR $\left(75 \mathrm{MHz}, \mathrm{CDCl}_{3}\right) \delta: 172.12,169.54,155.24$, 142.43 , 136.07, 134.96, 133.48, 129.73, 129.59, 129.09, 127.75, $127.11,125.02,123.28,121.92$, 119.46, 118.78, 111.32, 109.42, $79.96,58.24,54.48,46.02,41.70,35.53,28.35,28.02$. IR $\nu_{\max }$ (neat) $/ \mathrm{cm}^{-1} 3067(\mathrm{CH}), 1514(\mathrm{C}=\mathrm{C})$ and $1447(\mathrm{~N}=\mathrm{N}) . \mathrm{MS}(\mathrm{ESI})$, $m / z: 581.3[\mathrm{M}+\mathrm{H}]^{+}$.

(R)-(1-(3-(4-Methylbenzylamino)-3-oxopropyl)-1H-1,2,3-triazol4-yl)methyl 2-[(tert-butoxycarbonyl)amino]-3-phenylpropanoate (53). Creamish solid, yield $90 \% . R_{\mathrm{f}}=0.63(10 \% \mathrm{MeOH}$ in DCM). Mp 105-107 ${ }^{\circ} \mathrm{C}$. $[\alpha]_{\mathrm{D}}^{20}=-16.00 .{ }^{1} \mathrm{H}$ NMR $(300 \mathrm{MHz}$, $\left.\mathrm{CDCl}_{3}\right) \delta: 7.57(\mathrm{~s}, 1 \mathrm{H}), 7.26-7.21(\mathrm{~m}, 3 \mathrm{H}), 7.11-7.04(\mathrm{~m}, 6 \mathrm{H})$, $6.34(\mathrm{brs}, 1 \mathrm{H}), 5.21(\mathrm{~s}, 2 \mathrm{H}), 4.99(\mathrm{~d}, J=7.8 \mathrm{~Hz}, 1 \mathrm{H}), 4.65(\mathrm{t}, J=$ $6.3 \mathrm{~Hz}, 2 \mathrm{H}), 4.56-4.50(\mathrm{~m}, 1 \mathrm{H}), 4.33(\mathrm{~d}, J=5.7 \mathrm{~Hz}, 2 \mathrm{H})$, 3.11-2.96 (m, 2H), $2.83(\mathrm{t}, J=6.3 \mathrm{~Hz}, 2 \mathrm{H}), 2.31(\mathrm{~s}, 3 \mathrm{H}), 1.40(\mathrm{~s}$, $9 \mathrm{H}) .{ }^{13} \mathrm{C}$ NMR $\left(75 \mathrm{MHz}, \mathrm{CDCl}_{3}\right) \delta: 171.64,168.88,155.09$, $142.05,137.32$, 135.83, 134.74, 129.36, 128.49, 127.72, 126.99, 125.08, 80.02, 58.24, 54.40, 46.23, 43.45, 38.05, 36.35, 28.27, 21.07. IR $\nu_{\max }$ (neat) $/ \mathrm{cm}^{-1} 3067(\mathrm{CH}), 1521(\mathrm{C}=\mathrm{C})$ and 1462 $(\mathrm{N}=\mathrm{N})$. MS (ESI), $m / z: 522.2[\mathrm{M}+\mathrm{H}]^{+}$.

(R)-(1-(3-(4-Methylbenzylamino)-3-oxopropyl)-1H-1,2,3-triazol4-yl)methyl 1-(tert-butoxycarbonyl)pyrrolidine-2-carboxylate (54). Colorless oil, yield $83 \% . R_{\mathrm{f}}=0.67(10 \% \mathrm{MeOH}$ in DCM $) .[\alpha]_{\mathrm{D}}^{20}=$ -48.00. ${ }^{1} \mathrm{H}$ NMR (300 MHz, $\mathrm{CDCl}_{3}$ ) $\delta: 7.70(\mathrm{~s}, 1 \mathrm{H}), 7.12-7.03$ $(\mathrm{m}, 4 \mathrm{H}), 6.45$ (brs, 1H), $5.19(\mathrm{~m}, 2 \mathrm{H}), 4.69-4.64(\mathrm{~m}, 2 \mathrm{H})$, 4.34-4.32 (m, 2H), 4.23-4.19 (m, 1H), 3.51-3.37 (m, 2H), 2.87-2.79 (m, 2H), 2.31 (s, 3H), 2.19-2.12 (m, 2H), 1.95-1.81 $(\mathrm{m}, 3 \mathrm{H}), 1.42(\mathrm{~s}, 9 \mathrm{H}) .{ }^{13} \mathrm{C} \mathrm{NMR}\left(75 \mathrm{MHz}, \mathrm{CDCl}_{3}\right) \delta: 172.99$, 168.94, 154.42, 142.83, 137.26, 134.86, 129.32, 127.70, 124.97, 79.92, 58.98, 58.08, 46.62, 43.38, 36.52, 30.78, 29.78, 28.40, 24.33, 21.05. IR $\nu_{\max }$ (neat) $/ \mathrm{cm}^{-1} 3089(\mathrm{CH}), 1547(\mathrm{C}=\mathrm{C})$ and $1454(\mathrm{~N}=\mathrm{N})$. MS (ESI), $m / z: 358.3[\mathrm{M}+\mathrm{H}-\mathrm{Boc}]^{+}, 471.99$ $[\mathrm{M}+\mathrm{H}]^{+}, 494.13[\mathrm{M}+\mathrm{Na}]^{+}$.

(R)-(1-(3-(4-Methylbenzylamino)-3-oxopropyl)-1H-1,2,3-triazol4-yl)methyl 2-[(tert-butoxycarbonyl)amino]-3-(1H-indol-3-yl)propanoate (55). Light yellow solid, yield 83\%. $R_{\mathrm{f}}=0.67(10 \%$ $\mathrm{MeOH}$ in DCM). Mp 68-70 ${ }^{\circ} \mathrm{C}$. $[\alpha]_{\mathrm{D}}^{20}=-16.00 .{ }^{1} \mathrm{H}$ NMR $\left(400 \mathrm{MHz}, \mathrm{CDCl}_{3}\right) \delta: 8.75(\mathrm{~s}, 1 \mathrm{H}), 7.55(\mathrm{~d}, J=7.7 \mathrm{~Hz}, 1 \mathrm{H}), 7.38$ (d, $J=7.6 \mathrm{~Hz}, 1 \mathrm{H}), 7.19-6.99(\mathrm{~m}, 7 \mathrm{H}), 6.56$ (s, 1H), 5.98 (brs, 1H), 5.29-5.26 (m, 1H), 5.13-5.09 (m, 2H), 4.66-4.56 (m, 3H), 4.40-4.34 (m, 2H), 3.25-3.19 (m, 2H), 2.95-2.84 (m, 2H), 2.33 $(\mathrm{s}, 3 \mathrm{H}), 1.44(\mathrm{~s}, 9 \mathrm{H}) .{ }^{13} \mathrm{C} \mathrm{NMR}\left(75 \mathrm{MHz}, \mathrm{CDCl}_{3}\right) \delta: 172.13$, $169.44,155.24,142.42$, 141.22, 137.35, 136.09, 134.58, 129.39, $127.75,125.01,123.32$, 121.90, 119.44, 118.76, 111.37, 109.36, 79.97, 58.23, 54.54, 46.11, 43.49, 35.63, 28.35, 28.06, 21.07. IR $\nu_{\max }($ neat $) / \mathrm{cm}^{-1} 3089(\mathrm{CH}), 1514(\mathrm{C}=\mathrm{C})$ and $1462(\mathrm{~N}=\mathrm{N})$. MS (ESI), $m / z: 559.15[\mathrm{M}-\mathrm{H}]^{-}, 561.65[\mathrm{M}+\mathrm{H}]^{+}$.

(R)-(1-(3-(4-Methoxybenzylamino)-3-oxopropyl)-1H-1,2,3-triazol4-yl)methyl 2-[(tert-butoxycarbonyl)amino]-3-phenylpropanoate (56). Creamish solid, yield 95\%. $R_{\mathrm{f}}=0.76(10 \% \mathrm{MeOH}$ in DCM). Mp 108-110 ${ }^{\circ} \mathrm{C}$. $[\alpha]_{\mathrm{D}}^{20}=-16.00 .{ }^{1} \mathrm{H}$ NMR $(400 \mathrm{MHz}$, $\left.\mathrm{CDCl}_{3}\right) \delta: 7.60(\mathrm{~s}, 1 \mathrm{H}), 7.24-7.22(\mathrm{~m}, 3 \mathrm{H}), 7.10(\mathrm{~d}, J=8.5 \mathrm{~Hz}$, 
2H), 7.06-7.04 (m, 2H), $6.84(\mathrm{~d}, J=8.5 \mathrm{~Hz}, 2 \mathrm{H}), 5.79$ (brs, 1H), $5.22(\mathrm{~s}, 2 \mathrm{H}), 4.95$ (d, $J=7.8 \mathrm{~Hz}, 1 \mathrm{H}), 4.74-4.67(\mathrm{~m}, 2 \mathrm{H})$, 4.55-4.53 (m, 1H), 4.31 (d, $J=5.6 \mathrm{~Hz}, 2 \mathrm{H}), 3.78(\mathrm{~s}, 3 \mathrm{H})$, 3.11-2.99 (m, 2H), $2.83(\mathrm{t}, J=6.2 \mathrm{~Hz}, 2 \mathrm{H}), 1.40(\mathrm{~s}, 9 \mathrm{H}) .{ }^{13} \mathrm{C}$ NMR (75 MHz, $\left.\mathrm{CDCl}_{3}\right) \delta: 171.64,168.82,159.09,155.09$, 142.08, 135.83, 129.82, 129.34, 129.11, 128.50, 126.99, 125.06, 114.09, 80.02, 58.26, 55.29, 54.39, 46.23, 43.19, 38.04, 36.36, 28.27. IR $\nu_{\max }$ (neat) $/ \mathrm{cm}^{-1} 3070(\mathrm{CH}), 1514(\mathrm{C}=\mathrm{C})$ and 1458 $(\mathrm{N}=\mathrm{N})$. MS (ESI), $m / z: 538.1[\mathrm{M}+\mathrm{H}]^{+}$.

(R)-(1-(3-(4-Methoxybenzylamino)-3-oxopropyl)-1H-1,2,3-triazol4-yl)methyl 1-(tert-butoxycarbonyl)pyrrolidine-2-carboxylate (57). Light yellow oil, yield $86 \% . R_{\mathrm{f}}=0.71(10 \% \mathrm{MeOH}$ in DCM). $[\alpha]_{\mathrm{D}}^{20}=-44.00 .{ }^{1} \mathrm{H} \mathrm{NMR}\left(400 \mathrm{MHz}, \mathrm{CDCl}_{3}\right) \delta: 7.69(\mathrm{~d}, J=4.5 \mathrm{~Hz}$, $1 \mathrm{H}), 7.16-7.08(\mathrm{~m}, 2 \mathrm{H}), 6.86-6.83(\mathrm{~m}, 2 \mathrm{H}), 6.10$ (brs, $1 \mathrm{H})$, 5.26-5.21 (m, 2H), 4.73-4.66 (m, 2H), 4.33-4.32 (m, 2H), 4.24-4.12 (m, 1H), $3.79(\mathrm{~s}, 3 \mathrm{H}), 3.52-3.45(\mathrm{~m}, 2 \mathrm{H}), 2.86-2.78$ $(\mathrm{m}, 2 \mathrm{H}), 1.96-1.82(\mathrm{~m}, 2 \mathrm{H}), 1.70(\mathrm{~m}, 2 \mathrm{H}), 1.43(\mathrm{~s}, 9 \mathrm{H})$. ${ }^{13} \mathrm{C} \mathrm{NMR}\left(75 \mathrm{MHz}, \mathrm{CDCl}_{3}\right) \delta: 173.03,168.89,159.10,154.42$, 142.92, 129.95, 129.11, 124.97, 114.08, 79.92, 58.99, 58.12, $55.29,46.63,43.17,36.59,30.79,29.78,28.41,24.34$. IR $\nu_{\max }$ (neat) $/ \mathrm{cm}^{-1} 3095(\mathrm{CH}), 1514(\mathrm{C}=\mathrm{C})$ and $1462(\mathrm{~N}=\mathrm{N}) . \mathrm{MS}(\mathrm{ESI})$, $m / z: 388.2[\mathrm{M}+\mathrm{H}-\mathrm{Boc}]^{+}, 488.08[\mathrm{M}+\mathrm{H}]^{+}$.

(R)-(1-(3-(4-Methoxybenzylamino)-3-oxopropyl)-1H-1,2,3-triazol4-yl)methyl 2-[(tert-butoxycarbonyl)amino]-3-(1H-indol-3-yl)propanoate (58). Light yellow solid, yield 92\%. $R_{\mathrm{f}}=0.67(10 \%$ $\mathrm{MeOH}$ in DCM). Mp $72-74{ }^{\circ} \mathrm{C}$. $[\alpha]_{\mathrm{D}}^{20}=-20.00 .{ }^{1} \mathrm{H}$ NMR $\left(400 \mathrm{MHz}, \mathrm{CDCl}_{3}\right) \delta: 8.84(\mathrm{~s}, 1 \mathrm{H}), 7.55(\mathrm{~d}, J=7.8 \mathrm{~Hz}, 1 \mathrm{H}), 7.38$ $(\mathrm{d}, J=8.0 \mathrm{~Hz}, 1 \mathrm{H}), 7.19-7.15(\mathrm{~m}, 2 \mathrm{H}), 7.10-7.07(\mathrm{~m}, 3 \mathrm{H}), 6.83$ (d, $J=8.6 \mathrm{~Hz}, 2 \mathrm{H}), 6.52(\mathrm{~s}, 1 \mathrm{H}), 6.02$ (brs, $1 \mathrm{H}), 5.29-5.26(\mathrm{~m}$, 1H), 5.12-5.09 (m, 2H), 4.67-4.52 (m, 3H), 4.34-4.30 (m, 2H), $3.78(\mathrm{~s}, 3 \mathrm{H}), 3.26-3.20(\mathrm{~m}, 2 \mathrm{H}), 2.96-2.83(\mathrm{~m}, 2 \mathrm{H}), 1.44(\mathrm{~s}, 9 \mathrm{H})$. ${ }^{13} \mathrm{C}$ NMR (75 MHz, $\mathrm{CDCl}_{3}$ ) $\delta: 172.12,169.36,159.07,155.24$, 142.43, 136.09, 129.66, 128.93, 127.76, 125.00, 123.31, 121.91, $119.44,118.76,114.10,111.35,109.39$, 79.95, 58.23, 55.29, $54.54,46.10,43.23,35.61,28.35,28.02$. IR $\nu_{\max }$ (neat) $/ \mathrm{cm}^{-1}$ $3067(\mathrm{CH}), 1514(\mathrm{C}=\mathrm{C})$ and $1460(\mathrm{~N}=\mathrm{N}) . \mathrm{MS}(\mathrm{ESI}), \mathrm{m} / z: 575.37$ $[\mathrm{M}-\mathrm{H}]^{-}, 577.10[\mathrm{M}+\mathrm{H}]^{+}$.

(R)-(1-(3-(4-Trifluoromethylbenzylamino)-3-oxopropyl)-1H1,2,3-triazol-4-yl)methyl 2-[(tert-butoxycarbonyl)amino]-3-phenylpropanoate (59). White solid, yield 94\%. $R_{\mathrm{f}}=0.53(10 \%$ $\mathrm{MeOH}$ in DCM). Mp 103-105 ${ }^{\circ} \mathrm{C}$. $[\alpha]_{\mathrm{D}}^{20}=-20.00 .{ }^{1} \mathrm{H}$ NMR $\left(400 \mathrm{MHz}, \mathrm{CDCl}_{3}\right) \delta: 7.57-7.55(\mathrm{~m}, 3 \mathrm{H}), 7.33-7.22(\mathrm{~m}, 4 \mathrm{H})$, 7.05-7.04 (m, 2H), 6.19 (brs, 1H), $5.22(\mathrm{~s}, 2 \mathrm{H}), 4.94(\mathrm{~d}, J=$ $7.2 \mathrm{~Hz}, 1 \mathrm{H}), 4.75-4.68(\mathrm{~m}, 2 \mathrm{H}), 4.49-4.47(\mathrm{~m}, 1 \mathrm{H}), 4.43(\mathrm{~d}, J=$ $5.7 \mathrm{~Hz}, 2 \mathrm{H}), 3.09-2.98$ (m, 2H), 2.89 (brs, 2H), 1.39 (s, 9H). ${ }^{13} \mathrm{C}$ NMR (75 MHz, $\left.\mathrm{CDCl}_{3}\right) \delta: 171.68,169.22,155.14,142.24$, 141.96, 135.76, 129.30, 128.53, 127.82, 127.04, 125.62, 125.57, 125.09, 80.09, 58.19, 54.43, 46.23, 43.11, 37.96, 36.27, 28.26. IR $\nu_{\max }$ (neat) $/ \mathrm{cm}^{-1} 3032(\mathrm{CH}), 1529(\mathrm{C}=\mathrm{C})$ and $1447(\mathrm{~N}=\mathrm{N})$. MS (ESI), $m / z: 576.1[\mathrm{M}+\mathrm{H}]^{+}$.

(R)-(1-(3-(4-Trifluoromethylbenzylamino)-3-oxopropyl)-1H1,2,3-triazol-4-yl)methyl 1-(tert-butoxycarbonyl)pyrrolidine-2carboxylate (60). Colorless oil, yield $94 \%$. $R_{\mathrm{f}}=0.48(10 \%$ $\mathrm{MeOH}$ in DCM). $[\alpha]_{\mathrm{D}}^{20}=-40.00 .{ }^{1} \mathrm{H} \mathrm{NMR}\left(300 \mathrm{MHz}, \mathrm{CDCl}_{3}\right)$ $\delta: 7.52(\mathrm{~d}, J=7.8 \mathrm{~Hz}, 1 \mathrm{H}), 7.35-7.07(\mathrm{~m}, 4 \mathrm{H}), 6.76$ (brs, $1 \mathrm{H})$, 5.29-5.05 (m, 2H), 4.61-4.56 (m, 2H), $4.53(\mathrm{~d}, J=6.0 \mathrm{~Hz}, 2 \mathrm{H})$,
4.25-4.16 (m, 1H), 3.21 (brs, 2H), 3.03-2.86 (m, 2H), 2.21-2.15 (m, 1H), 1.94-1.86 (m, 3H), 1.42 (s, 9H). ${ }^{13} \mathrm{C}$ NMR (75 MHz, $\left.\mathrm{CDCl}_{3}\right) \delta: 172.12,169.72,155.27,142.58,136.06,127.65$, $125.61,123.18,119.50,111.29,80.01,58.16,54.48,46.09$, $43.14,35.51,29.70,28.32,27.91$. IR $\nu_{\max }$ (neat) $/ \mathrm{cm}^{-1} 3082$ $(\mathrm{CH}), 1546(\mathrm{C}=\mathrm{C})$ and $1452(\mathrm{~N}=\mathrm{N})$. MS (ESI), $\mathrm{m} / \mathrm{z}: 426.05$ $[\mathrm{M}+\mathrm{H}-\mathrm{Boc}]^{+}, 526.04[\mathrm{M}+\mathrm{H}]^{+}$.

(R)-(1-(3-(4-Trifluoromethylbenzylamino)-3-oxopropyl)-1H1,2,3-triazol-4-yl)methyl 2-[(tert-butoxycarbonyl)amino]-3-(1Hindol-3-yl)propanoate (61). Light yellow solid, yield 76\%. $R_{\mathrm{f}}=$ $0.47\left(10 \% \mathrm{MeOH}\right.$ in DCM). Mp 55-60 ${ }^{\circ} \mathrm{C}$. $[\alpha]_{\mathrm{D}}^{20}=-20.00$. ${ }^{1} \mathrm{H}$ NMR (400 MHz, $\left.\mathrm{CDCl}_{3}\right) \delta: 8.71(\mathrm{~s}, 1 \mathrm{H}), 7.54(\mathrm{t}, J=8.0 \mathrm{~Hz}$, $3 \mathrm{H}), 7.35(\mathrm{~d}, J=8.1 \mathrm{~Hz}, 1 \mathrm{H}), 7.24-7.14(\mathrm{~m}, 3 \mathrm{H}), 7.08(\mathrm{t}, J=7.4$ $\mathrm{Hz}, 2 \mathrm{H}), 6.50(\mathrm{~s}, 1 \mathrm{H}), 6.28$ (brs, 1H), 5.29-5.26 (m, 1H), 5.14-5.09 (m, 2H), 4.63-4.52 (m, 3H), 4.43 (s, 2H), $3.23(\mathrm{~s}, 2 \mathrm{H})$, 2.99-2.88 (m, 2H), $1.43(\mathrm{~s}, 9 \mathrm{H}) .{ }^{13} \mathrm{C} \mathrm{NMR}$ (75 MHz, $\mathrm{CDCl}_{3}$ ) $\delta: 172.99,169.43,154.47,153.76,143.02,142.26,137.93$, 136.29, 127.79, 126.04, 125.47, 125.08, 124.50, 121.87, 119.23, 118.45, 111.21, 109.34, 79.98, 58.96, 57.99, 46.66, 42.99, 36.54, 30.72, 28.37. IR $\nu_{\max }$ (neat) $/ \mathrm{cm}^{-1} 3091(\mathrm{CH}), 1510(\mathrm{C}=\mathrm{C})$ and $1460(\mathrm{~N}=\mathrm{N})$. MS (ESI), $m / z: 613.27[\mathrm{M}-\mathrm{H}]^{-}, 615.13[\mathrm{M}+\mathrm{H}]^{+}$.

(R)-(1-(3-(4-Trifluoromethoxybenzylamino)-3-oxopropyl)-1H1,2,3-triazol-4-yl)methyl 2-[(tert-butoxycarbonyl)amino]-3-phenylpropanoate (62). Light yellow solid, yield $89 \% . R_{\mathrm{f}}=0.69$ (10\% MeOH in DCM). Mp 110-113 ${ }^{\circ} \mathrm{C} .[\alpha]_{\mathrm{D}}^{20}=-24.00 .{ }^{1} \mathrm{H}$ NMR $\left(300 \mathrm{MHz}_{\mathrm{CDCl}}\right) \delta: 7.49(\mathrm{~s}, 1 \mathrm{H}), 7.28-7.21(\mathrm{~m}, 5 \mathrm{H}), 7.09-6.89$ (m, 4H), 5.91 (brs, 1H), $5.23(\mathrm{~s}, 2 \mathrm{H}), 4.67$ (d, $J=7.4 \mathrm{~Hz}, 1 \mathrm{H})$, $4.71(\mathrm{t}, J=5.8 \mathrm{~Hz}, 2 \mathrm{H}), 4.48-4.46(\mathrm{~m}, 1 \mathrm{H}), 4.41(\mathrm{~d}, J=5.4 \mathrm{~Hz}$, $2 \mathrm{H}), 3.12-3.01(\mathrm{~m}, 2 \mathrm{H}), 2.82(\mathrm{t}, J=6.8 \mathrm{~Hz}, 2 \mathrm{H}), 1.40(\mathrm{~s}, 9 \mathrm{H})$. ${ }^{13} \mathrm{C} \mathrm{NMR}\left(75 \mathrm{MHz}, \mathrm{CDCl}_{3}\right) \delta: 171.82,169.78,156.24,142.63$, 137.89 , 137.09, 135.86, 128.54, 127.61, 127.32, 124.78, 123.29, 121.56, 115.45, 79.32, 58.51, 54.71, 46.31, 43.71, 38.67, 35.55, 28.35. IR $\nu_{\max }$ (neat) $/ \mathrm{cm}^{-1} 3067(\mathrm{CH}), 1533(\mathrm{C}=\mathrm{C})$ and 1447 $(\mathrm{N}=\mathrm{N})$. MS (ESI), $m / z: 592.3[\mathrm{M}+\mathrm{H}]^{+}$.

(R)-(1-(3-(4-Trifluoromethoxybenzylamino)-3-oxopropyl)-1H1,2,3-triazol-4-yl)methyl 1-(tert-butoxycarbonyl)pyrrolidine-2carboxylate (63). Light yellow oil, yield 89\%. $R_{\mathrm{f}}=0.65(10 \%$ $\mathrm{MeOH}$ in DCM). $[\alpha]_{\mathrm{D}}^{20}=-44.00 .{ }^{1} \mathrm{H} \mathrm{NMR}\left(300 \mathrm{MHz}, \mathrm{CDCl}_{3}\right)$ $\delta: 7.71(\mathrm{~d}, J=9.7 \mathrm{~Hz}, 1 \mathrm{H}), 7.24-7.16(\mathrm{~m}, 2 \mathrm{H}), 7.02-6.95(\mathrm{~m}, 2 \mathrm{H})$, 6.43 (brs, 1H), 5.41-5.28 (m, 2H), 4.75-4.68 (m, 2H), 4.42-4.39 $(\mathrm{m}, 2 \mathrm{H}), 4.28-4.25(\mathrm{~m}, 1 \mathrm{H}), 3.67-3.47(\mathrm{~m}, 2 \mathrm{H}), 2.81-2.76(\mathrm{~m}$, 2H), 2.12-1.89 (m, 4H), 1.39-1.32 (m, 9H). ${ }^{13} \mathrm{C}$ NMR (75 MHz, $\left.\mathrm{CDCl}_{3}\right) \delta: 173.12,168.12,158.23,154.30,142.73,139.32$, $135.03,129.02,124.82,121.67,114.23,79.78,58.23,46.85$, $46.30,42.80,35.67,30.56,28.23,23.70$. IR $\nu_{\max }$ (neat) $/ \mathrm{cm}^{-1}$ $3056(\mathrm{CH}), 1544(\mathrm{C}=\mathrm{C})$ and $1460(\mathrm{~N}=\mathrm{N}) . \mathrm{MS}(\mathrm{ESI}), \mathrm{m} / \mathrm{z}: 542.3$ $[\mathrm{M}+\mathrm{H}]^{+}$.

(R)-(1-(3-(4-Trifluoromethoxybenzylamino)-3-oxopropyl)-1H1,2,3-triazol-4-yl)methyl 2-(tert-butoxycarbonyl)-3-(1H-indol-3yl)propanoate (64). Light yellow solid, yield $89 \% . R_{\mathrm{f}}=0.62$ (10\% MeOH in DCM). Mp 70-72 ${ }^{\circ} \mathrm{C}$. $[\alpha]_{\mathrm{D}}^{20}=-24.00 .{ }^{1} \mathrm{H}$ NMR $\left(300 \mathrm{MHz}, \mathrm{CDCl}_{3}\right) \delta: 8.92(\mathrm{~s}, 1 \mathrm{H}), 7.56(\mathrm{~d}, J=7.0 \mathrm{~Hz}, 1 \mathrm{H})$, 7.32-7.28 (m, 4H), 7.14-7.02 (m, 5H), 6.43 (s, 1H), 6.21 (brs, $1 \mathrm{H}), 5.46-5.41(\mathrm{~m}, 1 \mathrm{H}), 5.14-5.03(\mathrm{~m}, 2 \mathrm{H}), 4.65-4.51(\mathrm{~m}, 3 \mathrm{H})$, $4.23(\mathrm{~m}, 2 \mathrm{H}), 3.19-3.12(\mathrm{~m}, 2 \mathrm{H}), 2.87-2.72(\mathrm{~m}, 2 \mathrm{H}), 1.43(\mathrm{~s}$, $9 \mathrm{H}) .{ }^{13} \mathrm{C} \mathrm{NMR}\left(75 \mathrm{MHz}, \mathrm{CDCl}_{3}\right) \delta: 171.88,169.57,156.12$, 
$142.87,137.51,136.24,128.54,127.78,127.21,124.73,122.89$, $121.72,119.03,118.56,111.47,109.25,79.89$, 58.21, 54.76, 46.23, 43.53, 36.03, 28.42. IR $\nu_{\max }$ (neat) $/ \mathrm{cm}^{-1} 3078(\mathrm{CH}), 1510$ $(\mathrm{C}=\mathrm{C})$ and $1460(\mathrm{~N}=\mathrm{N})$. MS (ESI), $m / z: 630.1[\mathrm{M}+\mathrm{H}]^{+}$.

Deprotection of boc-protected triazole-amino acid hybrids

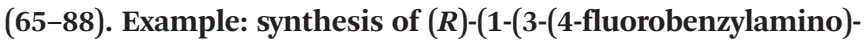
3-oxopropyl)-1H-1,2,3-triazol-4-yl)methyl 2-amino-3phenylpropanoate (68)

Compound 44 (0.57 mmol, $0.3 \mathrm{~g}$ ) was dissolved in dichloromethane $(10 \mathrm{~mL})$. To this solution $p$-toluene sulphonic acid ( $p$ TSA) (1.71 mmol, $0.32 \mathrm{~g}$ ) was added. The reaction was stirred for $3 \mathrm{~h}$ at room temperature. After completion of the reaction, it was neutralized by using sat. sodium bicarbonate solution and the compound was extracted by ethyl acetate, washed with water and brine to get final compound (68).

(R)-(1-(3-(Benzylamino)-3-oxopropyl)-1H-1,2,3-triazol-4-yl) methyl 2-amino-3-phenylpropanoate (65). Yellow solid, yield $85 \% . R_{\mathrm{f}}=0.69\left(10 \% \mathrm{MeOH}\right.$ in DCM). Mp 165-167 ${ }^{\circ} \mathrm{C} .{ }^{1} \mathrm{H}$ NMR (400 MHz, DMSO- $\left.d_{6}\right) \delta: 7.86(\mathrm{~s}, 1 \mathrm{H}), 7.29-7.15(\mathrm{~m}, 10 \mathrm{H}), 6.68$ (brs, 1H), $5.17(\mathrm{~s}, 2 \mathrm{H}), 4.57(\mathrm{t}, J=6.7 \mathrm{~Hz}, 2 \mathrm{H}), 4.49(\mathrm{~s}, 2 \mathrm{H}), 4.25$ (d, $J=5.6 \mathrm{~Hz}, 2 \mathrm{H}), 3.63-3.60(\mathrm{~m}, 1 \mathrm{H}), 3.17-3.12(\mathrm{~m}, 2 \mathrm{H}), 2.79$ $(\mathrm{t}, J=7.3 \mathrm{~Hz}, 2 \mathrm{H}) .{ }^{13} \mathrm{C} \mathrm{NMR}\left(75 \mathrm{MHz}, \mathrm{CDCl}_{3}\right) \delta: 173.89,169.13$, $162.49,142.56,137.85,133.70,129.54,128.68,127.69,127.31$, $126.85,123.08,57.28,55.91,46.19,43.63,40.65$, 36.42. IR $\nu_{\max }$ (neat) $/ \mathrm{cm}^{-1} 3290\left(\mathrm{NH}_{2}\right)$ and $3070(\mathrm{CH}) . \mathrm{MS}(\mathrm{ESI}), \mathrm{m} / \mathrm{z}$ : $408.2[\mathrm{M}+\mathrm{H}]^{+}$.

(R)-(1-(3-(Benzylamino)-3-oxopropyl)-1H-1,2,3-triazol-4-yl) methyl pyrrolidine-2-carboxylate (66). Yellow oil, yield 89\%. $R_{\mathrm{f}}=0.33$ (10\% MeOH in DCM). ${ }^{1} \mathrm{H}$ NMR (300 MHz, DMSO- $\left.d_{6}\right)$ $\delta: 8.51$ (brs, 1H), 7.87 (s, 1H), 7.32-7.15 (m, 5H), 5.14 (brs, 1H), $4.58(\mathrm{t}, J=6.9 \mathrm{~Hz}, 2 \mathrm{H}), 4.50(\mathrm{~s}, 2 \mathrm{H}), 4.26(\mathrm{~d}, J=5.7 \mathrm{~Hz}, 2 \mathrm{H})$, 3.64-3.59 (m, 1H), 3.23-3.17 (m, 2H), $2.78(\mathrm{t}, J=6.6 \mathrm{~Hz}, 2 \mathrm{H})$, 2.01-1.91 (m, 2H), 1.72-1.65 (m, 2H). ${ }^{13} \mathrm{C}$ NMR (75 MHz, $\left.\mathrm{CDCl}_{3}\right) \delta: 173.24,169.35,148.04,138.37,128.39,127.59$, 127.11, 122.66, 60.03, 56.07, 46.12, 43.20, 36.20, 30.78, 29.54, 24.32. IR $\nu_{\max }$ (neat) $/ \mathrm{cm}^{-1} 3290\left(\mathrm{NH}_{2}\right)$ and $3070(\mathrm{CH}) . \mathrm{MS}(\mathrm{ESI})$, $m / z: 358.6[\mathrm{M}+\mathrm{H}]^{+}$.

(R)-(1-(3-(Benzylamino)-3-oxopropyl)-1H-1,2,3-triazol-4-yl) methyl 2-amino-3-(1H-indol-3-yl)propanoate (67). Yellow oil, yield $88 \% . R_{\mathrm{f}}=0.41\left(10 \% \mathrm{MeOH}\right.$ in DCM). ${ }^{1} \mathrm{H}$ NMR $(300 \mathrm{MHz}$, $\left.\mathrm{CDCl}_{3}\right) \delta: 8.96(\mathrm{~s}, 1 \mathrm{H}), 7.48(\mathrm{~d}, J=7.5 \mathrm{~Hz}, 1 \mathrm{H}), 7.28(\mathrm{~d}, J=$ $7.8 \mathrm{~Hz}, 1 \mathrm{H}), 7.19-6.96(\mathrm{~m}, 8 \mathrm{H}), 6.74$ (brs, 1H), $6.66(\mathrm{~s}, 1 \mathrm{H})$, 5.13-4.97 (m, 2H), 4.59-4.46 (m, 2H), 4.27 (d, $J=5.4 \mathrm{~Hz}, 2 \mathrm{H})$, $3.75(\mathrm{t}, J=6.0 \mathrm{~Hz}, 1 \mathrm{H}), 3.07-3.04(\mathrm{~m}, 1 \mathrm{H}), 2.78-2.70(\mathrm{~m}, 3 \mathrm{H})$. ${ }^{13} \mathrm{C}$ NMR (75 MHz, $\mathrm{CDCl}_{3}$ ) $\delta: 174.98,169.45,142.46,137.78$, 136.22, 133.67, 128.67, 127.52, 124.81, 123.38, 121.88, 119.35, 118.70, 111.37, 110.13, 57.94, 55.16, 46.14, 43.62, 35.83, 30.41. IR $\nu_{\max }$ (neat) $/ \mathrm{cm}^{-1} 3391\left(\mathrm{NH}_{2}\right)$ and $3068(\mathrm{CH})$. MS (ESI), $m / z$ : 445.0 $[\mathrm{M}-\mathrm{H}]^{-}, 447.0[\mathrm{M}+\mathrm{H}]^{+}$.

(R)-(1-(3-(4-Fluorobenzylamino)-3-oxopropyl)-1H-1,2,3-triazol4-yl)methyl 2-amino-3-phenylpropanoate (68). Creamish solid, yield $85 \%$. $R_{\mathrm{f}}=0.67\left(10 \% \mathrm{MeOH}\right.$ in DCM). Mp $184-186{ }^{\circ} \mathrm{C}$. ${ }^{1} \mathrm{H}$ NMR (300 MHz, $\left.\mathrm{CDCl}_{3}\right) \delta: 7.51(\mathrm{~s}, 1 \mathrm{H}), 7.21-7.16(\mathrm{~m}, 3 \mathrm{H})$, 7.08-7.03 (m, 4H), 6.89 (t, $J=8.7 \mathrm{~Hz}, 2 \mathrm{H}), 6.52$ (brs, 1H), 5.09 $(\mathrm{s}, 2 \mathrm{H}), 4.57(\mathrm{t}, J=5.6 \mathrm{~Hz}, 2 \mathrm{H}), 4.26(\mathrm{~d}, J=5.4 \mathrm{~Hz}, 2 \mathrm{H})$,
3.66-3.62 (m, 1H), 2.99-2.93 (m, 1H), 2.81-2.72 (m, 3H). ${ }^{13} \mathrm{C}$ NMR (75 MHz, $\left.\mathrm{CDCl}_{3}\right) \delta: 174.59,169.07,160.52,142.28$, 136.92, 133.70, 129.41, 129.30, 128.54, 126.85, 125.03, 115.65, 57.84, 55.66, 46.19, 42.91, 40.89, 36.16. IR $\nu_{\max }$ (neat) $/ \mathrm{cm}^{-1}$ $3283\left(\mathrm{NH}_{2}\right)$ and $3074(\mathrm{CH})$. MS (ESI), $m / z: 426.2[\mathrm{M}+\mathrm{H}]^{+}$.

(R)-(1-(3-(4-Fluorobenzylamino)-3-oxopropyl)-1H-1,2,3-triazol4-yl)methyl pyrrolidine-2-carboxylate (69). Light yellow solid, yield $89 \%$. $R_{\mathrm{f}}=0.33(10 \% \mathrm{MeOH}$ in DCM $) . \mathrm{Mp}=70-76^{\circ} \mathrm{C}$. ${ }^{1} \mathrm{H} \mathrm{NMR}\left(400 \mathrm{MHz}, \mathrm{CDCl}_{3}\right) \delta: 7.60(\mathrm{~s}, 1 \mathrm{H}), 7.16-7.13(\mathrm{~m}, 2 \mathrm{H})$, 7.02-6.98 (m, 2H), 5.94 (brs, 1H), $4.75(\mathrm{~s}, 2 \mathrm{H}), 4.70(\mathrm{t}, J=6.1$ $\mathrm{Hz}, 2 \mathrm{H}), 4.36$ (d, $J=5.8 \mathrm{~Hz}, 2 \mathrm{H}), 3.62-3.57$ (m, 1H), 3.12-3.03 $(\mathrm{m}, 2 \mathrm{H}), 2.86(\mathrm{t}, J=6.2 \mathrm{~Hz}, 2 \mathrm{H}), 2.23-2.07(\mathrm{~m}, 2 \mathrm{H}), 1.86-1.74$ $(\mathrm{m}, 2 \mathrm{H}) .{ }^{13} \mathrm{C}$ NMR (75 MHz, $\left.\mathrm{CDCl}_{3}\right) \delta: 173.98,169.40,160.25$, 148.02, 134.24, 129.31, 127.74, 126.89, 122.70, 115.31, 56.09, 46.12, 42.49, 36.21, 29.53, 24.46. IR $\nu_{\max }$ (neat) $/ \mathrm{cm}^{-1} 3290$ $\left(\mathrm{NH}_{2}\right)$ and $3070(\mathrm{CH})$. MS (ESI), $m / z: 376.0[\mathrm{M}+\mathrm{H}]^{+}$.

(R)-(1-(3-(4-Fluorobenzylamino)-3-oxopropyl)-1H-1,2,3-triazol4-yl)methyl 2-amino-3-(1H-indol-3-yl)propanoate (70). Yellow oil, yield $90 \% . R_{\mathrm{f}}=0.41\left(10 \% \mathrm{MeOH}\right.$ in DCM). ${ }^{1} \mathrm{H}$ NMR $\left(300 \mathrm{MHz}, \mathrm{CDCl}_{3}\right) \delta: 8.81(\mathrm{~s}, 1 \mathrm{H}), 7.48(\mathrm{~d}, J=7.8 \mathrm{~Hz}, 1 \mathrm{H}), 7.27$ $(\mathrm{d}, J=8.1 \mathrm{~Hz}, 1 \mathrm{H}), 7.11-6.98(\mathrm{~m}, 5 \mathrm{H}), 6.87(\mathrm{t}, J=8.2 \mathrm{~Hz}, 2 \mathrm{H})$, 6.64-6.58 (m, 2H), 5.14-4.96 (m, 2H), 4.54-4.42 (m, 2H), 4.22 $(\mathrm{d}, J=5.7 \mathrm{~Hz}, 2 \mathrm{H}), 3.74(\mathrm{t}, J=6.0 \mathrm{~Hz}, 1 \mathrm{H}), 3.11-3.00(\mathrm{~m}, 2 \mathrm{H})$, 2.84-2.77 (m, 2H). ${ }^{13} \mathrm{C} \mathrm{NMR} \mathrm{(75} \mathrm{MHz,} \mathrm{CDCl}_{3}$ ) $\delta: 175.13,169.42$, $142.56,136.19,133.53,129.27,127.64,124.88,123.23,121.94$, $119.41,118.76,115.66,111.32,110.33,57.85,55.23,46.09$, 42.92, 35.73, 30.53. IR $\nu_{\max }$ (neat) $/ \mathrm{cm}^{-1} 3272\left(\mathrm{NH}_{2}\right)$ and 3074 (CH). MS (ESI), $m / z: 463.0[\mathrm{M}-\mathrm{H}]^{-}, 465.2[\mathrm{M}+\mathrm{H}]^{+}$.

(R)-(1-(3-(4-Chlorobenzylamino)-3-oxopropyl)-1H-1,2,3-triazol4-yl)methyl 2-amino-3-phenylpropanoate (71). Creamish solid, yield $88 \% . R_{\mathrm{f}}=0.43\left(10 \% \mathrm{MeOH}\right.$ in DCM). Mp $120-122^{\circ} \mathrm{C}$. ${ }^{1} \mathrm{H}$ NMR (400 MHz, DMSO- $\left.d_{6}\right) \delta: 7.97(\mathrm{~s}, 1 \mathrm{H}), 7.34(\mathrm{~d}, J=$ $8.2 \mathrm{~Hz}, 2 \mathrm{H}), 7.28-7.12(\mathrm{~m}, 7 \mathrm{H}), 6.92-6.88(\mathrm{~m}, 1 \mathrm{H}), 5.18-5.10$ $(\mathrm{m}, 2 \mathrm{H}), 4.61-4.55(\mathrm{~m}, 2 \mathrm{H}), 4.49(\mathrm{~s}, 2 \mathrm{H}), 4.24-4.23(\mathrm{~m}, 2 \mathrm{H})$, 3.61-3.58 (m, 1H), 2.88-2.77 (m, 4H). ${ }^{13} \mathrm{C}$ NMR (75 MHz, $\left.\mathrm{CDCl}_{3}\right) \delta:$ 173.66, 169.09, 157.13, 142.17, 136.45, 133.32, 129.31, 128.78, 128.52, 127.01, 125.07, 124.24, 58.20, 54.43, 46.25, 42.93, 40.92, 36.26. IR $\nu_{\max }$ (neat) $/ \mathrm{cm}^{-1} 3294\left(\mathrm{NH}_{2}\right)$ and $3070(\mathrm{CH}) . \mathrm{MS}(\mathrm{ESI}), \mathrm{m} / z: 442.0[\mathrm{M}+\mathrm{H}]^{+}$.

(R)-(1-(3-(4-Chlorobenzylamino)-3-oxopropyl)-1H-1,2,3-triazol4-yl)methyl pyrrolidine-2-carboxylate (72). Yellow oil, yield $90 \% . R_{\mathrm{f}}=0.37\left(10 \% \mathrm{MeOH}\right.$ in DCM). ${ }^{1} \mathrm{H}$ NMR $(300 \mathrm{MHz}$, $\left.\mathrm{CDCl}_{3}\right) \delta: 8.55(\mathrm{~s}, 1 \mathrm{H}), 7.86(\mathrm{~s}, 1 \mathrm{H}), 7.35(\mathrm{~d}, J=8.4 \mathrm{~Hz}, 2 \mathrm{H}), 7.17$ (d, $J=8.4 \mathrm{~Hz}, 2 \mathrm{H}), 5.16$ (brs, $1 \mathrm{H}), 4.57$ (t, $J=6.8 \mathrm{~Hz}, 2 \mathrm{H}), 4.49$ $(\mathrm{s}, 2 \mathrm{H}), 4.24(\mathrm{~d}, J=6.0 \mathrm{~Hz}, 2 \mathrm{H}), 3.65-3.60(\mathrm{~m}, 2 \mathrm{H}), 3.04-2.98$ $(\mathrm{m}, 1 \mathrm{H}), 2.78(\mathrm{t}, J=6.8 \mathrm{~Hz}, 2 \mathrm{H}), 2.01-1.89(\mathrm{~m}, 2 \mathrm{H}), 1.78-1.67$ $(\mathrm{m}, 2 \mathrm{H}) .{ }^{13} \mathrm{C} \mathrm{NMR}\left(75 \mathrm{MHz}, \mathrm{CDCl}_{3}\right) \delta: 172.24,169.18,148.20$, $138.78,128.92,127.67,127.42,122.02,61.24,56.29,46.23$, $42.84,36.28,31.83,29.56,24.56$. IR $\nu_{\max }$ (neat) $/ \mathrm{cm}^{-1} 3284$ $\left(\mathrm{NH}_{2}\right)$ and $3078(\mathrm{CH})$. MS (ESI), $m / z: 392.0[\mathrm{M}+\mathrm{H}]^{+}$.

(R)-(1-(3-(4-Chlorobenzylamino)-3-oxopropyl)-1H-1,2,3-triazol4-yl)methyl 2-amino-3-(1H-indol-3-yl)propanoate (73). Yellow oil, yield $87 \%$. $R_{\mathrm{f}}=0.67\left(10 \% \mathrm{MeOH}\right.$ in DCM). ${ }^{1} \mathrm{H}$ NMR $\left(400 \mathrm{MHz}, \mathrm{CDCl}_{3}\right) \delta: 8.57(\mathrm{~s}, 1 \mathrm{H}), 7.59(\mathrm{~d}, J=7.3 \mathrm{~Hz}, 1 \mathrm{H}), 7.37$ (d, $J=7.9 \mathrm{~Hz}, 1 \mathrm{H}), 7.28$ (brs, 2H), 7.19-7.11 (m, 2H), 7.15-7.07 $(\mathrm{m}, 3 \mathrm{H}), 6.68(\mathrm{~s}, 1 \mathrm{H}), 5.95$ (brs, 1H), 5.29-5.10 (m, 2H), 
4.63-4.58 (m, 2H), 4.35-4.34 (m, 2H), $3.87(\mathrm{t}, J=6.1 \mathrm{~Hz}, 1 \mathrm{H})$, 3.17-3.15 (m, 2H), 2.95-2.85 (m, 2H). ${ }^{13} \mathrm{C}$ NMR (75 MHz, $\left.\mathrm{CDCl}_{3}\right) \delta: 174.39,169.56,142.32,136.78,133.54,128.74$, $128.51,127.72,125.31,123.24,121.63,119.39,118.43,111.33$, 109.45, 58.01, 54.23, 46.57, 42.81, 35.76, 30.42. IR $\nu_{\max }$ (neat)/ $\mathrm{cm}^{-1} 3264\left(\mathrm{NH}_{2}\right)$ and $3063(\mathrm{CH})$. MS (ESI), m/z: $479.0[\mathrm{M}-$ $\mathrm{H}]^{-}, 481.2[\mathrm{M}+\mathrm{H}]^{+}$.

(R)-(1-(3-(2-Chlorobenzylamino)-3-oxopropyl)-1H-1,2,3-triazol4-yl)methyl 2-amino-3-phenylpropanoate (74). Yellow oil, yield $84 \% . R_{\mathrm{f}}=0.53\left(10 \% \mathrm{MeOH}\right.$ in DCM). ${ }^{1} \mathrm{H}$ NMR $(300 \mathrm{MHz}$, $\left.\mathrm{CDCl}_{3}\right) \delta: 7.49(\mathrm{~s}, 1 \mathrm{H}), 7.24-7.19(\mathrm{~m}, 5 \mathrm{H}), 7.04-6.99(\mathrm{~m}, 4 \mathrm{H})$, 6.58 (brs, 1H), $5.20(\mathrm{~s}, 2 \mathrm{H}), 4.58(\mathrm{t}, J=6.2 \mathrm{~Hz}, 2 \mathrm{H}), 4.38(\mathrm{~s}, 2 \mathrm{H})$, 4.20-4.16 (m, 2H), 3.72-3.68 (m, 1H), 3.01-2.76 (m, 4H). ${ }^{13} \mathrm{C}$ NMR (75 $\left.\mathrm{MHz}, \mathrm{CDCl}_{3}\right) \delta: 174.32,169.40,161.23,147.45$, 135.18, 133.49, 129.87, 129.52, 128.99, 128.26, 127.06, 125.91, 123.05, 56.09, 54.23, 46.14, 43.24, 41.56, 36.29. IR $\nu_{\max }$ (neat)/ $\mathrm{cm}^{-1} 3279\left(\mathrm{NH}_{2}\right)$ and $3067(\mathrm{CH})$. MS (ESI), $m / z: 442.2[\mathrm{M}+\mathrm{H}]^{+}$.

(R)-(1-(3-(2-Chlorobenzylamino)-3-oxopropyl)-1H-1,2,3-triazol4-yl)methyl pyrrolidine-2-carboxylate (75). Yellow oil, yield $92 \% . R_{\mathrm{f}}=0.35\left(10 \% \mathrm{MeOH}\right.$ in DCM). ${ }^{1} \mathrm{H}$ NMR $(300 \mathrm{MHz}$, $\left.\mathrm{CDCl}_{3}\right) \delta: 8.55$ (brs, 1H), $7.87(\mathrm{~s}, 1 \mathrm{H}), 7.44-7.41(\mathrm{~m}, 1 \mathrm{H})$, 7.31-7.27 (m, 2H), 7.17-7.14 (m, 1H), 5.14 (brs, 1H), $4.58(\mathrm{t}, J=$ $6.8 \mathrm{~Hz}, 2 \mathrm{H}), 4.50(\mathrm{~s}, 2 \mathrm{H}), 4.31(\mathrm{~d}, J=6.6 \mathrm{~Hz}, 2 \mathrm{H}), 3.78-3.62(\mathrm{~m}$, $1 \mathrm{H}), 3.21-3.14(\mathrm{~m}, 2 \mathrm{H}), 2.83(\mathrm{t}, J=6.6 \mathrm{~Hz}, 2 \mathrm{H}), 2.11-2.02(\mathrm{~m}$, $1 \mathrm{H}), 1.95-1.84(\mathrm{~m}, 3 \mathrm{H}) .{ }^{13} \mathrm{C} \mathrm{NMR}\left(75 \mathrm{MHz}, \mathrm{CDCl}_{3}\right) \delta: 173.42$, $169.44,147.49,135.22$, 133.46, 129.81, 129.50, 128.96, 128.43, 127.05, 123.02, 60.23, 56.09, 46.16, 41.53, 36.29, 29.69, 24.56. IR $\nu_{\max }$ (neat) $/ \mathrm{cm}^{-1} 3279\left(\mathrm{NH}_{2}\right)$ and $3074(\mathrm{CH})$. MS (ESI), $m / z$ : $392.0[\mathrm{M}+\mathrm{H}]^{+}$.

(R)-(1-(3-(2-Chlorobenzylamino)-3-oxopropyl)-1H-1,2,3-triazol4-yl)methyl 2-amino-3-(1H-indol-3-yl)propanoate (76). Yellow oil, yield $82 \%$. $R_{\mathrm{f}}=0.50\left(10 \% \mathrm{MeOH}\right.$ in DCM). ${ }^{1} \mathrm{H}$ NMR $\left(300 \mathrm{MHz} \mathrm{CDCl}_{3}\right) \delta: 8.83(\mathrm{~s}, 1 \mathrm{H}), 7.47$ (brs, 1H), 7.29-6.96 (m, $8 \mathrm{H}), 6.68(\mathrm{~s}, 1 \mathrm{H}), 6.59(\mathrm{~s}, 1 \mathrm{H}), 5.16-4.97(\mathrm{~m}, 2 \mathrm{H}), 4.58(\mathrm{~s}, 2 \mathrm{H})$, $4.53(\mathrm{t}, J=6.3 \mathrm{~Hz}, 2 \mathrm{H}), 4.36(\mathrm{~d}, J=5.4 \mathrm{~Hz}, 2 \mathrm{H}), 3.08-3.06(\mathrm{~m}$, $1 \mathrm{H}), 2.80-2.72(\mathrm{~m}, 3 \mathrm{H}) .{ }^{13} \mathrm{C} \mathrm{NMR}\left(75 \mathrm{MHz}, \mathrm{CDCl}_{3}\right) \delta: 174.65$, 169.52, 147.43, 142.39, 135.14, 133.49, 129.89, 129.53, 129.02, 127.06, 124.89, 123.03, 121.95, 119.44, 118.68, 111.36, 109.95, $57.96,56.04,46.12,41.58,36.25,29.68$. IR $\nu_{\max }$ (neat) $/ \mathrm{cm}^{-1}$ $3260\left(\mathrm{NH}_{2}\right)$ and $3063(\mathrm{CH})$. MS (ESI), m/z: 479.0 $[\mathrm{M}-\mathrm{H}]^{-}$, $481.2[\mathrm{M}+\mathrm{H}]^{+}$.

(R)-(1-(3-(4-Methylbenzylamino)-3-oxopropyl)-1H-1,2,3-triazol4-yl)methyl 2-amino-3-phenylpropanoate (77). Light yellow solid, yield $89 \%$. $R_{\mathrm{f}}=0.50(10 \% \mathrm{MeOH}$ in DCM $) . \mathrm{Mp}$ 168-170 ${ }^{\circ} \mathrm{C} .{ }^{1} \mathrm{H}$ NMR $\left(300 \mathrm{MHz}, \mathrm{CDCl}_{3}\right) \delta: 7.52(\mathrm{~d}, J=10.8 \mathrm{~Hz}$, $1 \mathrm{H}), 7.19-6.98(\mathrm{~m}, 9 \mathrm{H}), 6.54-6.36(\mathrm{~m}, 1 \mathrm{H}), 5.09(\mathrm{~s}, 2 \mathrm{H})$, 4.58-4.54 (m, 2H), 4.24 (s, 2H), 3.66 (brs, 1H), 2.81-2.74 (m, 2H), 2.47 (brs, 2H), 2.23 (s, 3H). ${ }^{13} \mathrm{C} \mathrm{NMR} \mathrm{(75} \mathrm{MHz,} \mathrm{CDCl}_{3}$ ) $\delta: 174.38,169.17,147.49,142.19,137.28,134.79,129.33$, 128.56, 127.70, 126.88, 125.06, 123.03, 57.94, 55.59, 46.21, 43.43, 40.66, 36.43, 21.07. IR $\nu_{\max }$ (neat) $/ \mathrm{cm}^{-1} 3298\left(\mathrm{NH}_{2}\right)$ and 3067 (CH). MS (ESI), $m / z: 422.2[\mathrm{M}+\mathrm{H}]^{+}$.

(R)-(1-(3-(4-Methylbenzylamino)-3-oxopropyl)-1H-1,2,3-triazol4-yl)methyl pyrrolidine-2-carboxylate (78). Light yellow solid, yield $83 \%$. $R_{\mathrm{f}}=0.26(10 \% \mathrm{MeOH}$ in DCM $) . \mathrm{Mp} 109-111{ }^{\circ} \mathrm{C}$. ${ }^{1} \mathrm{H} \mathrm{NMR}\left(300 \mathrm{MHz}, \mathrm{CDCl}_{3}\right.$ ) $\delta: 8.43$ (brs, 1H), 7.85 (s, 1H),
7.11-7.04 (m, 4H), $4.57(\mathrm{t}, J=6.8 \mathrm{~Hz}, 2 \mathrm{H}), 4.50(\mathrm{~s}, 2 \mathrm{H}), 4.21$ (d, $J=5.7 \mathrm{~Hz}, 2 \mathrm{H}), 3.68-3.63(\mathrm{~m}, 1 \mathrm{H}), 3.19-2.94(\mathrm{~m}, 2 \mathrm{H}), 2.77(\mathrm{t}$, $J=5.7 \mathrm{~Hz}, 2 \mathrm{H}), 2.29(\mathrm{~s}, 3 \mathrm{H}), 1.99-1.90(\mathrm{~m}, 2 \mathrm{H}), 1.71-1.64(\mathrm{~m}$, 2H). $\left.{ }^{13} \mathrm{C} \mathrm{NMR} \mathrm{(75} \mathrm{MHz,} \mathrm{CDCl}_{3}\right) \delta: 172.10,169.42,148.27$, 136.58, 136.26, 129.25, 128.56, 127.63, 123.25, 59.61, 55.51, 46.14, 42.92, 35.99, 30.65, 29.38, 21.11. IR $\nu_{\max }$ (neat) $/ \mathrm{cm}^{-1}$ $3294\left(\mathrm{NH}_{2}\right)$ and $3074(\mathrm{CH})$. MS (ESI), $m / z: 372.2[\mathrm{M}+\mathrm{H}]^{+}$.

(R)-(1-(3-(4-Methylbenzylamino)-3-oxopropyl)-1H-1,2,3-triazol4-yl)methyl 2-amino-3-(1H-indol-3-yl)propanoate (79). Yellow oil, yield $85 \%$. $R_{\mathrm{f}}=0.50\left(10 \% \mathrm{MeOH}\right.$ in DCM). ${ }^{1} \mathrm{H}$ NMR $\left(300 \mathrm{MHz}, \mathrm{CDCl}_{3}\right) \delta: 8.63(\mathrm{~s}, 1 \mathrm{H}), 7.52$ (brs, 1H), 7.32-6.97 (m, $8 \mathrm{H}), 6.64(\mathrm{~s}, 1 \mathrm{H}), 5.99-5.91(\mathrm{~m}, 1 \mathrm{H}), 5.19-5.00(\mathrm{~m}, 2 \mathrm{H})$, 4.65-4.51 (m, 2H), 4.27-4.25 (m, 2H), 3.79 (brs, 1H), 3.09-3.08 $(\mathrm{m}, 1 \mathrm{H}), 2.79-2.74(\mathrm{~m}, 3 \mathrm{H}), 2.25(\mathrm{~s}, 3 \mathrm{H}) .{ }^{13} \mathrm{C} \mathrm{NMR}(75 \mathrm{MHz}$, $\left.\mathrm{CDCl}_{3}\right) \delta: 174.89,169.76,142.41,137.54,136.38,133.45$, 129.54, 128.32, 127.43, 125.21, 123.67, 121.83, 119.75, 118.32, 111.63, 109.23, 58.42, 54.61, 46.21, 43.68, 35.42, 28.35, 21.07. IR $\nu_{\max }$ (neat) $/ \mathrm{cm}^{-1} 3279\left(\mathrm{NH}_{2}\right)$ and $3059(\mathrm{CH})$. MS (ESI), $\mathrm{m} / z$ : $459.2[\mathrm{M}-\mathrm{H}]^{-}, 461.2[\mathrm{M}+\mathrm{H}]^{+}, 483.2[\mathrm{M}+\mathrm{Na}]^{+}$.

(R)-(1-(3-(4-Methoxybenzylamino)-3-oxopropyl)-1H-1,2,3-triazol4-yl)methyl 2-amino-3-phenylpropanoate (80). Light yellow solid, yield $87 \% . R_{\mathrm{f}}=0.57\left(10 \% \mathrm{MeOH}\right.$ in DCM). Mp $168-170{ }^{\circ} \mathrm{C}$. ${ }^{1} \mathrm{H}$ NMR (400 MHz, DMSO- $\left.d_{6}\right) \delta: 7.85(\mathrm{~s}, 1 \mathrm{H}), 7.30-7.18(\mathrm{~m}$, $4 \mathrm{H}), 7.14-7.08(\mathrm{~m}, 3 \mathrm{H}), 6.86-6.83(\mathrm{~m}, 2 \mathrm{H}), 6.68-6.65(\mathrm{~m}, 1 \mathrm{H})$, 5.09 (s, 2H), 4.60-4.54 (m, 2H), 4.49 (s, 2H), 4.18 (d, $J=5.6 \mathrm{~Hz}$, $2 \mathrm{H}), 3.72(\mathrm{~s}, 3 \mathrm{H}), 3.58-3.56(\mathrm{~m}, 1 \mathrm{H}), 2.85-2.73(\mathrm{~m}, 4 \mathrm{H})$. ${ }^{13} \mathrm{C}$ NMR $\left(75 \mathrm{MHz}, \mathrm{CDCl}_{3}\right) \delta: 173.65,168.78,158.43,142.38$, $137.61,133.83,129.11,128.64,126.90,125.11,122.93,56.35$, 55.30, 52.39, 46.22, 43.24, 40.43, 36.36. IR $\nu_{\max }$ (neat) $/ \mathrm{cm}^{-1}$ $3286\left(\mathrm{NH}_{2}\right)$ and $3070(\mathrm{CH})$. MS (ESI), m/z: 436.5 [M - H] $]^{-}$, $438.1[\mathrm{M}+\mathrm{H}]^{+}$.

(R)-(1-(3-(4-Methoxybenzylamino)-3-oxopropyl)-1H-1,2,3-triazol4-yl)methylpyrrolidine-2-carboxylate (81). Yellow solid, yield $90 \% . R_{\mathrm{f}}=0.14\left(10 \% \mathrm{MeOH}\right.$ in DCM). ${ }^{1} \mathrm{H}$ NMR $(300 \mathrm{MHz}$, $\left.\mathrm{CDCl}_{3}\right) \delta: 8.46$ (brs, $\left.1 \mathrm{H}\right), 7.86(\mathrm{~s}, 1 \mathrm{H}), 7.09(\mathrm{~d}, J=8.4 \mathrm{~Hz}, 2 \mathrm{H})$, $6.85(\mathrm{~d}, J=8.4 \mathrm{~Hz}, 2 \mathrm{H}), 4.57(\mathrm{t}, J=6.8 \mathrm{~Hz}, 2 \mathrm{H}), 4.50(\mathrm{~s}, 2 \mathrm{H})$, $4.18(\mathrm{~d}, J=5.7 \mathrm{~Hz}, 2 \mathrm{H}), 3.72(\mathrm{~s}, 3 \mathrm{H}), 3.69-3.64(\mathrm{~m}, 1 \mathrm{H})$, 3.42-3.37 (m, 2H), $2.76(\mathrm{t}, J=7.0 \mathrm{~Hz}, 2 \mathrm{H}), 1.96-1.91(\mathrm{~m}, 2 \mathrm{H})$, 1.78-1.65 (m, 2H). ${ }^{13} \mathrm{C} \mathrm{NMR}\left(75 \mathrm{MHz}, \mathrm{CDCl}_{3}\right) \delta: 173.65$, $169.36,148.26,138.37,131.56,128.98,123.26,114.21$, 61.19, 57.23, 55.51, 46.15, 42.00, 36.01, 30.63, 29.37, 24.31. IR $\nu_{\max }($ neat $) / \mathrm{cm}^{-1} 3290\left(\mathrm{NH}_{2}\right)$ and $3074(\mathrm{CH})$. MS (ESI), $m / z$ : $388.2[\mathrm{M}+\mathrm{H}]^{+}$.

(R)-(1-(3-(4-Methoxybenzylamino)-3-oxopropyl)-1H-1,2,3-triazol4-yl)methyl 2-amino-3-(1H-indol-3-yl)propanoate (82). Yellow solid, yield $89 \%$. $R_{\mathrm{f}}=0.53(10 \% \mathrm{MeOH}$ in DCM $) . \mathrm{Mp}$ 150-154 ${ }^{\circ} \mathrm{C} .{ }^{1} \mathrm{H}$ NMR $\left(400 \mathrm{MHz}, \mathrm{CDCl}_{3}\right) \delta: 8.41$ (s, 1H), $7.91(\mathrm{~s}$, $1 \mathrm{H}), 7.48(\mathrm{~d}, J=7.8 \mathrm{~Hz}, 1 \mathrm{H}), 7.32(\mathrm{~d}, J=7.9 \mathrm{~Hz}, 1 \mathrm{H}), 7.09-7.06$ $(\mathrm{m}, 5 \mathrm{H}), 6.96(\mathrm{t}, J=7.4 \mathrm{~Hz}, 1 \mathrm{H}), 6.89(\mathrm{~m}, 2 \mathrm{H}), 5.06(\mathrm{~s}, 2 \mathrm{H}), 4.57$ $(\mathrm{t}, J=6.4 \mathrm{~Hz}, 2 \mathrm{H}), 4.17(\mathrm{~d}, J=5.6 \mathrm{~Hz}, 2 \mathrm{H}), 3.71(\mathrm{~s}, 3 \mathrm{H})$, 3.66-3.63 (m, 1H), 3.03-2.89 (m, 2H), $2.76(\mathrm{t}, J=6.5 \mathrm{~Hz}, 2 \mathrm{H})$. ${ }^{13} \mathrm{C} \mathrm{NMR}\left(75 \mathrm{MHz}, \mathrm{CDCl}_{3}\right) \delta: 173.12,169.45,142.79,136.32$, $133.59,129.54,128.43,127.61,125.51,123.21,121.87,119.37$, $118.63,114.21,111.53,109.25,58.53,55.21,54.76,46.62$, 43.38, 35.54, 30.56. IR $\nu_{\max }$ (neat) $/ \mathrm{cm}^{-1} 3279\left(\mathrm{NH}_{2}\right)$ and 3082 (CH). MS (ESI), $m / z: 475.2[\mathrm{M}-\mathrm{H}]^{-}, 477.2[\mathrm{M}+\mathrm{H}]^{+}$. 
(R)-(1-(3-(4-(Trifluoromethyl)benzylamino)-3-oxopropyl)-1H1,2,3-triazol-4-yl)methyl 2-amino-3-phenylpropanoate (83). Light yellow solid, yield $88 \% . R_{\mathrm{f}}=0.57(10 \% \mathrm{MeOH}$ in DCM). Mp 158-160 ${ }^{\circ} \mathrm{C} .{ }^{1} \mathrm{H}$ NMR (400 MHz, DMSO- $\left.d_{6}\right) \quad \delta: 7.87$ $(\mathrm{s}, 1 \mathrm{H}), 7.65(\mathrm{~d}, J=8.0 \mathrm{~Hz}, 2 \mathrm{H}), 7.36(\mathrm{t}, J=8.4 \mathrm{~Hz}, 2 \mathrm{H})$, 7.30-7.18 (m, 4H), $7.12(\mathrm{~d}, J=6.5 \mathrm{~Hz}, 1 \mathrm{H}), 6.68-6.66(\mathrm{~m}, 1 \mathrm{H})$, $5.09(\mathrm{~m}, 2 \mathrm{H}), 4.58(\mathrm{t}, J=7.7 \mathrm{~Hz}, 2 \mathrm{H}), 4.49(\mathrm{~s}, 2 \mathrm{H}), 4.34(\mathrm{~d}, J=$ $5.6 \mathrm{~Hz}, 2 \mathrm{H}), 3.60-3.57(\mathrm{~m}, 1 \mathrm{H}), 2.84-2.76(\mathrm{~m}, 4 \mathrm{H}) .{ }^{13} \mathrm{C} \mathrm{NMR}$ $\left(75 \mathrm{MHz}, \mathrm{CDCl}_{3}\right) \delta: 174.15,169.49,146.34,142.24,141.93$, 129.30, 128.89, 128.53, 127.76, 127.03, 125.61, 125.09, 123.15, 56.06, 52.65, 46.18, 43.10, 36.28. IR $\nu_{\max }$ (neat) $/ \mathrm{cm}^{-1} 3298$ $\left(\mathrm{NH}_{2}\right)$ and $3070(\mathrm{CH})$. MS (ESI), m/z: $474.8[\mathrm{M}-\mathrm{H}]^{-}, 476.3$ $[\mathrm{M}+\mathrm{H}]^{+}$.

(R)-(1-(3-(4-Trifluoromethylbenzylamino)-3-oxopropyl)-1H1,2,3-triazol-4-yl)methyl pyrrolidine-2-carboxylate (84). Yellow oil, yield $89 \%$. $R_{\mathrm{f}}=0.35\left(10 \% \mathrm{MeOH}\right.$ in DCM). ${ }^{1} \mathrm{H}$ NMR $\left(300 \mathrm{MHz} \mathrm{CDCl}_{3}\right) \delta: 8.43$ (brs, $\left.1 \mathrm{H}\right), 7.56(\mathrm{~s}, 1 \mathrm{H}), 7.40-7.21(\mathrm{~m}$, $4 \mathrm{H}), 5.23$ (brs, $1 \mathrm{H}), 4.64(\mathrm{~m}, 2 \mathrm{H}), 4.47(\mathrm{~s}, 2 \mathrm{H}), 4.34(\mathrm{~d}, J=$ $6.5 \mathrm{~Hz}, 2 \mathrm{H}), 3.78-3.64(\mathrm{~m}, 1 \mathrm{H}), 3.32-3.21(\mathrm{~m}, 2 \mathrm{H}), 2.87(\mathrm{t}, J=$ $8.8 \mathrm{~Hz}, 2 \mathrm{H}), 2.31-2.21(\mathrm{~m}, 1 \mathrm{H}), 2.08-1.77$ (m, 3H). ${ }^{13} \mathrm{C}$ NMR $\left(75 \mathrm{MHz}, \mathrm{CDCl}_{3}\right) \delta: 174.12,169.72,149.58,137.26,129.65$, 127.78, 126.92, 125.61, 123.18, 58.16, 54.48, 46.09, 43.14, 35.51, 31.03, 29.70, 24.32. IR $\nu_{\max }$ (neat) $/ \mathrm{cm}^{-1} 3298\left(\mathrm{NH}_{2}\right)$ and $3095(\mathrm{CH})$. MS (ESI), $m / z: 426.05[\mathrm{M}+\mathrm{H}]^{+}$.

(R)-(1-(3-(4-(Trifluoromethyl)benzylamino)-3-oxopropyl)-1H1,2,3-triazol-4-yl)methyl 2-amino-3-(1H-indol-3-yl)propanoate (85). Yellow oil, yield 85\%. $R_{\mathrm{f}}=0.64(10 \% \mathrm{MeOH}$ in DCM). ${ }^{1} \mathrm{H}$ NMR $\left(400 \mathrm{MHz}, \mathrm{CDCl}_{3}\right) \delta: 8.96-8.94(\mathrm{~m}, 1 \mathrm{H}), 8.15(\mathrm{~d}, J=$ $8.0 \mathrm{~Hz}, 1 \mathrm{H}), 8.06-8.00(\mathrm{~m}, 3 \mathrm{H}), 7.64(\mathrm{t}, J=7.2 \mathrm{~Hz}, 1 \mathrm{H})$, $7.57-7.51(\mathrm{~m}, 4 \mathrm{H}), 7.15(\mathrm{t}, J=7.1 \mathrm{~Hz}, 1 \mathrm{H}), 6.99(\mathrm{~s}, 1 \mathrm{H}), 4.97(\mathrm{~s}$, $2 \mathrm{H}), 4.65-4.59$ (m, 2H), 4.43-4.38 (m, 2H), 3.51-3.48 (m, 1H), 2.96 (brs, 2H), 2.88 (brs, 2H). ${ }^{13} \mathrm{C} \mathrm{NMR} \mathrm{(75} \mathrm{MHz,} \mathrm{CDCl}_{3}$ ) $\delta: 175.40,169.53,147.34,141.88,136.45,133.46,129.99$, 128.87, 127.76, 125.61, 124.54, 123.16, 121.78, 119.64, 118.74, $110.98,109.12,58.67,55.89,46.20,43.12,36.23,29.68$. IR $\nu_{\max }$ (neat) $/ \mathrm{cm}^{-1} 3284\left(\mathrm{NH}_{2}\right)$ and $3063(\mathrm{CH})$. MS (ESI), m/z: 515.3 $[\mathrm{M}+\mathrm{H}]^{+}$.

(R)-(1-(3-(4-Trifluoromethoxybenzylamino)-3-oxopropyl)-1H1,2,3-triazol-4-yl)methyl 2-amino-3-phenylpropanoate (86). Yellow oil, yield $89 \% . R_{\mathrm{f}}=0.57\left(10 \% \mathrm{MeOH}\right.$ in DCM). ${ }^{1} \mathrm{H}$ NMR $\left(300 \mathrm{MHz}, \mathrm{CDCl}_{3}\right) \delta: 7.57(\mathrm{~s}, 1 \mathrm{H}), 7.32-7.11(\mathrm{~m}, 9 \mathrm{H}), 6.54$ (brs, $1 \mathrm{H}), 5.14(\mathrm{~s}, 2 \mathrm{H}), 4.61(\mathrm{t}, J=5.8 \mathrm{~Hz}, 2 \mathrm{H}), 4.51(\mathrm{~s}, 2 \mathrm{H}), 4.33-4.25$ $(\mathrm{m}, 2 \mathrm{H}), 3.65-3.52(\mathrm{~m}, 1 \mathrm{H}), 3.12-3.01(\mathrm{~m}, 2 \mathrm{H}), 2.82(\mathrm{t}, J=$ $6.8 \mathrm{~Hz}, 2 \mathrm{H}) .{ }^{13} \mathrm{C} \mathrm{NMR}\left(75 \mathrm{MHz}, \mathrm{CDCl}_{3}\right) \delta: 172.87,168.71$, 157.26, 142.77, 137.56, 134.09, 130.45, 128.92, 127.87, 127.45, 126.09, 123.29, 121.56, 58.51, 54.71, 46.31, 43.71, 40.83, 35.55. IR $\nu_{\max }($ neat $) / \mathrm{cm}^{-1} 3287\left(\mathrm{NH}_{2}\right)$ and $3056(\mathrm{CH})$. MS (ESI), $\mathrm{m} / \mathrm{z}$ : $492.3[\mathrm{M}+\mathrm{H}]^{+}$.

(R)-(1-(3-(4-Trifluoromethoxybenzylamino)-3-oxopropyl)-1H1,2,3-triazol-4-yl)methyl pyrrolidine-2-carboxylate (87). Light yellow oil, yield $89 \% . R_{\mathrm{f}}=0.38\left(10 \% \mathrm{MeOH}\right.$ in DCM). ${ }^{1} \mathrm{H}$ NMR $\left(300 \mathrm{MHz}, \mathrm{CDCl}_{3}\right) \delta: 8.54$ (brs, $\left.1 \mathrm{H}\right), 7.89$ (s, 1H), 7.67-7.43 $(\mathrm{m}, 2 \mathrm{H}), 7.31-7.23(\mathrm{~m}, 2 \mathrm{H}), 5.20$ (brs, $1 \mathrm{H}), 4.64(\mathrm{t}, J=7.2 \mathrm{~Hz}$, $2 \mathrm{H}), 4.54(\mathrm{~s}, 2 \mathrm{H}), 4.29(\mathrm{~d}, J=6.7 \mathrm{~Hz}, 2 \mathrm{H}), 3.78-3.62$ (m, 1H), 3.28-3.21 (m, 2H), $2.89(\mathrm{t}, J=7.6 \mathrm{~Hz}, 2 \mathrm{H}), 2.22-2.04$ $(\mathrm{m}, 2 \mathrm{H}), 1.89-1.72(\mathrm{~m}, 2 \mathrm{H}) .{ }^{13} \mathrm{C} \mathrm{NMR}\left(75 \mathrm{MHz}, \mathrm{CDCl}_{3}\right.$ ) $\delta: 173.45,169.52,149.23,138.45,129.34,128.43,127.89$, 127.34, 122.89, 60.56, 56.45, 46.58, 43.76, 36.52, 30.93, 29.81, 24.56. IR $\nu_{\max }$ (neat) $/ \mathrm{cm}^{-1} 3290\left(\mathrm{NH}_{2}\right)$ and $3065(\mathrm{CH})$. MS (ESI), $m / z: 442.3[\mathrm{M}+\mathrm{H}]^{+}$.

(R)-(1-(3-(4-Trifluoromethoxybenzylamino)-3-oxopropyl)-1H1,2,3-triazol-4-yl)methyl 2-amino-3-(1H-indol-3-yl)propanoate (88). Yellow oil, yield $89 \% . R_{\mathrm{f}}=0.62(10 \% \mathrm{MeOH}$ in DCM). ${ }^{1} \mathrm{H}$ NMR $\left(300 \mathrm{MHz}, \mathrm{CDCl}_{3}\right) \delta: 8.73(\mathrm{~s}, 1 \mathrm{H}), 7.65(\mathrm{~d}, J=7.8 \mathrm{~Hz}$, $1 \mathrm{H}), 7.47$ (d, $J=7.8 \mathrm{~Hz}, 1 \mathrm{H}), 7.36-7.25(\mathrm{~m}, 5 \mathrm{H}), 7.12-6.99$ (m, $3 \mathrm{H}), 6.46$ (s, 1H), 5.23-5.14 (m, 2H), 4.60-4.53 (m, 2H), 4.32 (d, $J=6.0 \mathrm{~Hz}, 2 \mathrm{H}), 3.87-3.76(\mathrm{~m}, 1 \mathrm{H}), 3.25-3.11$ (m, 2H), 2.90-2.77 $(\mathrm{m}, 2 \mathrm{H}) .{ }^{13} \mathrm{C}$ NMR $\left(75 \mathrm{MHz}, \mathrm{CDCl}_{3}\right) \delta: 174.24,169.48,156.24$, 143.43 , 137.89, 135.23, 128.56, 127.51, 127.32, 124.43, 123.29, $122.56,121.76,119.32,118.67,111.48,109.62,58.45,54.76$, 46.23, 43.54, 35.72, 30.35. IR $\nu_{\max }$ (neat) $/ \mathrm{cm}^{-1} 3294\left(\mathrm{NH}_{2}\right)$ and 3066 (CH). MS (ESI), m/z: $531.3[\mathrm{M}+\mathrm{H}]^{+}$.

\section{Biology}

In vitro anti-Candida activity. The anticandidal assessment of title compounds (65-88) was performed by the broth dilution technique according to the standard protocol of NCCLS, 2012..$^{30}$ In this study, C. albicans ATCC 90028, C. albicans 10261, C. glabrata ATCC 90030, C. tropicalis ATCC 750 and FLC-sensitive/resistant clinical isolates of C. albicans were used for anticandidal activity assessment. Fluconazole was used as a positive control. Varying concentrations (1000 to $7.8 \mu \mathrm{g} \mathrm{mL}^{-1}$ ) of test compounds were dispensed into a 96-well plate in Sabouraud dextrose broth medium in a final volume of $100 \mu \mathrm{L}$. Candida cells were harvested and their turbidity was assessed according to the McFarland standards. Then, $100 \mu \mathrm{L}$ of cells (approximately $2.5 \times 10^{3}$ cells per $\mathrm{mL}$ ) were dispensed into the 96 wells and incubated at $37^{\circ} \mathrm{C}$ for $24 \mathrm{~h}$. After incubation, the growth was measured turbidometrically at $600 \mathrm{~nm}$ using a Thermo Multiskan spectrophotometer. IC $_{50}$ was determined as $50 \%$ inhibition of Candida growth and calculated by plotting a graph between the concentration $\left(\log _{10}\right)$ and $\%$ inhibition.

Time kill curve study. The fungicidal or fungistatic effect of lead inhibitors $\mathbf{6 8}$ and 70 was determined by the time-kill curve assay according to the method reported by Jiang et al. ${ }^{31}$ For standard as well as resistant strains of $C$. albicans, the cells were exposed to 60 and $120 \mu \mathrm{g} \mathrm{mL}^{-1}$ concentrations of 68 and 70. Fluconazole (125 and $1000 \mu \mathrm{g} \mathrm{mL}^{-1}$ ) was used as a positive control against standard and FLC-resistant $C$. albicans, respectively. The untreated cells were used as a negative control. All time-kill curve experiments were conducted in triplicate and the mean colony count data $\left(\log _{10} \mathrm{CFU} \mathrm{mL}^{-1}\right)$ were plotted as a function of time for each strain.

Proteinase and phospholipase assay. Previously identified proteinase positive standard C. albicans ATCC 90028 along with FLC-sensitive and resistant clinical isolates of $C$. albicans were used for this study. $1.5 \mathrm{~mL}$ of the $24 \mathrm{~h}$ old Candida cells were transferred into micro-centrifuge tubes and centrifuged at $3000 \mathrm{rpm}$ for $5 \mathrm{~min}$. The pellets obtained were washed in phosphate buffer saline (PBS) twice and centrifuged to remove the residual medium. After standardizing the suspensions 
(MacFarland standard), the cells were exposed to 60 and $120 \mu \mathrm{g} \mathrm{mL} \mathrm{m}^{-1}$ of lead inhibitors (68 and 70) for $1 \mathrm{~h}$. Then, $1 \mu \mathrm{L}$ from each cell suspension treated with the test compound was plated at equidistant points on proteinase and phospholipase agar media and incubated at $37{ }^{\circ} \mathrm{C}$ for $3-4$ days. ${ }^{32}$ The formation of a transparent halo around the Candida colonies indicated the effect of the test compounds on extracellular enzyme secretion. Enzyme activity was measured by dividing the diameter of the colony by the diameter of the colony plus zone of clearance. ${ }^{33}$ The experiment was performed in triplicate.

Transmission electron microscopy (TEM) analysis. The morphology of Candida cells was analyzed using TEM following the standard protocol. ${ }^{34}$ Mid-log phase cells were harvested, standardized $\left(A_{600} \approx 0.1\right)$ and exposed to a $120 \mu \mathrm{g} \mathrm{mL}{ }^{-1}$ concentration of test inhibitors 68 and 70 for $1 \mathrm{~h}$. Then, the cells were washed thrice with PBS to remove the residual medium and fixed overnight in $2.5 \%$ glutaraldehyde in phosphate/ magnesium buffer (40 mM K $\mathrm{HPO}_{4} / \mathrm{KH}_{2} \mathrm{PO}_{4}, \mathrm{pH} 6.5,0.5 \mathrm{mM}$ $\mathrm{MgCl}_{2}$ ). The cells were washed twice for $15 \mathrm{~min}$ in $0.1 \mathrm{M}$ sodium phosphate buffer ( $\mathrm{pH}$ 6.0) and post-fixed for $2 \mathrm{~h}$ in $2 \%$ osmium tetroxide. Again, the cells were washed twice for 15 min in distilled water and then en bloc stained with $1 \%$ uranyl acetate (aqueous) for $30 \mathrm{~min}$. After two further washes, the cells were dehydrated in $95 \%$ and $100 \%$ ethanol. The cells were exposed to propylene oxide for $2 \times 10 \mathrm{~min}$ and infiltrated for $1 \mathrm{~h}$ in a 1:1 propylene/epoxy embedding material (Epon) mixture and then overnight in fresh Epon. After polymerization for $48 \mathrm{~h}$ at $60{ }^{\circ} \mathrm{C}$, ultrathin sections were cut using a microtome (LeicaEM UC6) and transferred onto a copper grid. The samples were stained with uranyl acetate (saturated solution of uranyl acetate in $50 \%$ alcohol) followed by lead citrate. The samples were washed three times in Milli-Q (MQ) water and dried by touching with Whatman filter paper. The sections were examined with a Jeol (Japan) JEM-2100F transmission electron microscope at $120 \mathrm{kV}$.

Ergosterol estimation assay. The total intracellular sterols were extracted as reported earlier with slight modifications. ${ }^{22}$ Three separate conical flasks containing 30, 60 and $120 \mu \mathrm{g}$ $\mathrm{mL}^{-1}$ of compounds 68 and 70 in Sabouraud dextrose broth were inoculated with fresh cells of $C$. albicans ATCC 90028 (standard) and FLC-resistant C. albicans. Fluconazole $(40 \mu \mathrm{g}$ $\mathrm{mL}^{-1}$ ) was used as a positive control while the untreated cells as a negative control for comparison. All the conical flasks were incubated at $35{ }^{\circ} \mathrm{C}$ for $16 \mathrm{~h}$. After incubation, the cells were harvested at their stationary phase and the weight of the pellet was determined. The pellet was treated with $25 \%$ alcoholic potassium hydroxide $(\mathrm{KOH})$ solution followed by incubation at $85{ }^{\circ} \mathrm{C}$ for $1 \mathrm{~h}$. After incubation, sterol was extracted by the addition of the $n$-heptane:distilled water $(1: 3)$ mixture. The heptane layers were transferred into a fresh test tube, diluted five-fold in $100 \%$ ethanol and scanned spectrophotometrically between 240 and $300 \mathrm{~nm}$. The presence of ergosterol and the late sterol intermediate 24(28)DHE in the extracted sample resulted in a characteristic four peak curve.
The absence of detectable ergosterol in the extract was indicated as a flat line. The ergosterol content was calculated as a percentage wet weight of the cell by using the following the equation:

$\%$ Ergosterol $+\% 24(28) \mathrm{DHE}=\left[\left(A_{281.5} / 290\right) \times F\right] /$ pellet weight

where, \%24(28)DHE $=\left[\left(A_{230} / 518\right) \times F\right] /$ pellet weight, $A_{281.5}$ and $A_{230}$ are absorbances at $281.5 \mathrm{~nm}$ and $230 \mathrm{~nm}$, respectively, and $F$ is the factor for dilution in ethanol.

Cell proliferation assay. MTT (3-(4,5-dimethyl-2-yl)-2,5diphenyl tetrazolium bromide), Dulbecco's modified Eagle's medium (DMEM), 0.25\% trypsin, and a 0.02\% EDTA mixture were purchased from Hi Media (Mumbai, India). Fetal bovine serum (FBS) was obtained from Gibco (Grand Island, NY). The human embryonic kidney (HEK293) cell line was procured from the National Centre for Cell Sciences (NCCS), Pune, India. The cells were cultured and maintained as a monolayer in DMEM supplemented with 10\% FBS and antibiotics (100 units per $\mathrm{mL}$ penicillin and $100 \mu \mathrm{g} \mathrm{mL}^{-1}$ streptomycin) at $37{ }^{\circ} \mathrm{C}$ under a humidified atmosphere of $5 \% \mathrm{CO}_{2}$ in T-25 flasks. The cells were sub-cultured twice in a week. A cell count of approximately $2 \times 10^{4}$ cells per well were seeded in a 96 -well plate $(150 \mu \mathrm{L}$ per well) and incubated for $24 \mathrm{~h}$ before treatment. The cells were then treated with varying concentrations $\left(10-600 \mu \mathrm{g} \mathrm{mL} \mathrm{m}^{-1}\right)$ of the test compounds. After $48 \mathrm{~h}$ of incubation at $37^{\circ} \mathrm{C}$, the exhausted serum supplemented medium was removed and serum free media $(50 \mu \mathrm{L})$ was added into each well. After that, $20 \mu \mathrm{L}$ per well of MTT at a concentration of $5 \mathrm{mg} \mathrm{mL}^{-1}$ in PBS was added to each well and the plates were incubated for $4 \mathrm{~h}$ at $37{ }^{\circ} \mathrm{C}$. Formazan crystals, the metabolized MTT product, were solubilized in DMSO $(150 \mu \mathrm{L}$ per well $)$ and were quantified by reading the absorbance at $570 \mathrm{~nm}$ after incubation of 10 min on an iMark Microplate Reader (Bio-Rad, Hercules, CA). All assays were performed in triplicate. Percent viability was taken as the relative absorbance of treated versus untreated control cells. ${ }^{35}$

Hemolytic assay. The hemolytic activities of the test inhibitors 68 and 70 and the conventional antifungal drug FLC were determined on human red blood cells (hRBCs). ${ }^{36}$ Human erythrocytes from healthy individuals were collected in tubes containing EDTA as an anti-coagulant. The erythrocytes were harvested by centrifugation for $10 \mathrm{~min}$ at $2000 \mathrm{rpm}$ and $20{ }^{\circ} \mathrm{C}$, and washed three times in PBS. To the pellet, PBS was added to yield a $10 \%(\mathrm{v} / \mathrm{v})$ erythrocytes/PBS suspension. The $10 \%$ suspension of erythrocytes was then further diluted with PBS at a $1: 10$ ratio. $100 \mu \mathrm{L}$ of the final diluted erythrocytes was added to $100 \mu \mathrm{L}$ of PBS having a previously determined concentration gradient (1000 to $7.8 \mu \mathrm{g} \mathrm{mL} \mathrm{m}^{-1}$ ) of test compounds in micro-centrifuge tubes. Total hemolysis was achieved with $1 \%$ Triton $\mathrm{X}-100$. The tubes were incubated for $1 \mathrm{~h}$ at $37{ }^{\circ} \mathrm{C}$ and then centrifuged for $10 \mathrm{~min}$ at $2000 \mathrm{rpm}$ and at room temperature. From the supernatant fluid, $150 \mu \mathrm{L}$ was transferred to a flat-bottomed microtiter plate (Tarson), and the absorbance was measured spectrophotometrically at 
$450 \mathrm{~nm}$ by using a Thermo Multiskan spectrophotometer. The hemolysis percentage was calculated by following the equation: centrifuge) washed in PBS and re-suspended in PBS at a cell density of $5 \times 10^{5}$ per $20 \mu \mathrm{L}$. The larvae were inoculated by injecting $20 \mu \mathrm{L}$ through the last left pro-leg into the haemocoel

$$
\begin{aligned}
\% \text { Hemolysis }= & {\left[\left(A_{450} \text { of test compound treated sample }-A_{450} \text { of buffer treated sample }\right) /\right.} \\
& \left.\left(A_{450} \text { of } 1 \% \text { Triton X-100 treated sample }-A_{450} \text { of buffer treated sample }\right)\right] \times 100 \% .
\end{aligned}
$$

Where $A_{450}$ is the absorbance at $450 \mathrm{~nm}$.

Modeling the CYP51 like protein structure. The primary protein sequence of CYP51 was extracted from a protein database at $\mathrm{NCBI}^{37}$ and its homologous sequence from the PDB with PDB ID-4LXJ. ${ }^{38}$ Modeller $9.15^{39}$ was used to generate 5 models of the Candida CYP51 protein using the $S$. cervisiae CYP51 protein (PDB ID-4LXJ) as a template. Structure validation of these models was performed using Procheck, ${ }^{40}$ verified in $3 \mathrm{D}^{41}$ and superimposed using Chimera ${ }^{42}$ for structure comparison.

In silico docking. The $3 \mathrm{D}$ structures of the two shortlisted compounds, 68 and 70 were drawn using Chem Draw. ${ }^{43}$ We used model 3 for further in silico analysis. The computational docking method predicts the ligand-macromolecule bound states with their binding affinities using a scoring function. We have used AUTODOCK VINA 1.1.2 ${ }^{44}$ in the present study that uses Iterated Local Search Global Optimization algorithm for local minima search. ${ }^{45,46}$ We performed in silico blind docking of the complete protein molecule of model 3 against the two shortlisted compounds 68 and 70. We used ADT tools to process the protein and ligand PDBs into ADT desired format (PDBQT). Protein processing includes removal of water molecules, addition of hydrogen and charges to the protein and likewise the ligand was processed (68 and 70) for ADT format. The grid dimensions of $\mathrm{X}, \mathrm{Y}$ and $\mathrm{Z}$ covering the complete model 3 of the CYP51 protein molecule was 64, 60 and 52 with $1 \AA$ spacing. The dimensions of the centre grid box were 23.27, 15.94 and 19.74 in the case of whole CYP51 molecule blind docking. The complex with the minimum binding energy and involving more number of interactions were chosen as the basis for further interface analysis. We mapped and visualized these interacting partners in PyMol. ${ }^{47}$ Binding affinities of both lead compounds (68 and 70) with the modeled CYP51 were quantitated and are represented as $\mathrm{kcal} \mathrm{mol}^{-1}$. The images were prepared using the LIGPLOT visualizing program ${ }^{48}$ and the polar and hydrophobic contacts between them were noted down.

In vivo assessment of the efficacy of lead inhibitors (68 and 70) against Galleria mellonella larvae. The larvae of the sixth developmental stage of $G$. mellonella were obtained from the Meal Worm Company (Sheffield, England). The larvae of G. mellonella were stored in wood shavings in the dark at $15{ }^{\circ} \mathrm{C}$ prior to use. The larvae that were chosen for experiments weighed $0.21 \mathrm{~g}$ and were used within 3-4 weeks of receipt. Ten healthy larvae were placed in sterile $9 \mathrm{~cm}$ Petri dishes with Whatman filter paper inserted inside. A culture of $C$. albicans was grown to the stationary phase $\left(1-2 \times 10^{8} \mathrm{~mL}^{-1}\right)$ in YEPD broth at $30{ }^{\circ} \mathrm{C}$ and $200 \mathrm{rpm}$. The cells were harvested by centrifugation (2056 $g$ for 5 minutes on a Beckmann GS-6 bench using a Myjector syringe (Terumo Europe) and placed at $30{ }^{\circ} \mathrm{C}$ in the dark. One $\mathrm{h}$ post inoculation, the larvae were inoculated with compounds 68 and 70, both at a concentration of $2.5 \mathrm{mg}$ suspended in PBS, supplemented with 12.5\% DMSO (v/v), through the last right pro-leg. The larvae injected with $20 \mu \mathrm{L}$ of PBS supplemented with $12.5 \%$ DMSO (v/v) were used as controls. For assessment of larval viability, the larvae were gently probed with a needle and if no response was observed, the larvae were considered to be dead.

Three larvae were inoculated with $20 \mu \mathrm{L}$ of compounds 68 and 70 solutions at concentrations of 1.25 or $2.5 \mathrm{mg} \mathrm{mL}^{-1}$. The larvae were then incubated at $30{ }^{\circ} \mathrm{C}$, in the dark, for $24 \mathrm{~h}$. The haemocyte density in the larvae was ascertained by piercing the backs of the anterior end ('head') of the three larvae with a sterile needle and collecting the yellow haemolymph ('blood'), ensuring no white flocular material was removed this is the fat body and will impede counting. Haemolymph was diluted to 1 in 10 in cold PBS containing $0.37 \%(\mathrm{v} / \mathrm{v})$ 2-mercaptoethanol to reduce clotting and melanisation. The solution was mixed gently by pipetting. Haemocytes were counted on a haemocytometer $\left(0.0025 \mathrm{~mm}^{2}\right.$, BlauBrand, Germany) and the density in the original larvae was calculated.

Five larvae of $G$. mellonella were inoculated with $C$. albicans at a density of $5 \times 10^{5}$ per $20 \mu \mathrm{l}$ and incubated at $30^{\circ} \mathrm{C}$ in the dark. $1 \mathrm{~h}$ post inoculation, larvae were inoculated with compounds 68 and 70 both at a concentration of $2.5 \mathrm{mg}$ suspended in PBS supplemented with $12.5 \%$ DMSO (v/v). Three larvae were selected and placed in a sterile pestle with $3 \mathrm{~mL}$ of PBS and ground to a pulp with a mortar. The resulting homogenate was diluted with PBS and $100 \mu \mathrm{L}$ of the sample was plated onto three YEPD-erythromycin plates (to prevent bacterial growth). The homogenate was diluted to $1 / 10$ in PBS prior to plating. The plates were incubated at $30{ }^{\circ} \mathrm{C}$ for $24 \mathrm{~h}$ and the colony forming units were enumerated. The fungal load in the larvae was calculated by multiplying this figure by the relevant dilution factors.

\section{Conclusions}

In summary a novel series of 1,2,3-triazole-amino acid hybrids was prepared in an attempt to search for potent antifungal agents that can be effective against the FLC-sensitive and resistant strains of Candida species. Out of 24, twelve compounds $(65,67-71,73-74,79,82-83,85)$ showed comparatively lower $\mathrm{IC}_{50}$ values against various standard Candida strains and were found to be non-cytotoxic on the HEK293 cell line up to a concentration of $200 \mu \mathrm{g} \mathrm{mL} \mathrm{m}^{-1}$. Seven compounds (67-68, 70-71, 73, 79, 82) were selected for their inhibitory potential 
against FLC sensitive and resistant clinical $C$. albicans isolates and identified two lead compounds 68 and 70 with the most potent antifungal activity against all the strains used. Time kill testing assay confirmed the fungistatic nature of the lead compounds (68 and 70). They also effectively inhibited the extracellular secretion of the enzymes in proteinase and phopholipase assays against FLC sensitive and resistant clinical C. albicans isolates. These enzymes are responsible for the fungal invasion of host tissues and immune suppression. TEM analysis showed that compounds 68 and 70 caused significant damage to $C$. albicans cells. Alterations in the cell wall structure suggests that these antifungal compounds may cause cell death resulting from inhibiting the synthetic route of fungal cell wall formation. The effect of $\mathbf{6 8}$ and $\mathbf{7 0}$ on the intracellular ergosterol content in FLC-sensitive and resistant $C$. albicans clinical strains were also examined which revealed the inhibition of ergosterol biosynthesis thereby producing an antiCandida effect. An overall understanding of the interaction of the lead inhibitors $\mathbf{6 8}$ and $\mathbf{7 0}$ with the modeled Candida like CYP51 protein will help in knowledge based design of better leads with more potent antifungal activity. Compounds 68 and 70 not only proved to be the most potent anti-Candida agents in in vitro assays but also displayed promising in vivo efficacy in the $G$. mellonella larvae model. The administration of a dose of $2.5 \mathrm{mg} \mathrm{mL} \mathrm{m}^{-1}$ of 68 and 70 to the larvae did not affect the viability confirming their non-toxic behaviour. Also, no significant alteration in the haemocyte density was observed which indicated the lack of an immune response. Compound $\mathbf{6 8}$ caused about $50 \%$ inhibition to the larvae infected with C. albicans while $\mathbf{7 0}$ reduced $70 \%$ yeast replication in vivo as measured at $24 \mathrm{~h}$. Our results strongly support that the lead inhibitors (68 and 70) provide a good starting point for lead optimization and efficacy for clinical studies.

\section{Conflict of interest}

The authors declare no competing financial interest.

\section{Acknowledgements}

Mohammad Abid gratefully acknowledges UGC, Govt. of India for the major research Project (Grant No. 41-277/2012 (SR)) and for the Raman Postdoctoral Fellowship in USA (F. No. 5-123/2016 (IC)). BA acknowledges the BSR fellowship and MI acknowledges the Non-NET fellowship support from UGC, INDIA.

\section{Notes and references}

1 B. Yao, H. Ji, Y. Cao, Y. Zhou, J. Zhu, J. Lü, Y. Li, J. Chen, C. Zheng, Y. Jiang and R. Liang, J. Med. Chem., 2007, 50, 5293-5300.

2 S. Tobudic, C. Kratzer and E. Presterl, Mycoses, 2012, 55, 24-32.
3 A. H. Groll and J. Lumb, Future Microbiol., 2012, 7, 179-184.

4 CDC, Antibiotic resistance threats in the United States, U.S. Department of Health and Human Services, Atlanta, Georgia, 2013, pp. 63-64.

5 G. D. Brown, D. W. Denning, N. A. Gow, S. M. Levitz, M. G. Netea and T. C. White, Sci. Transl. Med., 2012, 4, 165 rv13.

6 X. Cao, Z. Sun, Y. Cao, R. Wang, T. Cai, W. Chu, W. Hu and Y. Yang, J. Med. Chem., 2014, 57, 3687-3706.

7 R. A. Calderone, Introduction and historical perspectives, in Candida and Candidiasis, ed. R. Calderone, ASM Press, Washington, DC, 2002, pp. 15-25.

8 C. A. Kauffman, J. A. Vazquez, J. D. Sobel, H. A. Gallis, D. S. McKinsey, A. W. Karchmer, A. M. Sugar, P. K. Sharkey, G. J. Wise, R. Mangi and A. Mosher, Clin. Infect. Dis., 2000, 30, 14-18.

9 S. Silva, M. Negri, M. Henriques, R. Oliveira, D. W. Williams and J. Azeredo, FEMS Microbiol. Rev., 2012, 36, 288-305.

10 R. M. Donlan and J. W. Costerton, Clin. Microbiol. Rev., 2002, 15, 167-193.

11 W. L. Chaffin, J. L. López-Ribot, M. Casanova, D. Gozalbo and J. P. Martínez, Microbiol. Mol. Biol. Rev., 1998, 62, 130180.

12 S. Wang, Y. Wang, W. Liu, N. Liu, Y. Zhang, G. Dong, Y. Liu, Z. Li, X. He, Z. Miao, J. Yao, J. Li, W. Zhang and C. Sheng, ACS Med. Chem. Lett., 2014, 5, 506-511.

13 R. Di Santo, A. Tafi, R. Costi, M. Botta, M. Artico, F. Corelli, M. Forte, F. Caporuscio, L. Angiolella and A. T. Palamara, J. Med. Chem., 2005, 48, 5140-5153.

14 M. A. Ator, S. J. Schmidt, J. L. Adams, R. E. Dolle, L. I. Kruse, C. L. Frey and J. M. Barone, J. Med. Chem., 1992, 35, 100-106.

15 C. Sheng, W. Zhang, H. Ji, M. Zhang, Y. Song, H. Xu, J. Zhu, Z. Miao, Q. Jiang, J. Yao, Y. Zhou, J. Zhu and J. Lü, J. Med. Chem., 2006, 49, 2512-2525.

16 K. Pawar, A. Yadav, P. Prasher, S. Mishra, B. Singh, P. Singh and S. S. Komath, MedChemComm, 2015, 6, 1352-1359.

17 M. Irfan, B. Aneja, U. Yadava, S. I. Khan, N. Manzoor, C. G. Daniliuc and M. Abid, Eur. J. Med. Chem., 2015, 93, 246-254.

18 B. Aneja, M. Irfan, M. I. Hassan, P. Amresh, U. Yadava, C. G. Daniliuc, M. Zafaryab, M. M. A. Rizvi, A. Azam and M. Abid, J. Enzyme Inhib. Med. Chem., 2015, 1-19.

19 M. M. Masood, V. K. Pillalamarri, M. Irfan, B. Aneja, M. A. Jairajpuri, M. Zafaryab, M. M. A. Rizvi, U. Yadava, A. Addlagatta and M. Abid, RSC Adv., 2015, 5, 34173-34183.

20 M. Schaller, C. Borelli, H. C. Korting and B. Hube, Mycoses, 2005, 48, 365-377.

21 A. B. Salake, A. S. Chothe, S. S. Nilewar, M. Khilare, R. S. Meshram, A. A. Pandey and M. K. Kathiravan, J. Chem. Biol., 2014, 7, 29-35.

22 B. A. Arthington-Skaggs, D. W. Warnock and C. J. Morrison, Antimicrob. Agents Chemother., 2000, 44, 2081-2085.

23 H. Ji, W. Zhang, M. Zhang, M. Kudo, Y. Aoyama, Y. Yoshida, C. Sheng, Y. Song, S. Yang, Y. Zhou and J. Lü, J. Med. Chem., 2003, 46, 474-485. 
24 K. Asai, N. Tsuchimori, K. Okonogi, J. R. Perfect, O. Gotoh and Y. Yoshida, Antimicrob. Agents Chemother., 1999, 43, 1163-1169.

25 J. Fallon, J. Kelly and K. Kavanagh, in Host-Fungus Interactions, Humana Press, 2012, pp. 469-485.

26 S. Zhang, J. Zou, M. Elsabahy, A. Karwa, A. Li, D. A. Moore, R. B. Dorshow and K. L. Wooley, Chem. Sci., 2013, 4, 21222126.

27 T. Asaba, T. Suzuki, R. Ueda, H. Tsumoto, H. Nakagawa and N. Miyata, J. Am. Chem. Soc., 2009, 131, 6989-6996.

28 R. Ramapanicker, R. Gupta, R. Megha and S. Chandrasekaran, Int. J. Pept., 2011, 854952.

29 S. P. Chakrabarty, R. Ramapanicker, R. Mishra, S. Chandrasekaran and H. Balaram, Bioorg. Med. Chem., 2009, 17, 8060-8072.

30 NCCLS, Reference method for broth dilution antifungal susceptibility testing of yeasts; Approved standard M27eA2, National Committee on Clinical Laboratory Standards, Wayne, P.a., 2002, vol. 22, pp. 8-9.

31 Z. Jiang, Y. Wang, W. Wang, S. Wang, B. Xu, G. Fan, G. Dong, Y. Liu, J. Yao, Z. Miao and W. Zhang, Eur. J. Med. Chem., 2013, 64, 16-22.

32 R. Rüchel, R. Tegeler and M. Trost, Sabouraudia, 1982, 20, 233-244.

33 M. F. Price, I. D. Wilkinson and L. O. Gentry, Sabouraudia, 1982, 20, 7-14.

34 A. Khan, A. Ahmad, L. A. Khan and N. Manzoor, Res. Microbiol., 2014, 165, 411-419.
35 A. Kumar, M. Zafaryab, A. Umar, M. M. A. Rizvi, H. Z. A. Ansari and S. G. Ansari, J. Biomed. Nanotechnol., 2015, 11, 1913-1926.

36 A. Khan, A. Ahmad, I. Xess, L. A. Khan and N. Manzoor, Phytomedicine, 2010, 17, 921-925.

37 Protein DB NCBI.

38 H. Berman, K. Henrick, H. Nakamura and J. L. Markley, Nucleic Acids Res., 2007, 35, D301-D303.

39 B. V. Reddy and Y. N. Kaznessis, J. Biosci., 2007, 32, 929-936.

40 R. A. Laskowski, M. W. MacArthur, D. S. Moss and J. M. Thornton, J. Appl. Crystallogr., 1993, 26, 283-291.

41 D. Eisenberg, R. Lüthy and J. U. Bowie, Methods Enzymol., 1997, 277, 396-404.

42 E. F. Pettersen, T. D. Goddard, C. C. Huang, G. S. Couch, D. M. Greenblatt, E. C. Meng and T. E. Ferrin, J. Comput. Chem., 2004, 25, 1605-1612.

43 Z. Li, H. Wan, Y. Shi and P. Ouyang, J. Chem. Inf. Comput. Sci., 2004, 44, 1886-1890.

44 O. Trott and A. J. Olson, J. Comput. Chem., 2010, 31, 455461.

45 J. Baxter, J. Oper. Res. Soc., 1981, 815-819.

46 Hybrid metaheuristics-an emerging approach to optimization, ed. C. Blum, A. Roli and M. Sampels, Springer-Verlag, Berlin, Heidelberg, 2008.

47 W. L. DeLano, PyMOL, DeLano Scientific, San Carlos, CA, 700, 2002.

48 A. C. Wallace, R. A. Laskowski and J. M. Thornton, Protein Eng., 1995, 8, 127-134. 